\title{
AUTONOMY, CHOICE AND TREATMENT: USING BOURDIEU'S THEORY OF PRACTICE TO EXPLORE BREAST CANCER PATIENTS' PRECONCEPTIONS AND EXPERIENCES OF PUBLIC AND PRIVATE HEALTH SYSTEMS \\ IN NEW ZEALAND
}

by

Kimberly Lyle Dobson

\begin{abstract}
A thesis
Submitted to Victoria University of Wellington in fulfilment of the requirements for the degree of Master of Arts in Sociology
\end{abstract}

Victoria University of Wellington 


\section{Abstract}

This thesis analyses 11 breast cancer patients' preconceptions and experiences of public and private health sectors in New Zealand. Previous studies exploring breast cancer have analysed a range of issues including race, socio-economic and age inequalities, issues occuring between the public and private sectors, and the communication strategies patients preferred with health providers. In contrast, this thesis uses concepts from Pierre Bourdieu's theory of practice to explore breast cancer patients' accounts of the public and private sectors and how these accounts are shaped.

For many of the women interviewed, cultural and social capital played an important role in the negotiation of the health system, whether public or private. This is because both sectors, at times, provided little information about the disease, treatment, side effects, and entitlements. In these circumstances, social and cultural capital were valuable resources providing alternative health assistance.

Participants' preconceptions when relating their choice of public or private health systems showed clear positive associations with the private health sector. When discussing their experiences, the women that used the public sector showed a positive turnaround in their opinions related to the public sector. In comparison, the women that used the private sector maintained their views regardless of some negative issues being experienced. Despite their personal experiences, both public and private participants maintained positive associations with the private sector.

The reliance many of the participants had on social and cultural capital in both the public and private health sectors raises questions regarding processes related to patient information, access to services, and about whether case management of cancer services might be appropriate. The contrasts between participants' preconceptions of the public sector in comparison to experiences highlights the need for a public campaign celebrating the successes of public cancer services. 


\section{Acknowledgements}

Thank you to the 11 women who shared their breast cancer experiences with me.

Thank you to the people who helped me to get in touch with the women I interviewed.

Thank you to my parents, Margaret and Nick Dobson, for your advice and support

To my fellow students and good friends, Hollie and Lynzi, as well as numerous other family and friends, a big thank you for your help, support, time and interest in my project.

Thank you to Victoria University of Wellington for the Small Research Grant which funded travel to interviews and thank you vouchers for participants. This grant also enabled me to present a paper at the Women's Studies Association of New Zealand 2010 Conference through funding my travel and conference fee.

Finally I would like to express my sincere gratitude to my supervisor Professor Kevin Dew. Your teaching, papers and work sparked my interest in the study of the Sociology of Health and Illness and your encouragement, guidance, and countless hours of support have helped me to complete this thesis. 


\section{Contents}

Abstract $\quad$ i

Acknowledgements $\quad$ ii

1) Introduction 1

Rationale for the research 1

Overview of the chapters 6

2) Literature review

Bourdieu's theory of practice and its implications for health

$\begin{array}{ll}\text { Capital } & 8\end{array}$

$\begin{array}{lr}\text { Cultural Capital } & 9\end{array}$

$\begin{array}{ll}\text { Health and cultural capital } & 13\end{array}$

$\begin{array}{ll}\text { Social capital } & 15\end{array}$

Habitus 20

Field 24

$\begin{array}{ll}\text { Summary } & 26\end{array}$

3) Methodology 28

$\begin{array}{ll}\text { Interviewing: reasoning and issues } & 28\end{array}$

$\begin{array}{ll}\text { Participants and recruitment } & 31\end{array}$

The interview 34

$\begin{array}{ll}\text { Analysis } & 36\end{array}$

$\begin{array}{ll}\text { Summary } & 39\end{array}$ 
Investigating the impact of capital on breast cancer patients' experiences in the public and private health sectors

Cultural capital 40

Social Capital 54

Summary 64

5) Public and private health sectors

Exploring the perceptions and experiences of breast cancer patients'

$\begin{array}{ll}\text { Defining concepts } & 66\end{array}$

Preconceptions and experiences of health sectors before breast cancer $\quad 68$

$\begin{array}{ll}\text { Experiences of health sectors } & 81\end{array}$

$\begin{array}{ll}\text { Summary } & 102\end{array}$

$\begin{array}{lr}\text { 6) Conclusion } & 104\end{array}$

$\begin{array}{ll}\text { Bibliography } & 113\end{array}$

Appendix A: Introductory email 126

$\begin{array}{ll}\text { Appendix B: Participant information sheet } & 128\end{array}$

Appendix C: Consent form 131

Appendix D: Demographic survey 134

Appendix E: Demographic survey information 135

$\begin{array}{ll}\text { Appendix F: Interview guide } & 138\end{array}$ 


\section{1) Introduction}

This qualitative thesis uses Bourdieu's theory of practice ${ }^{1}$ to investigate 11 breast cancer patients' preconceptions and experiences of the public and private health sectors. The research explores the impact of cultural and social capital on patients' negotiation of health sectors. It then uses the concepts of doxa and illusio to examine power issues embedded in participants' perceptions and experiences of these health sectors. This chapter notes the services in place and prevalence of cancer in New Zealand. It then provides a rationale behind the choice of topic and an overview of the chapters.

\section{Rationale for the research}

Cancer affects many people and families. In 2007 cancer was the leading cause of death in New Zealand across both sexes (MOH 2010: 11). Cancer treatment in this country is primarily funded by the public health sector, although patients still have to pay for primary care consultations (Jeffreys et al. 2009). Cancer patients also have the option of paying for surgery and treatment in the private sector, although only two facilities in New Zealand currently offer private radiotherapy treatment (Auckland Radiation Oncology 2008; St George's Hospital 2010). To address the effects of cancer on New Zealanders, the National Cancer Programme Work Plan ${ }^{2}$ sets out yearly goals for the Government (that are allocated to the Ministry of Health ${ }^{3}$ ) and cancer networks based around broader goals in the Cancer Control Strategy and Action Plan. ${ }^{4}$ This plan aims to: prevent cancer, improve screening, service delivery and diagnosis of cancer; have good support for cancer victims and their families; and increase effectiveness of cancer treatment (Ministry of Health 2010a: 17).

\footnotetext{
${ }^{1}$ Bourdieu's theory of practice uses different concepts such as capital, habitus, and field to show that social practices are a combination of both individual and societal factors. This theory is discussed in Chapter 2.

${ }^{2}$ See this website for the online version of the 2010/2011 National Cancer Programme Work Plan: http://www.moh.govt.nz/moh.nsf/pagesmh/8663/\$File/cancer-control-work-programme-2010-11.doc.

${ }^{3}$ The Ministry of Health is a principal advisor to the Government on health and disability policy and its mission statement claims that it works to improve New Zealanders' health through reducing inequalities, prevention campaigns and ensuring health services are centred on patients needs.

${ }^{4}$ See this website for the online version of the New Zealand Cancer Control Strategy: http://www.moh.govt.nz/moh.nsf/49ba80c00757b8804c256673001d47d0/cec6bba7543715e5cc256d8800 1628f7?OpenDocument.
} 
An independent advisory body, Cancer Control New Zealand (CCNZ) is also appointed to ensure the goals set in the Cancer Control Strategy are met. The 2010/11 goals included: a larger focus on lung and bowel cancer; improvements to palliative care and waiting times for cancer treatment; developing models of care and treatment; collecting and analysing cancer information; spending money more effectively; improving prevention campaigns; reducing risk factors; and identifying and addressing other issues that arise (Ministry of Health 2010b).

CCNZ recently completed a large-scale quantitative survey of 2221 New Zealand cancer patients experiences of public cancer services and almost all the patients surveyed indicated that they were very satisfied with their treatment in the public sector (Cancer Control New Zealand 2009: 5). CCNZ's report recommendations call for "qualitative patient experience research [...] to validate the results of the survey and form a much richer picture of the patients' experiences" (Cancer Control New Zealand 2009: 30). Following on from these recommendations, this thesis used qualitative methods to explore breast cancer patients' perceptions and experiences of public and private health sectors to provide a rich picture of their experiences.

Breast cancer was chosen as the focus for this thesis because of the large impact this disease has on New Zealand women. In New Zealand, breast cancer is the most common source of female cancer deaths (McKenzie et al. 2010; MOH 2010). Breast cancer has a prevention campaign organised by the National Health Board which includes: a National Screening Programme that funds free mammograms ${ }^{5}$; an interactive website with information and resources in a number of different languages; information booklets in health centres around New Zealand; a television advertising campaign; and a free telephone helpline (National Health Board 2009). The techniques this campaign uses to distribute information in a range of languages and methods helps assist the programme in reaching a wider range of women across different ethnicities and socioeconomic groups. The next part of this chapter discusses some previous quantitative and qualitative research related to breast cancer.

\footnotetext{
${ }^{5}$ For women aged between $45-69$, every two years.
} 
There has been a variety of quantitative studies and statistical analyses exploring breast cancer in New Zealand. These address a number of issues about screening (Brunton et al. 2005; Curtis et al. 2005b; Page and Taylor 2008; Richardson et al. 2005); demographic issues related to race and socio-economic status (Cunningham et al. 2010; Curtis et al. 2005a; Jeffreys et al. 2005; McCredie et al. 1999; Sarfati et al. 2006); rural and urban locations (Gollop et al. 2009); and support services (Marsh et al. 2010). The following outlines a few of these studies findings.

McCredie et al. (1999) did research exploring the effects of different variables, such as age, ethnicity, socio-economic status, education, children, duration, body mass, family history, and use of contraception, on breast cancer. They found that Maori under 40 had a higher risk of breast cancer, commenting that this could be due to their heightened body mass and use of Depo-Provera. Jeffreys et al. (2005) investigated aspects affecting higher rates of Maori cancer mortality, recommending that cost and access to the secondary health system, rural services, and cultural attitudes of health workers needed to be addressed. Sarfati et al. (2006) researched how aspects such as race and socioeconomic factors affected breast cancer. They found Maori breast cancer mortality between 1981 and 1999 was almost three-quarters higher than non-Maori and nonPacific women, during this period Pacific breast cancer mortality tripled and lower socio-economic groups' breast cancer mortality increased by 22\% (Sarfati et al. 2006). Jeffreys et al. investigated the link between socio-economic inequalities and cancer survival in New Zealand commenting that "more affluent or educated people may be better placed to navigate their way through the health system" (Jeffreys et al. 2009: 919). Marsh et al. (2010) surveyed doctors in New Zealand and Australia about their access to breast nurses. They found that breast cancer patients in the public sector had better access to breast cancer nurses and they recommended that there needed to be improvements in access to breast cancer nurses for patients in rural areas and the private sector. Recently, Cunningham et al. (2010) found that Maori women in New Zealand have higher incidences of breast cancer than non-Maori.

These quantitative studies reflect a range of issues occurring for breast cancer patients in New Zealand. There have also been a range of qualitative studies about breast cancer patients experiences examining issues such as communication (Ashing-Giwa et al. 2004); problems for patients of different ages (Pieters et al. 2011; Thewes et al. 2004; 
Wood and Della-Monica 2011); use of complementary therapies (Juraskova et al. 2010); experiences of surgery and care (Greenslade et al. 2010; Remmers et al. 2010); and patient information seeking and needs (Balka et al. 2010; Brown et al. 2000). The following will expand on some of these studies. Ashing-Giwa et al. (2004) combined 20 key informant interviews with health professionals and focus groups with 92 breast cancer survivors to highlight diversity of problems experienced across cultures ${ }^{6}$ and to emphasise the importance of person-centred health care. Burkitt Wright et al. (2004) interviewed 39 women with breast cancer about doctor communication, their study emphasised the importance of individual treatment, respect, and honesty between doctors and patients. Thewes et al. (2004) interviewed 18 younger and older breast cancer patients placed an emphasis on person-centred health care. She also commented that younger women with breast cancer experienced psychological, career, sex, fertility, and contraception issues. These qualitative studies discuss a range of issues experienced by overseas breast cancer patients.

The quantitative and qualitative studies mentioned show that there is much interest and investigation into breast cancer and the different issues that are occurring for patients. This thesis expands on the work in these investigations and is a response to calls for further research on personal factors affecting cancer (Jeffreys et al. 2009). It does this through exploring the effect of capital on participants' experiences of public and private health sectors as well as providing insight into issues facing breast cancer patients. The last part of this section discusses the reasoning behind using Bourdieu's theory of practice to explore the interview material.

Earlier, the choice of breast cancer for this thesis was linked with the high numbers of women affected by this disease. There was also a personal interest related to the choice of breast cancer for this thesis. Two family members have survived this disease and two are currently having treatment for breast cancer. The decision to use Bourdieu's theory of practice evolved from discussions with friends and family affected by breast cancer. Discussions emphasised a general fear and lack of faith in association with public sector cancer care. Attention was drawn to the importance of certain personality traits such as

\footnotetext{
6 These ranged from racism from health professionals, language difficulties, problems accessing insurance, affects on their employment and sexuality and pressures from family and the community.
} 
strength, and an ability to question systems and personally advocate for oneself to ensure proper treatment and positive outcomes. These conversations created a further interest in the area and a desire to explore these issues further. Bourdieu's theory of practice and its concepts allowed for an exploration of subtle, taken for granted aspects, and power dynamics in society related to breast cancer and health systems.

There has been a discussion about the gap in research linking sociological theory and health issues. Abel (2007: 47) has argued that power issues are often less obvious in health research and outcomes are considered matters of free choice, individual taste and consumer preferences. Malat (2006) has commented on the lack of theory within much public health research and calls for sociologists to investigate socio-economic inequalities by using theoretical concepts, such as cultural capital ${ }^{7}$, to further investigate health inequalities. Abel (2008) has also commented that there is much research linking lack of economic capital and health, which is why there is a need for more research exploring the link between health behaviours and people's norms and values. These comments further justified the decision to use Bourdieu's theory of practice to analyse the interview material.

As mentioned previously, there have been many qualitative and quantitative research projects exploring issues present for women with breast cancer, ranging from age, ethnicity, and socio-economic issues, to provider communication issues, and issues related to delayed diagnosis. However, qualitative and quantitative breast cancer research has not yet applied Bourdieu's theory of practice to analyse patient experiences. This theory has been used in other studies investigating health issues exploring cardiovascular risk (Angus et al. 2007), asthma (Grineski 2009), health strategies (Stoebenau 2009) and skin allergies (Noiesen et al. 2004). ${ }^{8}$ Bourdieu's theory of practice has already been shown to have implications for New Zealand society outside the health system through Jones' (1991) education research. This thesis will provide personal patient insights related to breast cancer care to complement and extend

\footnotetext{
${ }^{7}$ Malat calls specifically for an understanding of the impact of cultural capital upon health and that the sorts of cultural capital which improve people's health care need to be investigated, as well as whether race affects people's ability to employ cultural capital in health interactions

${ }^{8}$ These studies are discussed in Chapter 2.
} 
other studies on breast cancer, and provide a different lens to exploring breast cancer patients' experiences.

Overview of the chapters

Chapter 2 gives an overview of Bourdieu's theory of practice, summarising his concepts of capital, habitus, and field and discussing how other authors have used his work to investigate health issues.

Chapter 3 outlines the methodology used in the research, describing the research process, method of inquiry, participants, and method of analysis.

Chapter 4 analyses the participants' narratives in relation to Bourdieu's concept of capital. The first part explores the impact of cultural capital on the participants' negotiation of the health system and the second part investigates the implications of social capital on participants' experiences of the health system.

Chapter 5 analyses the participants' narratives about their preconceptions and experiences of health sectors using Bourdieu's concepts of doxa and illusio. The first part discusses participants' preconceptions of health sectors and the second part investigates the participants' experiences of the public and private health sectors.

Chapter 6 will discuss the findings from Chapters 4 and 5, discussing the strengths and weaknesses of the research, providing some recommendations, and suggesting some issues for future research in this area. 


\section{2) Literature review}

\section{Bourdieu's theory of practice and its implications for health}

French Sociologist Pierre Bourdieu argued that societal conditions are a combination of individual agency and structural elements (Bourdieu and Passeron 1965; Weininger and Lareau 2007). He noticed in French ${ }^{9}$ society that class structures tended to repeat themselves and he developed his theory of practice to explain this phenomenon. His research on schoolchildren and university students, and empirical surveys gave examples illustrating his theory and established a link between individual conditions and existing historical structures in society (Bourdieu 1979; Bourdieu and Passeron 1965; Weininger and Lareau 2007). Bourdieu's work with schoolchildren showed how the structure of educational institutions reproduced class differences in society. Showing educational differences among students of different social classes were not because of monetary aspects; instead, habits learnt from family influenced their progress in educational institutions (Weininger and Lareau 2007). His research on university students developed this idea further, highlighting the effect that structural elements had on students' understanding, comprehension, and confidence in class and that this in turn influenced their achievements in the course (Bourdieu and Passeron 1965). The theory of practice uses the concepts of capital, habitus, and field to describe the interaction between structure and individual choices (Bourdieu 1979; Samuelsen and Steffen 2004).

This study applies Bourdieu's theory of practice to investigate breast cancer patients' negotiation, perceptions, and experiences of public and private health sectors. To do this an explanation of Bourdieu's interrelating concepts: capital, habitus, and field is required. The first part of this chapter will describe the theoretical concept of capital, exploring specifically the concepts of cultural and social capital, which are used in Chapter 4 to analyse the interview material. The second part of this chapter looks at Bourdieu's concept of habitus, describing what this is, and discussing other studies that

\footnotetext{
9 Bourdieu (1998) emphasised in his work that his theory applied to French sensibilities and French examples as a case model but the general theory can be thought about in terms of general society.
} 
have used it to explore health issues. The final section describes the notion of field, defines public and private health sectors as fields, and comments on research exploring both sectors.

\section{Capital}

Bourdieu defined capital as "accumulated labour" or "reified or living labour" which assists individuals and groups in their negotiation of different fields ${ }^{10}$ (Bourdieu 1986: 46). This wider definition of capital encompassed aspects such as knowledge, skills, qualifications and networks drawn upon in their daily activities which are acquired through learning, life experience, and socialisation (Bourdieu 1986). Alternative forms of capital are an intricate part of individuals, assisting in their navigation of systems and domination of fields, further reaffirming their dominant position in society, and allowing them to define "superior" distinct knowledge due to their dominant position (Stuber 2009; Williams 1995). Bourdieu recognised that the navigation of systems without these alternate forms of capital is difficult which can make individuals accept their position in society as the natural place they belong (Harker 1990). Capital makes "the games of society [...] something other than simple games of chance" providing individuals with experience and skill to use to their advantage in their negotiation of different fields (Bourdieu 1986: 46).

Bourdieu and Passerson (1965) applied their theory of practice in their study on university students to demonstrate the power of alternative forms of capital in the field of education. They found students in the study possessing alternative forms of capital, such as familiarity of academic language and writing, understood lectures and assignment work more easily. These students also naturally conveyed their work in a tone, style, and quality that distinguished them from their peers, who had to work harder to decipher and interpret language and reproduce academic rhetoric. The combination of socialisation, experiences, and skills made the work familiar to students with capital, helping to distinguish them among their peers, justifying their position at the top of the

\footnotetext{
${ }^{10}$ Bourdieu developed the concept of field to describe different groupings and structures within society. Rather than viewing society as a whole, the concept of field, allowed the analysis of society as an "ensemble of relatively autonomous spheres" individuals encounter with varying rules, values, and structures (Bourdieu and Wacquant 1992: 18). This is discussed later in the chapter.
} 
class and providing further opportunities for them. Through identifying alternative forms of capital assisting individuals in their negotiation of systems, Bourdieu created a theory that allowed for an investigation of power dynamics and common sense assumptions in society.

Bourdieu identified four forms of dynamic, interchangeable capital existing in society that assist individuals in their struggle for dominance and thus the accumulation of more capital (Mahar et al. 1990). These forms of capital are economic, social, cultural and symbolic capital. Economic capital is income, resources and assets that are “immediately and directly convertible into money" (Bourdieu 1986: 47). Social capital is resources accessed through relationships, connections and membership in a community (Bourdieu 1986). Cultural capital describes the embodied knowledge individuals draw upon in their understandings and social practices. Symbolic capital is a form of recognition in society legitimating particular forms of capital, such as educational qualifications, titles, and honours (Bourdieu 1985; Mahar et al. 1990).

This thesis examines the concepts of social and cultural capital and the impact of these concepts on breast cancer patients' negotiation of health systems. It does not directly explore the aspects of economic and symbolic capital but it does address these forms of capital on a broader level to some extent. Participants in the study required economic capital to enable them to access their choice of health sector, and the research examines their perceptions and experiences of private sector care. Symbolic capital will be touched upon in the analysis when exploring the participants' narratives about the impact of physician statements on their perceptions and choice of health sector. This section has broadly defined capital; the next section discusses the concept of cultural capital in more depth and explores its criticisms.

\section{Cultural capital}

Cultural capital is the knowledge, resources, and skills individuals unconsciously draw upon in their negotiation of different fields. It distinguishes particular members of society, assisting them in attaining resources and privileges (Lamont and Lareau 1988). Bourdieu (1986) describes this concept by dividing it into three aspects: an embodied state, an objectified state, and an institutionalised state. 
Embodied cultural capital incorporates both social and learned aspects and takes time to accumulate. It includes values and habits that are passed on to an individual through the socialisation process and learned factors which help to secure an individual's profits, opportunities and status in a field (Bourdieu 1986: 49). Socialisation and early teaching of useful ${ }^{11}$ types of cultural capital benefits individuals in attaining further types of capital quickly and easily (Bourdieu 1986). As well as values and habits learnt through socialisation, embodied cultural capital is also different skills and knowledge that take time and personal effort to gain such as languages, reading and writing skills, and knowledge of systems (Tzeng 2010). Embodied cultural capital, in terms of health, could include aspects of health literacy such as knowledge surrounding the importance of maintaining a healthy lifestyle through such measures as eating fruits and vegetables, engaging in physical activity, performing preventative health measures such as screening and yearly dental exams (Abel 2007). Embodied cultural capital can positively affect an individual's health through influencing health interactions and guiding health behaviour, such as information seeking (Anspach 1993; Grineski 2009; Lutfey 2005; Noiesen et al. 2004).

Objectified cultural capital requires a combination of knowledge and skills to understand and appreciate particular objects and economic capital to purchase them. It includes activities such as collecting and enjoying art, wine, books or music (Bourdieu 1986). "It exists as symbolically and materially active, effective capital only insofar as it is appropriated by agents and implemented and invested as a weapon and a stake in the struggles which go on in the fields of cultural production" (Bourdieu 1986: 50). Objectified cultural capital requires strategic use by individuals to improve their position for it to be useful. For example, an intensive knowledge about different wines is only "useful" if it is strategically utilised to improve one's social position, for example, to impress friends or colleagues and thus highlight one's distinction. Objectified cultural capital in terms of health could include an individual's access to a computer and internet to access health resources and information, the skills and knowledge to understand the resources, as well as the economic capital to apply the resources to their lifestyle.

\footnotetext{
${ }^{11}$ Useful types of cultural capital are determined by dominant individuals in society
} 
Institutional forms of cultural capital require support from an institution to verify an individual's qualifications guaranteeing their competence to perform particular skills (Bourdieu 1986: 51). Doctors, nurses and other health professionals are examples of professionals possessing health-based institutionalised cultural capital. Anspach (1993) details how patients' institutional medical qualifications can have a positive impact on doctors communication with patients, and Grineski (2009) also commented that institutional qualifications positively affected participants' negotiation of their child's health condition.

Bourdieu's descriptions easily accommodate the definition of human capital encompassing "skills, knowledge and qualifications of an individual" (Shulz and Brese 2008: 10). Bourdieu's concepts of embodied cultural capital and objectified cultural capital align with "knowledge and skills" and "qualifications" relates to his description of institutionalised cultural capital. Interestingly, Bourdieu (1986: 48) noted that human capital overlooks the importance of cultural capital invested by family assisting individuals in their education, as well as the impact of social capital on cultural capital.

Many of the criticisms surrounding cultural capital are associated with its definition. Authors such as Sullivan (2002) state that Bourdieu is not clear enough in defining the resources linked with cultural capital, and other researchers such as Lamont and Lareau (1988: 156) state that Bourdieu's description of cultural capital has "incompatibilities between functions and forms of cultural capital." The lack of specificity with the description of cultural capital has also led to some authors forming their own definitions. Calhoun (1993: 70) describes cultural capital as simply "educational credentials" or "prestige" (Calhoun 2003: 294). Lamont and Lareau (1988: 156) propose a new definition altogether defining cultural capital as "institutionalised, i.e. widely shared, high status cultural signals (attitudes, preferences, formal knowledge, behaviours, goods and credentials) used for social and cultural exclusion." While Calhoun's simplistic definitions seem to take away from the complexity of Bourdieu's notion of cultural capital, Lamont and Lareau's definition seems to draw upon Bourdieu's lengthy description and nuances regarding domination in a more concise manner. 
Lovell (2000) has criticised Bourdieu's notion of cultural capital because it constructs culture as something solid, real, and difficult to shift despite the fact that the social world in reality requires constant "reiteration" of its "performance" (Lovell 2000: 15). Meinert (2004) and Retsikas (2010) criticise cultural capital for its emphasis upon socialisation and inability to incorporate the socialisation processes of other cultures. Meinert (2004) and Grineski (2009) also criticise Bourdieu's definition of cultural capital as being something that only exists within an individual despite their opposing evidence from their studies which shows how children's cultural capital works as a collective family asset in terms of advocacy.

Other authors interpret Bourdieu's description of cultural capital differently. Trueba (2002: 8) views cultural capital as a type of personal resilience allowing individuals to overcome oppressive situations and develop an ability and flexibility to "define oneself in multiple ways and fashions." Yosso (2005) embodies Trueba's notion of cultural capital as a form of "resilience" when she proposes a concept, "community cultural wealth", instead of cultural capital to address the racism entrenched within the term. Yosso (2005) critiques the work of Bourdieu using critical race theory to discuss how the concept of cultural capital, disempowering coloured people's knowledge by reinforcing white people's knowledge and culture as something of value, middle and upper class knowledge as standard and normal, and other knowledge as culturally poor. $^{12}$

Yosso (2005) also discussed how marginalised groups have different knowledge they bring to institutions, such as schools, that is not recognised because of societal definitions validated by symbolic capital that work to classify valued knowledge. This concept of community cultural wealth creates an alternative discourse, or heterodoxy ${ }^{13}$, for types of capital, broadening the concept to six types of capital including aspirational capital, familial capital, social capital, navigational capital, resistant capital and linguistic capital (Yosso 2005: 77). Through creating a new concept to value marginalised groups' knowledge and culture, Yosso "calls into question white middle class communities as the standard by which all others are judged" (Yosso 2005: 82).

\footnotetext{
${ }^{13}$ Heterodoxy is a concept Bourdieu uses to describe alternative discourses that bring into question ideas and processes that previously appeared as natural societal processes.
} 
While these authors have redefined and reconceptualised the concept of cultural capital, other authors have constructed understandings of cultural capital in relation to health. The next section discusses these understandings of cultural capital in relation to health.

\section{Health and cultural capital}

Abel (2008: 3) defines health-based cultural capital as "the culture-based resources that are available to people for maintaining and promoting their health." He gives specific examples of individual health-based capital such as "health values and norms, health knowledge and operational skills" (Abel 2008: 3). Shim (2010) has developed Abel's ideas further, defining a new form of cultural capital, cultural health capital, based around Bourdieu's work to explain the impact of resources and skills on health interactions and inequalities. Shim (2010) argues that individuals need specific abilities and resources, or cultural health capital, as a personal advocacy tool to help facilitate communication in medical interactions. Cultural health capital includes aspects such as patient knowledge of medicine and language, the ability to communicate health-based information effectively, a proactive attitude toward health, and positive encouragement from a physician as cultural health capital is a "a collective achievement of patientprovider interactions" and can be encouraged or discouraged through provider comments and signals in medical interactions (Shim 2010: 4).

Two health-based studies have used Bourdieu's concept of cultural capital to investigate health. Grineski's (2009) research interviewed 53 parents from different socio-economic and ethnicities about their experiences accessing the American health system to investigate the impact of parent's social and cultural capital on their children's asthma. In this study, cultural capital was linked with the parent's ability to negotiate the health system, with their skills and knowledge either limiting or restricting their expectations, requests, and access to health services for their child (Grineski 2009). This study and Noiesen's (2004) study which uses Bourdieu's notion of cultural capital to explore the way individuals negotiate their skin allergies, are discussed in the section on habitus. The remainder of this section examines some studies about patient-physician interactions. These studies refer to traits within patients that could be defined as cultural 
health capital, although these authors do not specifically refer to cultural health capital in their research.

Anspach's (1993) research on a premature baby intensive care unit identifies a number of issues related to age, class, and race. She does not specifically discuss cultural capital in her research, although parts of her work exploring the language of health professionals and the information they give patients, can be considered in relation to cultural capital. Anspach (1993: 104) reported that health professionals change their language depending on parents "moral sophistication". "Medically sophisticated" parents of patients received complex information from health professionals and played a larger decision-making role regarding their child's health (Anspach 1993: 133). In comparison, Anspach reported that health professionals used "simplified and euphemistic" language in their discussions with lower and working class parents (Anspach 1993: 110). She examined how simplifying language actually transformed the meanings, making decisions appear simple rather than discussing the different options that parents could consider. This in turn excluded some parents in her study from the decision-making processes regarding their child's survival. This information directly refers to the resources and abilities that Shim (2010) states are positive in medical interactions.

Other studies exploring doctor and patient communication can also align with Shim's (2010) definition of cultural health capital. Gordon et al. (2006) explored physician communication with lung cancer patients commenting that white patients' assertive behaviour and question asking in consultations meant their physicians provided them with more information and longer consultations. Street et al. (2007) investigated the impact of doctor's perceptions on their communication with lung cancer patients. Doctors in this study were "more responsive to the actively involved patient" providing these patients with more information and time to discuss their health issues (Street et al. 2007: 588). The Gordon et al. (2006) and Street et al. (2007) studies could be linked aspects of cultural health capital such as the ability to advocate and communicate with medical professionals. Shim (2010) commented that physician's encouragement affected whether or not their patients drew on their cultural health capital in consultations. Stimson and Webb's (1975) research on patient interactions support Shim's point through reporting on situations where confident patients changed their 
behaviour if their physician's reactions, comments and body language became negative in the consultation.

The above examples illustrate that despite the criticisms of the concept cultural capital as deployed by Bourdieu, it is a helpful concept to use to explore health issues. This is why researchers such as Malat (2006: 310) have called for more research to "examine the circumstances that promote activation of cultural capital among patients [and] what kind of cultural capital increases receipt of medical treatment."

Cultural capital and its effect on breast cancer patients' journey through the New Zealand health system was going to be the sole focus of this research at the beginning of project due to the few health related projects encompassing the concept, personal interest in the concept, and the criticisms and problems encompassing the concept of social capital. However, as the interviews progressed, the participants' social contacts emerged as an important part of their cancer experience and negotiation of health sectors in assisting participants in accessing different entitlements. The final part of this section will discuss some of the literature on social capital, the complexity of its definition, its criticisms and discuss some studies exploring its effect on health.

\section{Social capital}

The term social capital was first used in 1916 by Jane Jacobs to discuss the phenomenon she observed in older neighbourhoods, where children were given more freedom because people knew their neighbours were looking out for their children (Fukuyama 2000). Bourdieu (2005: 194-5) defines social capital as "the totality of resources (financial capital and also information etc) activated through a more or less extended, mobilizable network of relations which procures a competitive advantage by providing higher returns on investment." Trust affects social capital and access is influenced by the political environment, dominant societal norms, interaction, and resources (Robinson 2002). Williams and Robinson (2002: 14) describe social capital as relationships creating "a capacity to act for mutual benefit for a common purpose." Resources drawn upon through social capital refer to a range of factors "including status, mandate, attention, knowledge, and opportunities to participate and communicate" (Robinson and Robinson 2002: 42). Social capital brings people together 
through the creation of obligations and expectations of honest behaviour (Fukuyama 2000). It is also a way individuals maintain their dominance in society (Bourdieu 1979). This section explores some of the literature on social capital observing the strengths and weaknesses of this concept.

Social capital has an overlap with economic capital and cultural capital. Social capital can have liabilities such as dependence on others but this reduces when individuals have economic resources, as individuals are less reliant on social connections and can withdraw from groups and associations more freely (Wakefield and Poland 2005). People with high cultural or economic capital also find it easier to build social capital as other forms of capital help to create a sense of distinction that makes their association appealing to others (Bourdieu 1979, 1986; Wakefield and Poland 2005). People with high social capital also have the ability to "preserve or increase" their social capital for their benefit because of their vast social connections. Dominance over these connections allows individuals to perform many favours for other people creating a sense of obligation and responsibility among others (Wakefield and Poland 2005). Doing favours for other people generally can have little effect on an individual, particularly one with high economic capital, as favours often centre around the use of material possessions. For example, in Grineski's (2009) research a participant discussed occasionally asking a neighbour to pick up her sick child from school but avoided this measure unless the situation was serious. Driving to school does not represent much effort but it puts the neighbour in a dominant position, meaning the participant feels a sense of obligation if the neighbour asks them to do something.

Pierre Bourdieu, James Coleman, and Robert Putnam are the three main theorists social capital research is based upon and each describes social capital in slightly different ways. Moore et al. (2006: 729) defined Bourdieu and Coleman's approaches to social capital as social network approaches, "highlighting the influence of social structure, power, and disparities in access to resources on health". They also defined Putnam's approach as a communitarian approach, exploring the "effects of civic participation and trust on health" (Moore et al. 2006: 729). Coleman (1990: 304) defines social capital as "social organisation [...] facilitating the achievement of goals that could not be achieved in its absence or could be achieved at a higher cost." Like Bourdieu, Coleman noted the individual struggle for dominance through using this resource for individual benefits. 
Coradini (2010) commented that the differences between Bourdieu and Coleman's views on social capital come down to Coleman's discussion of modern society's diminishing social capital, the negative effects of this decline, and the importance in rebuilding this concept.

Putnam defined social capital as mutual obligations, reciprocity, and "generalised reciprocity" without expectations (Putnam 2000: 21). Putnam's (2000) research commented on the changing nature of American society, much of it relating to the decline in the public involvement and engagement with issues. Building social capital addressed this decline through the re-introduction of collective community action which created trusting communities, and respect and empathy among individuals (Putnam 2000). Putnam's explanation of social capital still has elements of individual expectation, as he comments that favours are performed for one's future benefit, in anticipation that others would act in a similar way in the future (Wakefield and Poland 2005).

Moore (2006) et al. analysed 277 texts on health based social capital. Their research called for further work exploring Bourdieu's social network approach to social capital in the health sector because it "would encourage the development of public health research that sees networks as social contexts that influence the behaviour and practices of individuals" (Moore et al. 2006: 733). Coradini (2010: 573) has explored the different critiques and understandings of social capital and commenting, "Bourdieu's notion of social capital is stressed positively" in much of the literature, compared to communitarian approaches to social capital, because it is "more theoretically defined." Authors such as Carpiano (2008: 90) note that Bourdieu's definition of social capital emphasises the nature of power dynamics, struggle, and competition in the access of different resources while social cohesion overlooks these vital factors that assist in understanding health disparities.

Social capital has been critiqued for its inability to be discussed in isolation from other issues. Pearce and Davey Smith (2003: 125) have criticised links between high social capital and health as it is difficult to separate social capital from "income, education, occupation [...] and it is even more difficult to do so with factors defined at the community level." The Veenstra et al. (2005) research on social capital and health in 
communities has acknowledged similar concerns, noting how social capital's scale and relationship with other factors makes it complicated to conceptualise and measure. Nonetheless, they also commented that this concept is still relevant for health researchers, despite its shortcomings, if based on Bourdieu's theoretical understanding (Veenstra et al. 2005: 2815).

Some researchers comment that health based social capital should not be encouraged because of its ability to create obligations and pressure among individuals in the community. Drevdahl et al. (2001:28) commented that instead of trying to build social capital health professionals need to "embrace a personal ethic of social responsibility and service." Other research has shown the positive impacts for building social capital among health organisations. Gillon's (2002) research observed how increasing social capital among health groups in Porirua, Wellington made their health systems much more efficient. To increase their connections health groups began meeting with one another, forging various links and setting up a network that encouraged trust and confidence. The network that was created among the organisations meant that instead of working separately health groups worked together, sharing resources and information and making all of their services more efficient for the community (Gillon 2002).

Social capital has been criticised for its individualistic epistemological understanding. Williams and Robinson (2002) state social capital is based around Pakeha epistemological understandings that view social capital as networks outside the family. Maori define social capital differently being a concept centred on family and familial obligations. Maori also view cultural capital and social capital as intrinsically linked, rather than separately defined like Bourdieu, because the values and networks that social capital are built upon are at the centre of Maori cultural capital in practice (Williams and Robinson 2002). Meinert's (2004) research on African understandings of health also have critiqued Bourdieu's theory of practice generally as culturally specific to a more individualised type of lifestyle different than that of the people she studied. Family was at the centre of African society, family was an important support system and economic unit, and people without a strong large family were seen as disadvantaged (Meinert 2004; Samuelsen and Steffen 2004). 
Abel et al. (2007) noted that health-related cultural capital cannot be looked at in isolation from social and economic capital because of their constant interaction and overlap. The inability to separate different forms of capital from one another is also illustrated in Stuber's (2009) research exploring the perceptions of different college students on the importance of extra-curricular activities, identifying the significance of social capital for building cultural capital and emphasising the integrated nature of these concepts.

Research using social capital has also has positive effects on health. Social capital affects health through providing support, influence and engagement that can directly influence health behaviours and can indirectly improve health through affecting "social, political and environmental factors" (Veenstra et al. 2005: 2800). As mentioned above, Gillon's (2002) research found increasing social capital among health agencies made them more efficient. Campbell and McLean (2002: 645) in their research on social capital and its effect on health for Caribbean communities in the United Kingdom discussed the strengths of Bourdieu's definition of social capital for the "critical conceptualisation of social capital". They found policy initiatives related to improving health through social capital could be successful as long as policy makers understood and addressed obstacles within different communities they worked with.

This section has described the diverse views on the concept of social capital, discussed some health research that has applied this concept and addressed some criticisms of the concept. The sheer amount of work around social capital shows the importance of social networks as a resource for individuals. Authors concerns about looking at social capital in isolation were taken into account in this thesis, with both social and cultural capital being explored in the analysis. A specific definition of social capital was not relied upon in this thesis, instead, participants' narratives were explored with aspects of both network and communitarian approaches to show why and when the participants used social capital during their breast cancer treatment. The next two sections of this chapter will describe Bourdieu's notions of habitus and field. The next section on habitus will define this concept, discuss research that uses habitus to investigate health issues and explore some criticisms surrounding this concept. 


\section{Habitus}

Habitus is an individual's dispositions ${ }^{14}$ that construct their habitual, uncoordinated behaviour and responses in their daily life (Abel 2007; Lovell 2000; Samuelsen and Steffen 2004; Thompson 1991). The habitus provides individuals with an instinctual sense of what to do, acting as a type of "cognitive map of an individual's social world" through incorporating different forms of capital, personal history, and understandings in a randomised yet competitive game-like manner providing creative and immediate game play (Cockerham et al. 1997: 327). Habitus is the "set of basic, deeply interiorised master-patterns constituting a cultural unconscious which may govern and regulate mental processes without being consciously apprehended and controlled" (Codd 1990: 137). "Collectively structured without being the action of the orchestrating action of a conductor", habitus addresses the unknown allowing the social world to be described as both random and organised at the same time (Bourdieu 1977: 72).

Individuals structure their practises and personal choices related to health behaviours, decisions, and investment in health around dispositions that are interconnected with capital and field. Dispositions encompassing health prevention and body conscious behaviours interrelate with capital in terms of time and money, as these require investment to act upon and thus embody, but are also a means of achieving distinction and dominance in different fields in parts of society that value particular body types (Shilling 2002). The next part of this section explores how different health researchers have used the concepts of habitus and capital in their work.

The interrelation between health-related behaviours and habitus is discussed in the Noiesen et al. (2004) research on purchasing behaviours among women with skin allergies. This study uncovered that purchasing practices and behaviours were influenced by capital and habitus which overall affected the participants' health. Capital impacted on participants' reading and comprehension abilities and self-confidence, and an individual's dispositions in the manner they purchased skin products which in turn

\footnotetext{
${ }^{14}$ Dispositions describe an individual's unconscious behaviour, ranging from how they eat, walk, speak, their body language, control, likes and dislikes giving individuals a sense of their place in society and societal structures (Bourdieu 1977; Mahar et al. 1990). According to Bourdieu, those in control define valuable dispositions in society.
} 
affected the participants' health conditions. The research concluded that the participants' allergy management was influenced by the interaction between capital and habitus.

The Angus et al. (2007) research on cardiovascular risk and stress also analysed the impact of habitus on health behaviours. Poor health was an outcome of an individual's habitus and dispositions being in tune with daily lives that incorporated long work hours, long periods of time inside and short breaks. Poor health habits were an outcome of a habitus that aligned with pressures. Short breaks and long hours also affected an individual's dispositions in relation to food choice both during and after work and the manner in which they consumed their food. The research concluded that cardiovascular stress was a "deep entanglement of the body and the social world" and an individual's dispositions were based upon their social position which had an effect on their health (Angus et al. 2007: 1093)

Habitus is shaped by its relationship with capital in the field of health influencing individuals in their struggle for health resources. Grineski's (2009) research specifically explores this issue through examining the ways that different forms of capital interacted with the decisions and behaviours of parents regarding their child's asthma. Grineski (2009) commented that participants in the study with low cultural, symbolic, and economic capital (due to factors such as immigration status, education, and language skills) had different dispositions and ways of approaching their children's health and the health field. Parents' dispositions within the public and private programmes and the health field they accessed were shaped by an interaction between capital such as literacy, language, education, and immigration status. Parents' dispositions and interactions with physicians were also influenced by hierarchy and dominance of physicians in the field and the capital that the physicians had in terms of language skills and cultural identity. ${ }^{15}$ Habitus is also shaped by other types of capital.

Symbolic, institutional and cultural capital embodied within medical professionals, as well as societal beliefs surrounding the field of medicine, can create a "habitus of trust

\footnotetext{
15 Some parents discussed feeling more comfortable with physicians who were the same culture or ethnicity as them and preferred school nurses due to their assistance with other outside issues affecting the child's health.
} 
and deference" among patients towards their health professionals' opinions influencing their dispositions (Callaghan and Wistow 2006: 10). It has already been noted that Anspach's (1993) research showed that parents and physicians behaviour were affected by capital, with parents with higher cultural capita suspicious of physician claims and parents with lower cultural capital accepting physician statements. Lo and Stacey (2008) have explored similar issues using Bourdieu's theory of practice, commenting that aspects such as ethnicity and cultural norms were embedded in people's habitus and impacted their dispositions in health interactions. The final part of this section addresses critiques surrounding the concept of habitus.

Criticisms relating to habitus link with its confusing definition, its pessimistic deterministic outlook, as well as questions around whether the concept allows for individual autonomy. Retsikas (2010) has commented how Bourdieu's theory is full of oxymorons and she gives an example showing how he defines the concept of habitus in four different ways which seem to contradict each other within four pages of his work in one paper. Authors such as Wacquant (1989: 31) respond to such criticisms noting that Bourdieu's theories and language employed within these theories are deliberately confusing "to break with the common language [...] and convey the essentially relational and recursive character of social processes."

Lovell (2000: 43) discussed how the notion of habitus is pessimistic about social movements such as feminism as it suggests that instead of a push towards change, individuals are simply trying to compete with one another "to reproduce class and race hierarchies" rather than acknowledging their work for "models of alternative forms of social and intellectual life." Crossley et al. (2001: 478) has similar comments, criticising habitus for being deterministic and centred around the reproduction of ideas in society instead of the evolution and transformation of ideas, but they also comment that "neither of these faults are intrinsic to the concept of habitus."

Meinert (2004) has critiqued the concept of habitus for being a "mysterious, powerful, and invisible black-box, which explains everything." Williams (1995: 588) argued that with the concept of habitus "choice is largely underplayed [... and] deliberative decision-making is grossly underestimated." He commented that risky decisions that individuals make are an example showing how individuals can overlook and defy their 
habitus. Gatrell et al. (2004) addressed criticisms of habitus centred around the lack of agency, noting that although habitus regulates the behaviour of individuals they move freely, improvising as they go, much like a sports player controlling their movements and strategies freely yet within the set of rules. Bourdieu directly addressed the issue of individual autonomy in relation to an interview with Wacquant commenting that "we can always say that individuals make choices, as long as we do not forget that they do not choose the principle of these choices" (Wacquant 1989: 45). Bourdieu (1977: 95) himself recognised issues encompassed in the concept of habitus "this paradoxical product is difficult to conceive, even inconceivable, only so long as one remains locked in the dilemma of determinism and freedom, conditioning and creativity." To understand habitus one must move outside of questions of practices being determined by either structure or agency and instead realise that habitus describes the integration of these in individual action. Bourdieu's whole point of developing his theory of practice was to combine subjectivism and objectivism and overcome various dichotomies associated with these approaches (Johnson 1993: 3). "Subjectivism fails to grasp the social ground that shapes consciousness, while objectivism [...] fail[s] to recognise that social reality is to some extent shaped by the conceptions and representations which individuals make of the social world" (Johnson 1993: 4).

Despite these criticisms, the research discussed above reinforces that there is value in examining the concept of habitus in relation to health. Williams (1995: 598), although critical of some aspects of habitus commented on the need for further investigation of this concept as "it helps us to understand and explain health and lifestyles." Through exploring the notion of habitus researchers are able to examine aspects of inequalities in health that are overlooked. Habitus has the power to influence "the individual's capacity to act, perceive, and prefer in a specific way in different social contexts." However, it is also strongly influenced by field and capital and this will be emphasised in Chapter 4's analysis of patient preconceptions and experiences of health systems aligned with their decision-making (Noiesen et al. 2004: 190). The final section of this literature review will discuss the concept of field which directly intercepts with capital and habitus. 
A field is a place of struggle over resources with each field having a specific, "taken for granted" content and tenets which individuals unconsciously understand, as "each field has its own logic and its own hierarchy that prevails among different kinds of capital" (Bourdieu 1985: 724). Field directly interacts with habitus and capital. Individuals interpret fields based on their previous experiences or habitus and an individual's position in the field is directly influenced by capital (Calhoun 1993: 66). Abel (2007: 50) described fields as different patterns of power relations with shared interests that compete over resources or to define need and supply. An emphasis around competition, struggle, and dominance aligned to its interaction with capital and habitus is compared to the concept of a game to describe the values of probability and chance embedded this concept. When an individual plays a game, they have an unconscious understanding of the rules, just as when someone enters a field, they bring their understandings and habitus (Mahar et al. 1990). In games, just like in a field, available capital means a greater chance of better outcomes, for example, in monopoly purchasing more properties gives a greater chance of winning the game. For Bourdieu (1985: 724) "the kinds of capital, like the aces in a game of cards, are powers that define the chances of profit in a given field."

This thesis argues that the public and private sectors can insightfully be viewed in relation to the concept of field. A field is a space of positions where every position is determined in terms of values (Bourdieu 1985). Researchers have used the concept of field to define and examine different areas as fields such as snowboarding (Thorpe 2009), journalism (Das 2007), sex-work (Stoebenau 2009), and translation sociology (Wolf 2007) whilst other studies have described fields in a broader sense characterising education as a field (Chirnside 2006) and the countries of New Zealand and Samoa as different cultural fields (Schmidt 2005). Bourdieu stated in relation to his definition of field:

I define a field as a network, or a configuration, of objective relations between positions objectively defined, in their existence and in the determinations they impose upon their occupants, agents or institutions, by their present and potential situation in the structure of the species of the distribution of power (or 
capital) whose possession commands access to the specific profits that are at stake in the field, as well as by their objective relation to other positions (Wacquant 1989: 39).

This statement can be used to define the public and private health sectors' different fields. These sectors are influenced by different ideologies, hierarchies, and capital constructs. The health public sector is a necessity; their logic is that they provide a service that is supposed to be determined through need and patients are ranked in a hierarchy balanced under specific criteria that takes into account other users' needs (Howden-Chapman and Ashton 2000). The private health sector, in comparison, is not a necessity and they focus almost completely on elective surgery providing a service ,depending on an individual's ability to pay. Bourdieu also stated that "different types of assets tend to impose their own logic on the other fields" (Bourdieu 1985: 724). The private sector imposes its logic of speed and quality in the competition for patients. In New Zealand, both sectors are controlled by rules and obligations under the Health and Disability Act. Public sector users typically receive their services free of charge, whereas private users pay extra for services. The public and private sectors compete for "capital" or health professionals to work in their fields. The private health sector directly affects the supply of doctors able to work within the public system, thus increasing public demand for the private system (Besley et al. 1999). Economic capital can also influence doctors' decisions to encourage patients to have private care: "physicians can improve their income by maintaining waiting lists that encourage more affluent patients to jump the queue" (Jacobson 2004: 56). The public and private health sectors could be aligned to the notion of a game (patients are the counters and medical professionals are the players). A patient's place in the system, as well as their journey through the system, is an interplay between societal understandings of health and health priorities at the time and their own and their medical professionals' symbolic, social and cultural capital.

Public and private health fields differences have been widely explored by different researchers in many countries. Studies observe the similar issues surrounding public health care in terms of public dissatisfaction associated with facilities (Besley et al. 1999; Jabnoun and Chaker 2003), waiting times (Blendon et al. 2003; Jabnoun and Chaker 2003), staffing, treatments (Parsons et al. 2010) and so on whilst also 
emphasising the merits associated with private care. Health care companies must perpetuate this discourse, as private health care would be redundant if people did not believe that they were getting something better with private care. This discourse identifiess how the public and private health fields are directly influenced by capital, specifically economic capital, and habitus surrounding people's assumptions linked with each of the fields.

Jenkins (2002) has made comments that the concept of field needs a more complete, comprehensive definition as the current explanation makes it unclear where fields exist, and how a field is determined. Bourdieu's broad definition has meant that different authors have applied the concept of field to investigate a range of areas, such as a general area like education or health or a more specific area such as in the field of sexwork. For example, from characterising the field of health in general, to defining separate health fields such as public and private health, or primary and secondary health, to further classifying separate areas of health as fields such as the field of the emergency room, waiting room, doctors surgery and so on. Although the definition of field can be widely defined, it is clearly described by Bourdieu in his work and its wide definition means the concept of field is able and applied to critically examine a range of issues and areas across society.

This research explores aspects of competition, hierarchy, and domination further through using Bourdieu's theory of practice to investigate breast cancer patients' perceptions of the public and private health fields, as well as the interaction and influence of cultural and social capital on patients' experiences in these fields. This section has briefly discussed the concept of field, and has applied Bourdieu's definition of field to define the public and private health sectors.

\section{Summary}

This chapter has addressed Bourdieu's theory of practice and its implications for health through defining field, habitus, and capital, highlighting the critiques and health research associated with them. Capital, field, and habitus are used to analyse the interview material in Chapter 4, exploring the effect of social and cultural capital on the participants' breast cancer experiences, and in Chapter 5 analysing the notion of habitus 
in relation to the participants' perceptions of public and private health. In order to address the interview material in relation to these concepts it is important to discuss how the interview material was collected. The next chapter will address the research methodology used to explore breast cancer experiences in the public and private health sectors in New Zealand. 


\section{3) Methodology}

Qualitative research explores representations of the world through techniques such as interviews, focus groups, and participant observation. This style of investigation attempts "to make sense of, or interpret phenomena in terms of the meanings people bring to them" (Denzin and Lincoln 2008: 4). "The logic of qualitative research is concerned with in-depth understanding" with researchers closely analysing people's thoughts on a situation and commenting on the meanings that can be drawn rather than trying to generalise (Hesse-Biber and Leavy 2006: 70). A qualitative research approach drawing on Bourdieu's concepts in this thesis allowed for both an enquiry into the effects of cultural capital on breast cancer patients' experiences of health systems and an exploration into participants' opinions and experiences of public and private health systems and the power dynamics between these different health fields. This study received ethical approval from the Multi-region Ethics Committee, which reviews multi-region or national health and disability research occurring in New Zealand. This chapter outlines the reasoning and issues reasoning for choosing interviews and some of the ethical considerations considered when choosing how participants would be recruited, issues that could occur with interviewing. It then discusses the reasoning behind using Bourdieu's theory of practice to analyse the interviews.

\section{Interviewing: reasoning and issues}

Last year I participated in a two-hour face-to-face survey with a researcher from Television New Zealand. It had closed questions, not allowing for further conversation, even when I added points. One of the first questions I was asked was, 'do you have a television?' The answer was more complex than yes or no. Our flat had a special device that allowed us to watch television though our computer. When I explained this, the researcher ticked no, did not take any further notes, and moved onto the next question. Different ways of viewing television were overlooked, meaning their study lacked information around new ways of watching television. This experience taught me the importance of being flexible in interviews and listening to my participants. Interviews provide insight and nuances to issues, bringing meaning and lived experience. This 
section will explore the reasoning behind the choice of semi-structured interviews for this project and addresses criticisms and issues associated with this form of data collection.

The thesis used semi-structured ${ }^{16}$ qualitative interviews to draw upon participants lived experiences of public and private health systems. Semi-structured interviews appealed because they allowed for an exploration of the participants' beliefs (Barnball and While 1994). There are many positive attributes to "spontaneous interviewer-interviewee interaction", including the ability to shape and broaden the questions and issues to fit the material, psychological benefits for participants in sharing their story, and benefits for researchers in gathering a reflection on participants' experiences "rather than mere reporting" (Crouch and McKenzie 2006: 486-7). A particularly appealing aspect of this method linked with comments about its practical use for investigating and testing theories because this thesis was specifically investigating Bourdieu's theory of practice (Wengraf 2001: 62). Other researchers have made positive comments about this research style with David and Sutton (2004: 87) commenting that "the more unstructured interview seeks to emphasise the depth validity of each individual interview" while Reinharz and Davidman (1992: 18) state that this style of interviewing "maximises discovery and description."

Semi-structured interviews particularly appealed because they allowed flexibility in relation to the interview guide ${ }^{17}$, but these interviews also had some structure, which was important because as a first time interviewer I was nervous and wanted to use an interview guide to lead the questions. Having a basic structure appealed on another level. Having experienced my mother's breast cancer it was important for me to let the participants discuss their experiences, occasionally engaging with them on various issues, but keeping the focus of the interview around their thoughts and experiences.

\footnotetext{
${ }^{16}$ Wengraf (2001) defines semi-structured interviews as interviews with some planned questions. He comments: "the term semi-structured suggests a certain degree of standardisation of interview questions, and a certain degree of openness of response by the interviewer" (Wengraf 2001).

${ }^{17}$ See Appendix F.
} 
Focus groups ${ }^{18}$ were another qualitative method considered for gathering participants opinions in this thesis after reading Ashing-Giwa and colleagues (2004) and Wood and Della-Monica's (2011) articles about their breast cancer studies using interview material to explore different issues. Focus groups can be less threatening than interviews, allowing participants to share ideas and opinions with each other, but these group interviews require a skilled moderator to guide the process, can silence some individuals, and limit the number of questions (Patton 2002). The method of recruiting participants, discussed in the next section, as well as the tight framework for participants in the study, meant that participants were from a range of places across New Zealand and that conducting focus groups would have been difficult to organise.

The number of participants in this study as well as the sampling technique ${ }^{19}$ used to recruit participants means that the thesis analysis cannot be generalised to the New Zealand population. Some researchers have made comments questioning criticisms in reference to qualitative research generalisation. Gerson and Horowitz (2002: 211) commented that a series of interviews always show general patterns from what "once appeared to be unique stories." Guest et al. (2006: 79) specifically investigated how many interviews is enough through investigating new themes they got from interviews. They state: "to understand common perceptions and experiences among a group of relatively homogenous individuals, twelve interviews should suffice." 20 They also comment that 6-12 interviews will not be enough for all research projects.

There are other criticisms regarding interview research. Briggs (2002: 915) commented that "such notions as bias, distortion, reliability, and validity reveal a great deal about the assumptions that commonly underlie interview-based research." Rosenblatt (2002) commented interviewers construct their own realities and perspectives around the interview affecting the interview and the writing up of interviews. The nature of qualitative interviews means there is a power imbalance with the interviewer asking the questions and interpreting the conversation. Interviews can be a manipulative dialogue

\footnotetext{
18 These are in-depth group interviews of 6-10 key informants which last between one and two hours (Rabiee 2004).

${ }^{19}$ Hesse-Biber and Leavy (2006: 73) commented that data saturation is slower and more difficult when using a snowball recruitment technique.

${ }^{20}$ This is based on their analysis of 30 interview transcripts where they found 109 codes overall; 80 were identified in their first six interviews, and 100 in the first 12 interviews.
} 
and the interviewer interprets the conversations holding a "monopoly of interpretation" over how their statements are construed (Kvale 2006: 484).

Kvale (1996: 241) suggested that these issues can be somewhat addressed through working on validity of craftsmanship, communication, and action in interviews through: clarifying terms with participants, exploring cases within a study that do not support your main findings, addressing the strengths and weaknesses of the study, examining alternative arguments, and investigating participants' comments on the interpretation of the interviews. Most of Kvale's (1996) suggestions have been followed throughout this study. Participants' definitions of particular aspects were clarified through interviews, within the analysis cases have been explored that do not fit with the main findings, and strengths and weaknesses of the study have been addressed. Participants were not asked about the researcher's interpretation of the interviews, although they will be sent a summary of the findings at the end of the project.

The goal of qualitative research tends to focus more on investigating the meaning of interview material, "not necessarily to make generalisations" (Hesse-Biber and Leavy 2006: 70). Gubrium and Holstein (2002: 16) noted that interviews assist in the investigation of others experiences and "the value of interview data lies in both their meanings and how meanings are constructed." These meanings are a product of history, politics and society which is important to keep in mind when reading participants' comments in qualitative interview research (Fontana and Frey 2008). Although these interviews cannot be generalised to the New Zealand population they have been able to provide a unique insight into the participants' negotiations and experiences of health systems.

\section{Participants and recruitment}

Participants were recruited through personal networks using a snowball technique. This method of recruitment relies on using participants who fit the description, who are available and who are willing to be interviewed (Hesse-Biber and Leavy 2006). An email $^{21}$ about the research was sent around friends and family and a message was posted

\footnotetext{
${ }^{21}$ See Appendix A for a copy of the email.
} 
on Facebook asking for interested women who had "completed their breast cancer treatment in New Zealand between 2000 and 2007" to take part in an interview exploring their perceptions and experiences of the health care systems. Friends and family talked to their contacts, passing on the information about the study to interested participants, so they initially became the first point of contact. Several of the participants were also recruited through other participants after they sent on information to personal contacts after their interview.

It is still important to be aware of the possible effect discussing their illness can have on participants. Crouch and McKenzie (2006) and Little et al. (1998) have written about the psychological stages experienced by cancer patients. The first stage is the diagnosis and treatment stage where patients cannot see far from their illness, in the second stage individuals use narratives to reconstruct the meaning of their experience, and in the final stage 5-12 years after diagnosis some individuals view themselves as a cancer free person again (Crouch and McKenzie 2006; Little et al. 1998). There is an emphasis that some cancer patients never reach the final stage and this has been important to be aware of when planning this study (Little et al. 1998). This is why the participants chosen for this thesis had their cancer treatment and cancer clearance at least three years prior. This is also why the participants were questioned around their opinions, preconceptions, and experiences of health systems, and how they navigated these health systems during their cancer treatments, rather than speaking to them specifically about their cancer experience.

Watching family members experience breast cancer, as well as discussions with family and friends over time, provided interest, understanding, empathy and some insider knowledge about breast cancer. Other aspects such as age, education, and non-cancer status meant that participants in the study could also feel uncomfortable because an outsider was conducting the research. There are different views expressed in the literature about interviewer-interviewee matching. Researchers such as Gunaratnam (2003) warn against interviewers trying to match themselves to their participants in studies, suggesting that they instead fine-tune their research and interview skills and acknowledge the different identity and power relations in society. Other researchers such as Seidman (2006) caution that having too much familiarity with research participants can create greater risks of exploiting them. Benefits of insider research 
include the familiarity, contacts, and rapport researchers have with individuals within the setting (Birks et al. 2007).

The rich discussions, debates, and information about this topic that came through in prior conversations with friends and family during and after their breast cancer meant that personal networks were chosen for recruitment of participants in this study. Comments by Seidman (2006) and Gunaratnam (2003) were taken into account in the recruiting processes. Participants were contacted using a general email, highlighting the optional nature of the study and that it would not be discussed further with them unless they emailed back. Not all of the participants in the study were personal contacts before the study; some were friends of friends, which is why participants who conveyed interest in being involved in the study were asked if they could be contacted by telephone. This allowed for a proper introduction and discussion around the study, and if the participant was still interested after this telephone call, a specific time and place was organised for an interview.

The interview guide, questions, and digital recording device were practised with friends before the interviews took place to test the questions and calm my nerves. Gillham's (2000) suggests that new interviewers go through this process. Gillham's advice about bodily gestures, facial and verbal expression, allowing periods of silence, following up on unclear issues, being aware of voice tone, and not over-talking participants was also followed when conducting the interviews.

Eleven women ${ }^{22}$ were interviewed for the research ranging between the ages of 53 and 88 from a number of places around New Zealand, with the majority from urban areas and three from rural areas. Participants were asked to specify their ethnicity ${ }^{23}$, and the majority of the participants identified themselves as "New Zealander" or "Pakeha" in their surveys. Three participants identified themselves in different ethnic groups including "Maori," "Cornish" and "English". Five of the participants had their treatment in the private sector, and six had their treatment in the public sector. Participants' cancer treatments ranged from surgery, to surgery and a combination of chemotherapy,

\footnotetext{
${ }^{22}$ See Appendix E for more detailed information gathered from the demographic survey

${ }^{23}$ See Appendix D
} 
radiotherapy, and long-term drug treatment. Of the five participants who had their treatment in the private sector, three of the participants in this group were also treated in the public system. Two of these women had their radiotherapy treatment in the public sector. One of these women had a more complex treatment journey receiving a combination of private and public treatment with her private radiotherapy treatment in Australia being funded by the New Zealand Government because of issues surrounding access to radiotherapy at the time of treatment.

\section{The interview}

As mentioned in Chapter 1, some rapport was established with participants before the interviews through email and phone contact. Due to the nature of the recruitment, I knew or knew of many of the participants. The interviews took place in a location and a time chosen by the participant where they felt the most comfortable. Birks et al. (2007) suggested interviews should occur in a neutral location. Herzog (2005) suggested allowing participants to choose the location for interviews as it helps create a more equitable relationship. She notes that by agreeing to be interviewed, the participants were performing a favour, which meant it was more important to be flexible around their schedules and not dictating an interview location. Herzog (2005: 27) supports this notion because "the interviewer is the "taker" and the participant is the "giver"; hence, the interviewer must be flexible and willing to adapt him or herself to the preferences of the participant." It has been suggested that for interviews on private issues, the participant's home is often the best place because this is where the participant would feel most at ease talking about such issues (Herzog 2005). I travelled to other places around New Zealand to meet participants in a place of their choice. Interviews mainly occurred in the participants' homes but also occurred in my home, at a participant's workplace, and at a participant's family member's home. Sharp and Kremer's (2006) advice was taken regarding researcher safety, a trusted friend was informed of the location and time of the interview, a cell phone was taken to the interview, and the friend was contacted after the interview to inform them that the researcher was alright.

Going through cancer treatment is a traumatic experience, and issues such as potential harm and flexibility were important to consider. Many researchers warn about the potential harm that interviews can cause. Patton commented (2002: 405) "interviews are 
interventions, they affect people." Potential harm is particularly important to consider for researchers working with ex-patients. Warren (2002) emphasised how her interviews with ex-patients was damaging for one of her participants, reminding the participant of her old identity that and her family had distanced themselves from since she had recovered from her illness. Montazeri et al. (1996: 447) did research exploring 232 cancer patients' experiences as an interview participant. Most (96\%) stated that being involved in the research was acceptable because "the interview was not disturbing, they felt relaxed and at ease, they liked to talk, and the interview was conversational" (Montazeri et al. 1996: 447). These considerations were taken into account in the research design with research questions being focused around experiences of health systems.

The participants were informed both verbally at the beginning of the interview and through their participant information sheets ${ }^{24}$ and consent forms ${ }^{25}$ that participation in the study was voluntary and they could withdraw from the study at any time without having to put forward a reason.

Participants were also informed that they could have a friend or whanau present during the interview and three of the participants chose to have a support person present during their interviews. Three of the participants chose to have a support person present in the interviews. This dynamic created a type of synergy in the interviews allowing these three participants to refer back to aspects of their cancer treatment and different issues and expand upon these points.

The participant information sheet was read to participants before the consent form was signed. Interviews were digitally recorded after gaining the participant's permission both verbally and through the consent form. Allmark (2009) commented that informing participants both orally and verbally is important to ensure participants are still comfortable. Participants were informed that their names and names they mentioned would be changed $^{26}$ for confidentiality following advice from Allmark (2009). Participants were given the option of having a copy of the digital recording of their

\footnotetext{
${ }^{24}$ See Appendix B for a copy of the participant information sheet.

${ }^{25}$ See Appendix $C$ for a copy of the consent form.

${ }^{26}$ The names used in this thesis were chosen at random by the researcher.
} 
interview as well as a paper transcript. For the participants who requested these copies, they were both sent via track-and-trace courier labelled 'private and confidential' to ensure their identity and information was kept safe and confidential. During the interviews, advice from Devault (1990) and Kvale (1996) was followed in relation to getting participants to define concepts that they talked about to ensure their proper meaning was understood and interpreted.

There is an emphasis about the importance of giving back to participants and reciprocity within the interview relationship (Patton 2002). The participants in this study were given a $\$ 15$ Farmers voucher $^{27}$ for their time and they were also offered a copy of the interview transcript and recording of the interview. Literature has also discussed how participants can get other benefits from research. Rosenblatt (2002) noted that people can be grateful that someone listens to them and actually have the opportunity to hear the story for themselves, learning new things about themselves. A couple of the participants in this research commented after the interview that it was the first time they had been able to talk about their cancer story for a long time.

Analysis

Researchers have used Bourdieu's theory of practice in different ways. In Distinction Bourdieu (1979) explored the concept of cultural capital further, measuring how much cultural capital his participants had through examining the goods they consumed, music, films, books, art, food as well their qualifications and careers. Prieur (2008) et al. did a similar study recently in Denmark to investigate the relevance of this concept 30 years later in relation to a different country. Khawaja and Mowafi (2006) used a questionnaire to explore the impact of cultural capital on the health of lower income women and defined cultural capital through different questions surrounding whether the individual was involved in specific cultural activities, as well as questions around activities such as the number of hours individuals watched television. Flere et al. (2010), measured cultural capital among secondary students, constructing a measure of cultural capital through the "educational level of each parent, frequency of visiting exhibitions and the

\footnotetext{
27 The participants were not informed at the beginning of the study that they would receive any remuneration for their time and these were given at the end of the interview with a card to say thank you.
} 
theatre, frequency of reading, and frequency of artistic activity" (Flere et al. 2010: 51). Yamamoto and Brinton (2010) constructed their participants' cultural capital on their answers to specific questions related to childhood experiences of reading, listening to classical music and, attending art galleries and museums. Veenstra et al. (2005), in their study on social capital and health, constructed their participants' social capital through analysing their involvement in the neighbourhood and voluntary associations, and linked this with health through measuring the participant's body mass index, emotional distress and health conditions. All of these types of definitions are quite structured in the way in which they explore capital, setting out to specifically measure the amount of capital individuals have.

Qualitative studies explore Bourdieu's theory of practice in a different manner using the concepts as a means of providing a lens to explore their interviews. These researchers discuss Bourdieu's concepts in relation to their research and use the concepts to explain particular situations experienced by their participants. As explored in Chapter 2 qualitative researchers have used Bourdieu's concepts as a way exploring various issues providing insight into power issues (Angus et al. 2007), decision making (Crossley 1999; Crossley and Crossley 2001; Noiesen et al. 2004; Stoebenau 2009) and the relevance of such concepts outside of European culture (Meinert 2004; Retsikas 2010). This study followed other qualitative work, analysing the interview material collected in interviews through using Bourdieu's concepts.

This study used a thematic analysis ${ }^{28}$ to group together similar narratives, using an inductivist model advocated by Glaser and Strauss (1967) which looks for themes emerging in the interview material rather than fitting interview material into already decided themes. This model was useful because the interviews changed the initial focus of the research and this model allowed for an investigation of other issues that arose. After the interviews were completed and transcribed, there were 580 pages of transcripts. The interview material became somewhat familiar to the researcher due to hearing it once during the interviews and again when transcribing them. The first step of

\footnotetext{
${ }^{28}$ A thematic analysis is a way of coding interview material by looking for patterns and similarities among data. Once similar categories develop these are referred to as themes (Shank 2002). It requires a lengthy process of looking through interview transcripts several times, consulting similar literature, coding and re-coding material into themes.
} 
the analysis process was becoming more familiar with the interview material by reading the transcripts, making comments, and highlighting parts of interest using the review commenting feature on Microsoft Word. After this process was completed Rubin and Rubin's (2005) suggestions of thematic analysis were followed. Ideas for themes and concepts were found through reading Bourdieu's work and other literature which had used his concepts to analyse their interview material (Rubin and Rubin 2005). Ideas for themes and concepts were also established through looking back at the interview guide, exploring common themes mentioned, looking at aspects that were indirectly mentioned, comparing interviews, as well as exploring metaphors and stories (Rubin and Rubin 2005). After reading through all of the interviews, the transcripts were coded into four main themes: cultural capital, social capital, public and private. Quotes relating to these themes were moved into separate computer files (Rubin and Rubin 2005).

Each computer file was read through again, analysed and grouped into further themes (Rubin and Rubin 2005). At this stage, it was useful having initial general comments made at the first stage of the analysis process as they identified the initial aspects of interest. At this stage, it became clear that cultural capital was important for some women in accessing information and entitlements, but social capital, impacted on all women in the study one way or another. Themes that explored elements of the concept of cultural capital included: the impact of different skills and life experiences on the participants' health journey, how embodied cultural capital had assisted them in obtaining their entitlements, the impact of research and information-seeking, and different difficulties and problems that occurred were identified. Themes based around social capital included social contacts assisting the participants in their informationseeking, the impact of other people's friends and networks, and the impact of contact with other breast cancer patients and survivors. Themes around public and private comments were coded differently. These comments were analysed further and first divided into private health field assumptions, private health field experiences, public health field assumptions, public health field experiences and reasoning and thoughts around medical insurance. After these groupings were made, the literature was addressed again to explore which of Bourdieu's concepts could relate to these themes. The interview material was then further divided into groups that logically fitted with one another, as well as the participants' descriptions of their preconceptions and experiences, and Bourdieu's concepts were used to further analyse these themes. As 
emphasised earlier, Kvale's (1996) suggestions were taken into account and quotes that opposed the main themes and were also included in the specific categories.

Due to the sheer amount of interview material, even after the analysis process specific quotes were chosen to illustrate the particular themes. Blauner (1987) discusses issues associated with editing interview transcripts and the processes the researcher goes through in determining the best themes. Quotes from participants initially started out reasonably long and unedited in an attempt to keep participants' voices. This was following suggestions from Reinharz (1992) and Devault (1990) that unedited speech can help the reader to hear what the participant says. Blauner (1987) suggests that slight changes are made to interview transcripts with words being added or deleted for clarity, and names and other identity details changed to protect participants. Blauner's analysis advice was eventually followed and quotes were shortened and repeated words (and utterances such as "um") were removed to make quotes less ambiguous and because of word limit of the thesis, the large amount of interview material, and to make the quotes succinct and relevant to the issue being discussed. Natural talking can be disjointed. One of the participants made a comment about this after reading her transcript, and I had similar feelings about my own speech after listening to my liberal use of the word 'like' and the utterance 'um' when asking the interview questions. Despite these hesitations and the slight alterations discussed, quotes maintain the participants' voices throughout, leaving in phrases such as "you know". ${ }^{29}$

\section{Summary}

This chapter outlined methodological issues that affected the research design by addressing the reasoning behind the choice of semi-structured interviews and issues related to interviewing, the sample and recruitment processes, and the analysis methods used for this project. The following chapters explore the interview material analysing the talk of participants using concepts from Bourdieu's theory of practice.

\footnotetext{
${ }^{29}$ Devault (1990: 103) emphasised in particular the importance of leaving small speech expressions such as "you know" in participants' quotes as they represent an important emphasis in the participants' "request for understanding" from the interviewer.
} 


\section{4) Social and cultural capital}

\section{Investigating the impact of capital on breast cancer patients' experiences in the public and private health sectors}

This research began with a focus on cultural capital and its impact on health, with an interest in investigating the impact of knowledge on the way breast cancer patients' experienced the health system during their treatment. As the interviews progressed, social capital emerged as a compelling factor with all of the participants mentioning social connections and networks whilst discussing their negotiation of health systems.

This chapter will explore some of the interview material to illustrate the impact of social and cultural capital on the participants' breast cancer. This research does not attempt to “measure" participants' social or cultural capital. Instead, it explores their experiences of health systems, identifying aspects in their narratives that can be linked with social and cultural capital. The first part will briefly explore cultural capital and discusses three themes linked with this concept. The first two themes, knowledge of rights, and control and access to information, are used to illustrate the importance of embodied cultural capital for patients. The third theme, limits to cultural capital, is used to identify issues that occur despite patients' health-orientated cultural capital. The second half of this chapter explores the different ways participants utilised social capital during their breast cancer treatment. It does this through analysing social connections discussing how personal connections, and others' connections facilitated participants access to extra services, information and treatment.

\section{Cultural capital}

Cultural capital is a combination of experiences and knowledge that assist individuals in their negotiation of different fields. This section examines the impact that cultural capital had on breast cancer patients' negotiation of the health system. This first part of this section on cultural capital will comment on situations where embodied cultural capital assisted participants in their access to the health sector and entitlements. The 
second part will explore the impact of cultural capital on participants' informationseeking behaviours. The final part will explore some of the issues that arose for some of the participants in the study despite their "high" cultural capital.

\section{Knowledge of rights}

Cultural capital is the knowledge and skills a person acquires throughout their life. "Like the acquisition of a muscular physique or a suntan" this type of capital requires personal interest, motivation, time, and effort to achieve (Bourdieu 1986: 48). Once attained, cultural capital becomes an integral part of a person's habitus, playing out in their actions, decisions, and thoughts (Bourdieu 1986). Participants' comments were centred on one aspect of Bourdieu's cultural capital, embodied cultural capital. As discussed in Chapter 2, embodied cultural capital can have a positive impact on an individual's health experiences affecting the way they approach health issues (Grineski 2009; Noiesen et al. 2004) and their interactions with physicians (Anspach 1993). Embodied cultural capital that was useful for the participants during their breast cancer treatment included their knowledge of systems, policy, procedures, and personal entitlements. This section will analyse comments from Mary, Patricia and, Linda about aspects of their breast cancer experiences that were influenced by their embodied cultural capital.

Mary is an occupational therapist. Her work in the health sector built embodied cultural capital such as knowledge of health systems, institutional processes, and patient rights. This embodied cultural capital helped to shape Mary's breast cancer experiences and expectations assisting her in critically questioning the health systems and procedures throughout her cancer treatment. Caplan and colleague's (1996) study discussed how 99 out of 367 women had delays in their treatment due to physician inaction and issues scheduling an appointment. Mary did not wait to hear from specialists, adopting a proactive approach. In reference to attaining an initial appointment with a specialist, she made comments about her proactive approach:

Ringing the health department and saying I want to be on your list and I haven't heard from you for four days - Mary 
Mary's embodied cultural capital informed her knowledge about her rights to receive timely contact and treatment in the health system. This knowledge allowed her to question the time delays within the system and inform hospital administration.

Mary's embodied cultural capital also informed her decision to take personal notes during her breast cancer appointments after her breast cancer diagnosis. Specialists can sometimes misplace notes, forget to pass information onto their patient or overlook issues (Bhasale et al. 1998; Britt et al. 1997). Mary noted in her interview two situations where her notes were lost. The following quote details two separate situations where Mary's notes were lost during her breast cancer treatment:

I may have been just an unfortunate case you know I may well have slipped through cracks you know, I know how paperwork gets lost. - Mary

He made me wait three-quarters of an hour, they'd lost my files, he was quite grumpy when I went in there. - Mary

Mary's note taking was not just for a back up. Note taking helped Mary to manage stress and take some control back over the situation. She was aware that having so many cancer appointments with different specialists could be confusing and note taking was a strategy that allowed Mary to refer back to what she had discussed with each specialist. The following quote shows Mary's awareness of the importance of taking notes to maintain perspective and control over the doctor-patient relationships and her cancer:

I write down everything. I have a book and right from the start I wrote down notes because I realised how much you forgot and that's been, that's a great control. - Mary

Research has also suggested that patients, like Mary, who manage their medical issues, have more effective interactions with their health care professionals. Wagner (2001: 68) states patients who are more informed about their health conditions, take better care of their health, are more aware of their body and health symptoms which leads to "better disease control, higher patient satisfaction, and better adherence to guidelines." Patient note taking and organisation of health consultations is also useful because medical 
professionals have little time during consultations and their haste can sometimes mean patients forget to bring up specific issues (Lutfey and Freese 2005; Shim 2010; Stimson and Webb 1975). Mary's note taking during her appointments meant that she made the most of her consultations, putting her in a strong position to raise all the issues she needed to. Moreover, she had specific details if she wanted to refer back or discuss issues with different specialists:

Having copies has been great because you do refer back and, especially because I had cancer again, it was really great to be able to refer back. - Mary

As well as taking notes, Mary had an interest in obtaining copies of specialist notes of her appointments. Initially hospital administration staff were apprehensive about giving Mary copies of her notes. In this situation, Mary's embodied cultural capital informing her knowledge of her rights as a patient allowed her to question staff comments:

And getting and asking for copies, at the start I didn't. Private sector they did give them and then I found you needed to ask for things. And they are your notes, you're allowed to have them. [...] At the start oh, 'I'm not allowed to do that'. - Mary

Health behaviours are enacted by individuals through an individual's habitus and are influenced by capital (Singh-Manoux and Marmot 2005). These situations show how Mary's embodied cultural capital as a health professional helped to inform her of her rights and responsibilities within the hospital system. Her knowledge and past experiences shaped the manner in which she approached situations allowing her to question hospital staff and procedures. Patients without Mary's knowledge might have just given up after being informed by hospital staff that patient files cannot be copied, and some patients may be unaware that they could even ask for copies of their files. Self-esteem and health knowledge are important traits that positively affect patient communication with their health professionals, these aspects in Mary's circumstances also impacted on her negotiation of the hospital system, influencing her decisions to question staff and procedures (Shim 2010). Mary's situation documents how embodied cultural capital can be an advantage in the negotiation of the health system. 
Embodied cultural capital increases with age and life experience. Jenkins (2002: 70) notes that experiences are an integrated part of a person's habitus informing their "practical logic" and guiding their actions and decisions in different situations. Age and experience can have a positive effect on patients' confidence in consultations (Stimson and Webb 1975).

One of the participants, Patricia, a scientist in her early fifties, discussed the importance of age and life experience in shaping her ability to advocate and speak up for herself during her cancer. Patricia commented that life experience (or habitus) positively impacted on her cancer journey giving her the confidence to continue questioning her surgeon, who was overlooking problems she was experiencing with a bleeding nipple. Her life experience also gave her the confidence to follow up with her concerns and ask for extra tests from her oncologist when her surgeon ignored her attempts to discuss the issue:

I had radiotherapy, then my nipple was still sore and bleeding. After a couple of goes I actually had to get the oncologist onto it. Because everyone else was saying 'oh no I don't think it's a problem' and I'm going 'it is a problem I think it's Paget's Disease'. So finally he wrote a letter and sent me back to X hospital to get a biopsy of it. [...] And it was. [...] I actually think in that case if I'd been really young and not known to just put my foot down and say look I think that this is a problem and I'm not moving till [...] you do something about this. Patricia

Her suspicions were correct, as she did in fact have Paget's Disease. In reflecting on this situation Patricia notes that age and life experience can give individuals confidence in health interactions to question issues. Patricia drew on embodied cultural capital when negotiating her breast cancer, trusting her instincts, rather than relying upon the opinion of her specialist, which meant that her Paget's disease was dealt with sooner. ${ }^{30}$

\footnotetext{
${ }^{30}$ This links back to the discussion of the "habitus of trust and deference" which can affect patient outcomes discussed in the literature review (Callaghan and Wistow 2006: 10).
} 
Patricia also discussed a second situation where she felt her life experience gave her the confidence to speak up. Patricia was unhappy that she was meeting with different registrars for each of her cancer appointments. This was because of the different registrars' inability to read her medical notes before the appointments. Patricia details the situation:

The first time I saw $\operatorname{Dr} X$ the surgeon. The second time or the third $[\ldots]$ they give you the registrar [...]. He hadn't read my file and he started asking me things and I'm going well, 'it's in the file, why have you not read the file?'. And I put my foot down. And I said to the nurse, [...] coz I had [...] some kind of issue and something I actually wanted to ask him about and I said 'look I'm not leaving here until you get me to see Dr X. [...] I've come out here on the bus, taken time off work [...] and this guy's useless' [...]. The last guy I had [...] was a registrar $[\ldots]$ had read my file and was really helpful. The last couple have been really good [...]. The quality of registrars seemed to improve after that. I doubt if I was the only one that complained actually. Bunch of stroppy middleaged women that had gone through hell and back, well you know. - Patricia

Life experience informed Patricia's opinions regarding the service she was being given by registrars as unacceptable. It also gave her the confidence to speak out. Patricia specifically commented in her discussion about following up with her Paget's disease and how age is something that gives an individual the strength to speak up in situations where they are unhappy with the treatment they are receiving from health professionals.

Embodied cultural capital is also useful for patients allowing them to pursue different health entitlements. Linda, who works in the health sector, talked about instances during her private sector breast cancer care where embodied cultural capital assisted with her pursuit of different health services:

The disconnectiveness of the private sector meant that you were reliant on your own ability to access. [...] Unless you're the sort of person that has the ability to pursue and follow things through yourself and has a strong connectedness to the community, $[\ldots]$ understandings of systems, [...] accessing systems, or $[\ldots]$ you're able to [...] pursue your GP or pursue somebody else to follow-up on that 
then I think that you are definitely in danger of being side-lined. Fortunately for me [...] I've got a really strong personality and I will question and ask for everything. I was able to pursue that myself but I believe that that is a significant concern for women in the private sector. - Linda

Linda's habitus, which incorporated her experiences working in the health sector, meant that she was relatively comfortable asking questions if she was not happy with the services she was receiving. Bourdieu (1986) commented that often the impact of alternative forms of capital can be overlooked when in fact capital transforms a game, or in this case the private sector, giving Linda an advantage to secure more capital (in terms of health services). However, because of her job as a Case Manager, Linda was aware of the value of her knowledge and skills in the health sector in terms of being able to advocate for herself.

Linda's embodied cultural capital gave her an advantage, helping her to access different services personally even when she was not informed about the specific services. She comments:

But we had enough knowledge of the community and for example [...] when I experienced difficulties with my hand I would just cut to the quick by ringing the lymphoedema nurse and just cut everybody else off in the process and just take myself. - Linda

This first section shows how embodied cultural capital assisted Mary, Patricia and Linda in their negotiation of their breast cancer treatment. This alternative capital influenced their expectations and ability to advocate for themselves and follow-up issues. This section highlights the positive impacts that embodied cultural capital has for breast cancer patients in their negotiation of the health system, entitlements, and their breast cancer in general. To close this section, Linda succinctly defines the importance of embodied cultural capital for patients for a person's health and survival:

It's your persistence [...] your ability to advocate for yourself, the ability to understand what your rights are as a patient. - Linda 


\section{Control and access to information}

As illustrated in the above section, cultural capital, particularly embodied cultural capital, can assist patients in taking charge of their treatment journey. Some of the participants in this study mentioned the importance of obtaining additional knowledge about breast cancer. Additional information, or embodied cultural capital, acquired through personal research helped some participants obtain a better understanding about what was going on with their body, their illness, and their treatment. Additional knowledge assisted participants with the types of questions that they asked their specialists, and the decisions they made about their cancer treatment. This section will investigate the impact of personal research and information seeking on participants' breast cancer journeys.

The hospital library enabled Mary to get extra information about drug side effects that were not provided by her doctor or pharmacist. This extra information reassured her that various physical things that were happening to her body were consequences of the cancer drugs and not the effect of other factors. The extra knowledge empowered Mary informing her that her whole body was not closing down. Instead, her symptoms were due to the medication she was taking:

I had read quite a bit about [...] the side effects. [...] Doctors definitely play down side effects [...] I guess they don't want to worry you. But I yeah I had to do a bit of research when funny things would happen and I would think oh you know am I getting older? Once you're 50 you think everything's cracking up but then once I discovered it was to do with the drug you know I cope much better. - Mary

Wagner (2001) comments that patient awareness about different issues means they can be more proactive about their health. Personal research also helped another participant, Karen, to feel more in control of her body before her cancer was diagnosed by researching what happens in breast cancer biopsies:

And prior to that, I had no thought of breast cancer. He said that he couldn't tell at the time. I'm a bit Pinocchio [meaning nosey] so I looked up prior to, [...] if 
you suck out through the biopsy, you know, [...] if you get fluid. [...] If you can't get fluid you're maybe looking in, [...] I'm nosy I watched. And there wasn't a lot, it was really quite difficult to get anything, so I'd already thought. - Karen

Karen's personal research allowed her mentally and emotionally prepare for what the likely outcome of the biopsy could be because of the research she did.

In medical encounters, there can be a power imbalance and patients' opinions can be overlooked because of their non-expert stance. Stimson and Webb (1975:10) comment that a patient is often a "passive and obedient recipient of medical instructions". Embodied cultural capital patients acquire through personal research can help to empower patients. The following example shows how the knowledge Patricia gained through extra research assisted her in challenging the decisions her cancer specialists were suggesting to her:

[The specialists gave me] a little bit of information, [...] it wasn't enough information for me [...] so I went and bought a book [...] on the subject. [...] I think without the book I would have been struggling [...]. The attitude was kind of well you've got cancer and we might have to do all these things. In fact the more I read in the book when I go back and sort of challenge them on it. I think at one point they suggested chemical sterilisation, which I didn't think it was, that was later on. I thought well just seemed really kind of draconian and over the top for what I actually had. - Patricia

For another participant Rose, the combination of embodied cultural capital and institutionalised cultural capital in relation to her herbal medicine qualification made her more apprehensive about conventional medicine and the effects that it can have on the body. Her suspicions influenced the way she approached her cancer influencing her decision to do more research and ask her specialist specific questions. This next quote identifiess why she sought this extra information:

I read a lot of articles online. I actually asked the doctor, were there any side effects? And he [...] didn't say no, he said reluctantly, [...] there has been research $[\ldots]$ that $[$ Tamoxifen] can sometimes cause $[\ldots]$ cervical cancer. And 
so I thought, well I'm just dealing with one cancer, don't want to actually try to encourage another one. [...] I'm a person that always asks about side-effects of drugs. I don't like taking drugs and so I asked him because that's the one of the general questions I ask when I get prescribed anything. And then I went online and I saw a lot of information about Tamoxifen. The research that I did was what led me to not taking the Tamoxifen so that's where I did have control. Rose

Rose's cultural capital gave her more power in the doctor-patient relationship. It also allowed her to ask specific questions and gain specific information about the side effects of oral cancer drugs that three of the other participants did not receive (this is discussed in the next section).

This section commented on how information seeking and obtaining further embodied cultural capital helped some of the participants feel more empowered and in control of their illness and play a larger role in decisions related to their breast cancer. Other participants with high cultural capital did not have the same sort of power and control in the doctor-patient relationship. This next section will explore some of the participants' narratives to highlight the limits of cultural capital.

\section{Limits of cultural capital in a health context}

There were limits to the impact of cultural capital on participants' health experiences. Bourdieu (1985) defines fields as a constant struggle for hierarchy that is mediated by capital. Patients are not experts in health consultations, despite the different forms of knowledge they can draw upon, still maintain their identity as a patient that has chosen to see a doctor, an expert, with institutional and embodied cultural capital as well as symbolic capital based around their position in society. This section explores the limits of cultural capital noting how participants overlooked their concerns because of advice from health professionals, and how three participants with high cultural capital still did not receive information about the side effect of drugs they were prescribed.

As discussed earlier, Mary is an occupational therapist with knowledge of the health sector. During her treatment, Mary did extensive research at the local hospital's library 
and discussed the topic with different medical friends to increase her knowledge about breast cancer. As mentioned in the previous sections Mary's cultural capital had positive effects, influencing her proactive health behaviour, empowering her, and helping her to get some control over her cancer. However, Mary's cultural capital and concerns were also overlooked in one situation with her specialist. The manner that the specialist dealt with Mary silenced her concerns about another tumour and led to the tumour developing into a more serious form of breast cancer that required further surgery and treatment:

He wrote to the GP and he said something like, you know, 'thank you for asking me to see Mary who as you know is a very anxious lady who [...] should be cured of her cancer that she had in 2001'. Well he had just examined me, I actually had a tumour there. He perceived me as being anxious because I had mentioned this bump on my chest and I read this and I thought, oh I'm obviously incredibly anxious. So that completely threw me off the scent from doing anything for 12 months. Now, I'm actually now a health professional, I should know better. But I didn’t, I was completely overruled by a specialist. Mary

In the last part of this quote, Mary mentioned that despite her position as health professional and the health knowledge she possessed, she was silenced by her specialist. Shim (2010: 4) emphasises that physicians are "agents who can solicit, evaluate, shape, and foster cultural health capital." Stimson and Webb (1975: 38) discussed how physicians use different strategies to "maintain" their expert position. In the situation discussed above the physician used his cultural capital as a doctor in the field of medicine to place the label "anxious" on Mary. This label reaffirmed his professional opinion and dismissed Mary's concerns about the lump in her chest as trivial, excessive, and unwarranted.

The next two quotes explore how Susan and Jan, despite their high cultural capital, overlooked their initial thoughts related to their illness. Their comments emphasise the limitations of participants' cultural capital in health interactions because of an 
overarching societal understanding or $\operatorname{doxa}^{31}$, which recognises scientific medical knowledge as fact.

Susan commented that she had overlooked a lump in her breast, after intensive testing, a few years before she was diagnosed with breast cancer:

A few years prior, coz I thought I found a lump, [...] they all assured me after three weeks of rigorous testing that there was no breast cancer there. But there obviously was coz it was in the exact, the main tumour was in the exact place I said. [...] They're the professionals. I like to believe that if you go for a haircut the professional knows what they're doing, you don't have to tell them how to cut your hair. [...] Doctors are supposed to know more than me. But then I came to the belief that you actually know your body better than anybody. - Susan

When her cancer was diagnosed a few years on, it was significantly worse. The cancer had spread through Susan's body and required extensive treatment. The "taken for granted" understandings related to the field of medicine, the way the body is examined, and the interpretation of scientific results by doctors is recognised as authoritative in society due to recognition by the Government (Labisch 1992). Bourdieu (1977: 168) commented that doxa is only ever revealed, "when negatively constituted by a field of opinion." Susan never had any reason to question the scientific field of medicine and the opinions of doctors and her experience is now a part of her embodied cultural capital changing her outlook about her opinion.

Another participant, Jan, who had knowledge about the health system, also had issues despite the cultural capital she possessed. She went into her initial appointment with her specialist wanting to have a full mastectomy on one side. Her surgeon strongly advised her instead to have a lumpectomy. This led to her having to go through two operations, the first to remove the lump and the second to remove the whole breast a week later due to the size and nature of the breast tumour:

\footnotetext{
${ }^{31}$ Bourdieu (1977) uses the concept of doxa to refer to "taken for granted" knowledge in society which is misrecognised by individuals as something natural. Doxa assists to "instil a sense of reality as given" (Retsikas 2010: s144).
} 
Well I had less control because I had to believe what he was saying. He was the surgeon, he's the specialist, he knows what he's talking about, I don't. - Jan

Again, Jan's comments emphasise societal valuing of the physician and the scientific medical field of knowledge. As she comments, her physician's embodied cultural capital as a surgeon meant that his opinions as a professional based upon the field of medical science were recognised by her as legitimate. Despite Jan's embodied cultural capital, she overlooked her initial thoughts because of her surgeon's advice.

Studies referred to in the literature in Chapter 2 argued that educated patients received more complex information from their physicians (Anspach 1993; Gordon et al. 2006; Siminoff et al. 2006). Mary, Carol, and Patricia were all educated and proactive in investigating various aspects of their cancer. These participants were still not properly informed about the side effects of the cancer drugs they were prescribed despite their cultural capital:

I got a sheet, [...] it was all done through a private specialist, I got a sheet on the information [...] and 'oh no this is great this is what you need to be on'. And I just read the sheet. I was actually incredibly nauseated on it at the start, it took me probably six months to settle down with it and so no I didn't get information. - Mary

So $31^{\text {st }}$ of August 2004 I had my last radiotherapy. Um and then I went on Tamoxifen which was to be for five years because I was pre-menopausal. And so the Arimidex wasn't suitable for me. No real explanation I have to say [...], I just had the instructions on the pills and I read them and I heard [...] about the putting on weight thing and I thought well that's not happening to me [...]. It's put me into menopause but it may have happened anyway around this time probably. But I have had a couple for breakthrough periods that have been revolting and I've actually had to have a hysteroscopy and D and C's to stop the bleeding, that's twice now. - Carol

So basically what it means is that sex is nothing for me anymore. Yeah so I have lost all sensation down there and apparently it's quite common, but nobody told 
me about that. [...] When I went back for my last appointment with him and he said [...] 'well I'm sorry to have to tell you that it's probably permanent because once function down there is lost it very rarely comes back'. Yeah but Patricia's the same, she gave me permission to tell you [...] that she's the same. - Carol

Physicians in Anspach's (1993) study commented that they did not give specific parents of low socio-economic groups and different cultures all the facts about their sick baby. This was because they feared the parents would question the choice that the doctor wanted to make, which for them was the best choice about the baby's life. Perhaps, like in Anspach's (1993) study, some physicians thought that their patients might not take the cancer drug. This could have informed Mary, Carol, and Patricia's doctor's decisions to not tell them about the potential side effects of the drugs.

This section has discussed the limit of participants' cultural capital in health interactions by showing that health interactions are influenced by physicians' capital and general societal understandings. Because of their institutionalised and embodied cultural capital doctors are the authority in the consultation and their place in society to grant access to services, surgical treatment, restricted medication, and define patient behaviour as sickness rather than deviance grants them the "ability to act as the primary decision maker in the consultation" (Stimson and Webb 1975: 57). The comments highlight the limits of cultural capital in health interactions through showing that these interactions play out as a part of an overall struggle between individuals for authority and are understood and "taken for granted" as part of natural societal understandings around one's place in society.

\section{Findings on cultural capital}

This first half of this chapter has illustrated the impact of cultural capital on participants' breast cancer journeys. It highlighted how embodied cultural capital such as knowledge of health systems and life experiences positively impacted on some participants access to health services, information seeking, and sense of control over their cancer. It also addressed some situations where women in this study had issues despite their cultural capital. As mentioned at the beginning of this chapter, social capital has emerged as an important concept in this research with participants in both 
the public and private sectors identifying different situations in relation to their treatment where social contacts have had a positive impact on their cancer treatment. Bourdieu's writing on capital noted the overlap between cultural, social, and economic capital. Thomas Abel (2008) takes this a step further, commenting that health-related cultural capital cannot be looked at in isolation from social and economic capital because of their constant interaction and overlap. The next section explores the impact of social capital on participants' breast cancer experiences.

\section{Social capital}

Social capital refers to the resources an individual can access through their social connections and networks (Bourdieu 2005). Chapter 2 emphasised the complexity, different interpretations, and criticisms associated with this concept. Health entitlements can be difficult to decipher and access. Friends, social contacts, and contacts of contacts were an important resource for many the participants. Personal relationships with health providers, friends, and contacts with knowledge of the health field meant participants could gain extra information, advice, and treatment to deal with problems that the health system was not addressing. The interview material related to social capital was compelling because the participants were not specifically questioned about this concept. The following section discusses the impact of social capital on participants' negotiation and experiences of the health system. It discusses how personal networks created opportunities for the participants and comments on the impact of others' social capital.

\section{Access to information and treatment}

Social capital provided participants with detailed information and explanations about their cancer and access to health services. For many of the participants, advice from friends and social contacts was an important source of power that provided them with information.

Mary had friends in the medical profession that helped her to access information, after care, and rehabilitation during her breast cancer when she could not access these services through the private sector. In the following excerpts, Mary comments how her friends explained breast cancer concepts and language that she found confusing: 
I've got GP friends and so I sort of got a couple of things, you know, [...] I had access to finding out about what things meant a little bit more so that didn't seem quite so overwhelming, although, I mean I can say that now, at the time it was all new language really. - Mary

Friends explanations helped Mary to understand of her illness, the treatment she was receiving, and language and aspects that she did not understand from her consultations and the research she did. Grineski (2009: 124) notes that doctors in particular "are arguably a more powerful source of social capital in the healthcare field" because of their knowledge and access to services and treatment. Mary commented that her medical friends' knowledge helped her to feel at ease. This was because of their familiarity working with breast cancer patients:

I've got a lot of medical friends, physio's were great coz they were real. They were the ones working with people with breast cancer and I hadn't. - Mary

Social capital with other health professionals was also important. Linda's social contacts with different health professionals through her employment in a health-related sector were useful during her breast cancer for locating different opinions and information. She comments:

At that time I actually worked in the disability sector. [...]. I worked with social workers and I worked at [...] the Ministry of Health [...]. So I got a lot of advice from colleagues and friends within those settings. - Linda

Participants also received advice from their clients from their employment in a healthbased field. Jan approved and organised her client's surgeries in the public health sector as a part of her job. This aspect of Jan's employment meant she heard client's opinions on surgery, relating to a surgeon's clinical work and their people skills. When Jan was diagnosed with breast cancer, she chose her surgeon based on the feedback she had received from her clients: 
I've known Dr X through my job. And I just know that if anything surgical has to happen that $\mathrm{I}$ would have $\operatorname{Dr} \mathrm{X}$ do the surgery. Through dealing with claimants that come in and Dr X with my job. [...] I always get a feedback from the claimants $[\ldots]$ he is just thought of so highly in our community that we're very lucky to have such wonderful surgeon. - Jan

Social capital was also useful for further developing Mary's embodied cultural capital, keeping her up to date with research and new developments on different treatments she was taking for her cancer. Mary's relationship with the librarian meant that it was easy for her to access the hospital library resources and up-to-date information about breast cancer treatments:

I know the librarian at the local hospital library so I go and say ' $\mathrm{X}$... Is there anything, can you just check and see whether there is any latest research on Arimidex and standard treatment?' and she'll pull out stuff. [...] Sometimes it's completely over my head but she's great, she'll find things. So it's a case of who you know. - Mary

Social capital also acted as a means for participants to acquire information they could not obtain from their health professionals during their breast cancer treatment. Patricia interested in acquiring in-depth information and understanding medical terms associated with her cancer. Unfortunately, her specialists did not take the time to explain reports to Patricia. Patricia instead accessed explanations and interpretations about her cancer through discussions with a friend. These discussions were a vital part of Patricia's research and information-seeking process assisting her in building embodied cultural capital specific to her illness. These conversations also affected Patricia's habitus, building her cultural health capital, helping her to understand her specialists and affecting the way she made decisions about her health and treatment:

But nobody sat down when I demanded print-offs of the reports. And nobody actually sat, apart from biopsies and things, nobody actually sat down and explained them to [...] It would have been good if they had actually sat down and discussed it with me instead of saying 'oh yeah the report says it's fine'. $[\ldots]$ There were a couple of occasions $[\ldots]$ when I was $[\ldots]$ really struggling to 
get any results out of them. And as a scientist, you know, I wanted to see the results [...] I wasn't getting the information I wanted. [...] I used to demand the reports and then I'd ring up a friend of mine, who has a phys-ed degree and used to lecture in nursing, and I'd go to her 'what does this mean, what does that mean?' and then next time I'd be ready for them. - Patricia

The important role of physicians in building and maintaining cultural capital is affirmed by Shim (2010: 4) who argues that cultural health capital is a "collective achievement of patient-provider interactions." Patricia's actions touch on a further part of cultural health capital not discussed by Shim, how patients can actively ignore provider comments and continue to build their own cultural health capital. Patricia relied on social capital as a means of further building her cultural health capital.

Experiencing a system as a patient gives an individual invaluable knowledge and insight into that system. Relationships participants had with different breast cancer survivors also helped to give them information, reduce their fears, and gave them mentor who had survived the cancer and who was getting on with their life:

Hearing about a friend getting breast cancer helped Nancy make the decision to have a lump in her breast get checked out:

That was through $\mathrm{X}$ wasn't it? (going to get her lump checked out was from hearing about her friend having cancer) - Nancy

She'd had the lump for a wee while I think and I mentioned about X coz X rang me and told me about hers and I mentioned it to Mum. And that was the first we knew about that she had a lump you see. And so then she went off to the doctor. And then the doctor from there referred her to the hospital. - Nancy's daughter

Nancy also mentioned in that her friend who was slightly ahead of her with the breast cancer helped to put her mind at ease by telling her about the different processes and what they were like: 
She was good X. Well we just talked about what they do, what they don't do. $\mathrm{Coz}$ there is the sort of fear in the background. What's going to happen, she certainly helped. - Nancy

Insider contacts that had survived breast cancer were also important for other participants. Linda, Heather, and Carol emphasised the value in talking about their breast cancer with other women who had been through the illness and how this was important for passing on information about different services. These conversations also helped to give these participants hope that they could survive their treatment and breast cancer because it gave them living proof that others had survived similar treatment:

I think it was positive to share with other women who had been on the journey before you. I found that really helpful and really enlightening. You know whether it was things that you're worried about such as you know a drug that you might be going to take. Or whether it was about you know a good physiotherapist that might see you to look after your arm or whether it was that someone said to you look listen I have a pain in my arm too, you know, so I think it helped from people who've been in a similar kind a situation to yourself. Knowing that those women had had a similar type of diagnosis where they might have also been also high risk people to survive. - Linda

It was always very nice to hear of other people who'd gone through the same experience but had been very positive and to hear of the thing that they were doing now and to know that you can. That you can still have a really good life. Heather

When I went to pick up the first prescription the lady behind the counter at the chemist said 'oh ok', she said, 'I was on this', I said 'oh really'. I said 'how long since?'. She said 'oh I've been 12 years'. Brilliant. That was so good, and that's why I talk to people coz I think it's really handy. That was one of the best things. [...] The best thing for me was when the nurse who had told [my friend from work] to get me to the doctor, her mother was still alive 30 years later. And then this lady was 12 years out and I think we women have got to talk to each other and give each other the good news as well. - Carol 
The above examples illustrate how social capital or connections with other women who had been through or were going through breast cancer were invaluable for many women in the study in dealing with their illness, reducing stress through addressing the fears associated with the illness and accessing different advice.

Social capital was not only invoked for information seeking and reassurance. Participants also used social capital to access resources during their treatment. Mary deployed social capital when she was having difficulty accessing resources. Mary discussed that the follow-up after her initial breast cancer surgery in the private sector was poor. She had little contact and follow-up from her surgeon after her operation, and was not told about her entitlements which created issues later when she developed lymphoedema. Social capital provided Mary with access to advice, services, and care from professionals working in the public system without cost, having to make appointments, or waiting in line with other public sector patients:

I've got quite a few physiotherapy friends and they all helped, they came and did massage and got me a sleeve and did all sorts of things like that, so I actually was able to access the public system [...] because I knew people in it. - Mary

Mary's friendships with physiotherapists were an important resource she drew upon when she developed lymphoedema in her arm. These relationships put Mary at an advantage giving her access to physical rehabilitation in her friend's own time, "free of charge, often after hours."

Social contacts can also assist individuals in justifying their decisions through obtaining their advice and expertise. Rose's friend that was a naturopath, helped by providing advice about alternative medicine. Rose did have conventional medical treatment for her breast cancer, going through surgery and radiotherapy. However, she decided that the oral cancer five-year drug course was not right for her because of the effects it could have on her body. Rose had a friend that was involved in alternative medicine and her friend's knowledge of alternative therapies provided her with another option for treatment when she did not want to have conventional drug treatment: 
I've got a friend [...] who owns the health shop in town [...] and [...] I've got a friend who's a naturopath [...]. I went and saw that friend who's the naturopath and told her. [...] Together we did all sorts of things, [...] I was also already into doing meditation and I was just, it was a matter of keeping positive. She put me on $[\ldots]$ progesterone. [...] She gave me some of that and some other stuff [...] and I felt really positive about that. - Rose

The above examples show that friends and social contacts assisted participants in obtaining extra information, advice, reassurance, and services during their breast cancer treatment. Social capital for Mary, Patricia, and Linda helped them to build their embodied cultural capital in relation to their breast cancer as well as obtain extra advice and opinions surrounding the illness. Social capital and relationships with her clients meant that Jan had an insider view into people's experiences of surgery and surgeons. Relationships with other breast cancer patients helped Nancy, Heather, Carol, and Linda received value information and advice as well as gave them a positive role model to look up to that had survived the disease. Social capital also helped participant access different services assisting Mary in accessing physiotherapy and expanding Rose's options for breast cancer treatment. Social capital through relationships, contacts, and networks opened up options for participants. The next section will explore how friends and contacts relationships with other people opened up opportunities to assist participants with different elements of their breast cancer treatment.

\section{The impact of other people's social capital}

In addition to resources accessed through personal social networks participants in the study also discussed how they accessed assistance through their friend's contacts. This section discusses how friend's contacts assisted participants through validating their concerns, and accessing information and resources

Friend's contacts assisted participants through validating their concerns. Research has shown that people often require friends or family to validate their illness before they go and see a doctor: "the greater the uncertainty the greater the importance in others to consult $[\ldots]$, 'to prove that you've got something wrong', [...] as it is often not clear to the person whether their problem merits medical attention" (Stimson and Webb 1975: 
21). Friend's social contacts were important for both Jan and Carol in justifying the seriousness of their concerns before they followed through with going to the doctor about the issue. Both of these participants commented that discussions with work colleagues encouraged them to address their initial breast cancer symptoms. Both Jan and Carol's friends after their discussions spoke with their social contacts in the medical profession about the women's issues and symptoms they had discussed:

There were nurses that work here, one of the nurses came running to me as soon as she heard that I was diagnosed with breast cancer, she said she was shocked and said 'look can I speak to Dad (her father's a GP) and get some advice off him, would you like me to do that?'. And I'm saying 'yes, I need all the advice, yes please'. So the next day she comes back, she said her dad had actually said once you have that sort of diagnosis [...], he would say have both breasts off. Jan

I thought oh I must have pulled a muscle. But there was a little voice in the back of my head that said 'you stupid woman there are no muscles in your boob'. But you know I was busy [...]. I went to work on Monday the next day. [...] My friend at work went and talked to her friend who's a nurse and said Carol's found this sort of puckering. She said tell her to get to the doctor, that's how her mother almost 30 years before had found her breast cancer, it was a pucker on the side of her breast. So the tumour was actually growing back into the breast rather than coming out. And it had attached obviously and what it attached to was just pulling the skin in a little bit and distorting it. So it was just the way it was growing that alerted me to it. The doctor when I went to the GP couldn't even find the lump. I mean she did, eventually, sort of think that she could feel something. But it was upper outer quadrant and it was quite far in. - Carol

Contact with other friend's social contacts was also useful for finding out different information related to managing breast cancer-related issues. Carol had a friend that was friends with a nurse. The nurse arranged so that Carol attend a special lecture about lymphoedema and also learnt about different therapies and treatments she could pay for to control her lymphoedema: 
My friend [has] another friend who is a nurse. She is a district nurse [...] and she found out that $\mathrm{X}$ was giving a lecture and so she got me in there as well. [...] Only a portion of it was relevant to me [...], but I was really impressed with this woman. [...] So I actually went to her quite a few times for massage [...] and so she did a bit of jet therapy. - Carol

In addition to validating participants' illness and informing them about different treatments, other physician's social contacts opened choices and opportunities for two of the participants. The next excerpts explore how physician's social contacts assisted the Linda and Mary with issues associated with their breast cancer.

Linda built a strong working relationship with her cancer specialist keeping him informed with her concerns, treatment path, and decisions. One of Linda's friends had a particularly negative experience with a certain radiologist. This individual continually preached her friend's life statistics in appointments and maintained a negative perspective and outlook regarding her treatment. After hearing her friend's story, Linda was afraid of having her radiotherapy treatment. However, Linda's relationship with her specialist allowed her to utilise embodied knowledge from her friend:

So I was lucky enough because of the relationship I had with the oncologist. He went along and basically put a piece of paper he told me in the radiotherapist's pocket saying [...] we selected the person [...] I was to see. [...] I was frightened of having one of the other people that I heard was in the system that was very good at telling people what their chances of surviving were, I'd already heard that [from] one of the women that was also in the same setting. - Linda

Mary's relationship with her physician also assisted her in accessing special treatment. When Mary was supposed to have her radiotherapy there had been strikes among radiologists, which had created a significant backlog of patients. The Government arranged for many cancer patients to have treatment in Australia, but an initial appointment was necessary to get a place on the waiting list. Mary could not get an appointment, deploying all the avenues she could. Eventually her physician's friend created an opportunity for an after-hours appointment: 
It was an extraordinarily long time and I'm reasonably proactive and I rang. I actually knew the number of one of the booking officers. Her son was playing soccer with mine you know so it was through that combination. And she said 'no you're in the system but you're quite low priority'. [...] They were completely booked out [...], they had to assess me before the Government would give the go ahead [...]. So that was where the breakdown was and we kept ringing and saying, in fact, my husband in the end said we'll go and camp, we'll go and sit in the waiting room until there is a cancellation. We'll be there every day. And in the end our GP actually pulled a string, he's South African, he had a South African doctor friend up there and he rang him and I got an after-hours appointment. - Mary

Wider relationships were important for participants following up with initial health concerns, finding out about different services, being warned about negative experiences and acquiring an otherwise unattainable specialist appointment.

Chapter 2 defines social capital and reveals the two main approaches, the network and communitarian approaches, used to analyse this concept. To recap these approaches, the network approach defines social capital as a "resource used to reinforce the prestige and power of affluent social groups to the detriment of others in society" (Wakefield and Poland 2005: 2822). The communitarian approach, in comparison, views social capital as a way of improving society through increasing trust and interdependence in society. As mentioned in Chapter 2, Fine (2010) is critical of Bourdieu's definition of social capital because, like similar other concepts in his theory of practice, he portrays human nature as something that is selfish, only performing tasks for other members of the community because they will get something in return.

The way participants' discussed the favours performed for them by other people and the things they did for others in relation to their breast cancer aligns more with Putnam (2000) or Healy's (2005) description of social capital with the idea of paying a favour forward. Healy (2005) comments that when obligations are performed there is an expectation of the favour being returned in the future, but not necessarily from the person they did the favour for. Healey (2005) gives an example of helping a stranger whose car has broken down; one does not expect that individual to return the favour but 
hopes if something similar happens to them that someone would help them, drawing on the notion of general reciprocity discussed by Putnam.

Physicians' performing different favours for patients did not have anything to gain from their patients; favours performed could have perhaps been to their detriment, indebting them to performing similar favour for their colleague in the future. Although this type of favour easily builds a physician's reputation as a better doctor and reputation does helps a physician distinguish themselves among their fellow professionals and thus dominate their medical field. Participants' in the study, who benefited from different favours from other people did not mention others expectations although, many chose to do different things to help or assist other cancer patients and their families ${ }^{32}$. This shows that there was still a sense of obligation to give back to others. It also highlights how social capital in practice can combine parts of Putnam's and Bourdieu's definitions through Healey's definition which describes individual obligations arising out of social capital as a combination of community spirit, good faith as well as individualism with favours perhaps adding to some people's dominance within a field.

\section{Findings on social capital}

The second half of this chapter investigated the impact of social capital on the participants' breast cancer experiences. Social capital emerged as something that was useful for participants' in both public and private health sectors to access different information about treatments and resources. Friends of friends or other people's social capital were also important for many participants in accessing different treatments, services, advice and information.

\section{Summary}

This chapter discussed the impact of cultural and social capital on the participants' experiences and negotiation of the public and private health systems. Cultural capital was discussed highlighting how embodied cultural capital positively influenced

\footnotetext{
${ }^{32}$ Such as sharing their knowledge with friends and contacts, working to improve breast cancer services in their areas and developing trusts to help assist those with cancer treatments that are not publically funded.
} 
participants' health experiences and information-seeking behaviours, as well as the limits of this concept. Social capital assisted many of the participants with issues they experienced throughout their breast cancer with contacts helping participants to access information, treatment, and services. Many of the participants had a strong reliance on social networks to negotiate public and private health systems and receive information and services. Participants' reliance on both social and cultural capital raises issues regarding inequalities and problems that may occur for breast cancer patients that do not have the same knowledge and access to social networks. The next chapter will use Bourdieu's notion of habitus to explore participants' collective habitus aligned with their preconceptions of public and public health sectors and compare these with their experiences of these sectors. 


\section{5) Public and private health sectors}

\section{Exploring the preconceptions and experiences of breast cancer patients}

There has been a focus on exploring breast cancer patients' preconceptions and experiences of the public and private sectors from when this research commenced. Initially this was to explore how these sectors differed and how cultural capital influenced participants' experiences. There were few differences in the public and private services offered to the participants in both sectors with participants receiving similar treatment, in similar timeframes. But the way participants' described the public and private sectors followed a similar pattern. Participants made positive comments about the private sector in their discussions of their preconceptions of health systems, and linked negative attributes such as waiting and inattention to detail with the public sector. In addition, both sectors had their strengths and weaknesses although participants using the private sector were more forgiving of the weaknesses. This chapter briefly defines the public and private health sectors and the concepts of doxa and illusio. It then uses these concepts to examine the participants' comments about their preconceptions and experiences of the public and private sectors linking the public sector with waiting and the private sector with speed and the role physicians' play opposing or reinforcing these opinions. It then explores the participants' experiences of different aspects of their public and private sector care to show how the participants in this study experienced similar experiences for their cancer treatment in terms of speed, quality of staff service and access to staff.

\section{Defining concepts}

In different countries there are different rules regarding health care and what the Government covers. New Zealand has a mixed health care system with a significant amount of secondary health care costs covered under the public hospital scheme and elements of care covered in the primary health scheme under an eligibility basis: " $78 \%$ of total health expenditure is financed from public sources $[\ldots$ and a ...] further $16 \%$ of 
expenditure comes from out of service payments and $6 \%$ from private health insurance" (Ashton et al. 2005: 254).

In this chapter, the terms public and private will refer to what health sector patients receive their treatment in. Marsh et al. (2010: 143) have described these sectors in relation to health: "public refers to services based on eligibility criteria. Private refers to services for which all or part of the costs are covered by the patient's private health insurer or at their own cost."

Different authors have put forward different reasoning behind consumer decisions to choose private health care. Private health care has been said to increase the amount of services and technology offered to the consumer as the fee charged covers more than simply the labour (Ferguson 2003: 610). Some patients choose private health sector care because they want a combination of health care, comfortable facilities and friendly staff and they also want to avoid the waiting lists (Jabnoun and Chaker 2003: 291). Other reasoning for going privately includes what authors like Besley (1999: 156; New Zealand Public Service Association 1985) refer to as "hotel benefits" such as access to their own room, nice food, an ensuite, privacy and so on. This first half of this chapter examines the participants' reasoning and preconceptions associated with the public and private health sectors. In order to discuss these comments in relation to public and private and Bourdieu's concepts it is necessary to describe these concepts.

An illusio is a "belief in the game" (Bourdieu 1979). This belief is at the centre of belonging to a field, encouraging people to invest and participate in activities. An individual's investment and participation in a particular field is determined by their position in the game which is in turn determined by capital and habitus: "each field calls forth and gives life to a [...] specific illusio [...], implied by one's participation in the game [and] specifies itself according to the position occupied in the game" (Wacquant 1989: 42). Crossley (1999) has used the concept of illusio to explore people's work for social movements, commenting that an illusio means individuals involved see their work as meaningful and worthwhile. Crossley (1999) notes that activists from radical mental health movements visit utopias to provide them with an illusio reminding them of the outcomes that their actions can achieve. These utopias allow them to visualise and anticipate the future of mental health in their country, justifying and validating their 
work, and giving them a reason to continue. Illusio and doxa are interconnected and Bourdieu (1990) comments that illusio gives people interest in the assumptions or doxa embedded within the game.

Fields are comprised of assumptions that affect individual's practices. Doxa is a term Bourdieu uses to describe these assumptions. Doxa, or "core values and discourses" (Webb et al. 2002: 27), which is implied when entering a game, is intimately linked with an individual's habitus and field assisting them in making sense of different situations (Bourdieu 1990). Bourdieu (1977: 164) uses the concept doxa to describe the common sense, natural beliefs produced by the dominant class which reproduce power relations "by securing the misrecognition, and hence the recognition, of the arbitrariness on which they are based." Doxa makes classification systems in society "appear to be grounded in reality [...] and not only in the eyes of those whose interests are served by the prevailing system of classification" (Bourdieu 1990: 71). Doxa means that people invest in ideologies, even when they are unhappy with them because other actions and ways of doing things seem unthinkable. Doxa is reinforced through structures and procedures or orthodoxy ${ }^{33}$ and weakened through contradictory discourses or heterodoxy ${ }^{34}$ (Miller 2008). Later in the chapter these concepts will be explored by analysing how physicians, who are dominant members of society, can either strengthen the doxa associating public sector health services with waiting or expose a different discourse surrounding public sector cancer services.

\section{Preconceptions and experiences of health sectors before breast cancer}

This section examines the participants' comments about their preconceptions and experiences of health systems before their breast cancer treatment. It explores the participants' decision-making processes regarding health sectors, examining excerpts about public and private health sectors, preconceptions associated with waiting lists and the speed, and the impact of physicians' statements on the participants' preconceptions.

\footnotetext{
${ }^{33}$ Orthodoxy refers to structures, processes and procedures that defend and reinforce the current doxa and its privileges (Swartz 1997).

${ }^{34}$ Heterodoxy is when taken for granted structures within society are exposed as one of many truths instead of a singular taken for granted truth (Dougherty 2011).
} 
This section uses the concept of illusio to highlight some of the participants' narratives about their previous experiences of the public sector and the private sector. As discussed earlier, an illusio further encourages individuals to invest in a particular field, in this situation the illusio acts as justification or validation of the participants continued investment in the private sector. The first three narratives are stories from two of the participants - Eleanor and Carol - detailing their experiences of the public sector. These women commented in their interviews that they had been paying for private medical insurance and using health services in the private sector for quite some time. The following stories detail their previous experiences of the public system.

When asked about their preconceptions of the public system Eleanor and her partner discussed a couple of their experiences. One of their stories was about their experience of her partner's elderly mother's time in the public hospital. They emphasise a lack of basic care and attention by public sector staff to this woman:

Eleanor - Well I thought that with your mother it was quite poor.

Partner - It was appalling.

Eleanor - She had breast cancer. But that side of things wasn't so bad, it was what happened later $[. .$.$] .$

Partner - She had ended up with bowel cancer [...]. And the treatment was you know you ended up with an apple with your meal which you couldn't eat coz she didn't have her teeth.

Eleanor - She wasn't wearing any teeth.

Partner - And so basically, you know, she would have probably starved to death. 
Eleanor - And she was left uncovered so as you walked down the corridor which was in a private room. But if you, as you looked in you could see [...], she could be uncovered from the waist down. So that aspect was exceedingly bad.

Eleanor's other story about the public sector detailed their experience of her father's time in the public hospital where they emphasised both a lack of attention to detail by staff as well as disrespect shown in the public hospital:

Eleanor - When Dad became ill, [...] he's been dead over a year now, and he was in a home for 18 months, [...] last [...] stages and he went blind, [...] he was taken to [the public] hospital and [...] it was never noted that he was visually impaired. So they would put pills down in front of him, he couldn't see them to take them and they'd put his food there and just walk away and leave it. I did put in writing my concerns to the hospital board at that stage because I just thought it was just appalling.

Partner -They talk about people having rights in hospital, but they don't follow them through. You know like he might have had tablets in foil, you know, and he'd be handed them as they were in foil and he couldn't see to open them.

Eleanor - If we weren't there to feed him he just didn't eat. [...] They put him in naps. And yet he was perfectly okay, he didn't have bowel problems [...] he wasn't incontinent. They put him in naps because it was easier than to take him to the toilet.

In Eleanor's experience, the public sector was inattentive, forgetting to check aspects such as patient's visual and eating impairments. The public sector was also disrespectful of the elderly, removing their personhood and dignity in hospital by leaving them exposed and placing them in nappies.

Carol detailed similar inattention to detail when she discussed her previous experience of the public sector and how she was ignored for several days in the hospital by staff: 
I've had $[\ldots]$ an acute visit to the hospital. They did forget about me [...] I went in with acute and unexplained stomach pains cramps, that was after I'd had one child coz I could liken it to being worse than labour, that's what I told the doctor, and they couldn't find out what was wrong so they admitted me to public. And it was fine but three days later I was still sitting there and the doctor walked in and said what are you doing here? [...] Waiting for food coz I was still nil by mouth [...] they'd forgotten to discharge me so that was amusing. - Carol

The concept of illusio can be used to think about these narratives. The narratives infer that the public service is inattentive to patient needs and care and work as an orthodoxy supporting the current doxa in society that the private sector is superior. Bourdieu (1990) comments that an illusio is central to belonging to a field. If Eleanor and Carol did not hold an illusio supporting their belief that the public sector was not meeting patient needs their use of this alternative health field would be irrelevant and unjustified. These two stories act as an important validation for Eleanor (and her partner) and Carol's investment into their medical insurance. Stories work as an illusio justifying their investment and choice to use the private sector, implying that the game they are playing in is worth the effort and the economic capital that they are investing is worthwhile (Webb et al. 2002: 26). These narratives work to inform and anticipate the rules of the game and the nature of service in the public sector as well as providing validity behind their decisions to go privately for their breast cancer treatment.

The next two narratives from Rose and Karen detail their previous experiences of health systems. Both participants chose the public sector for their breast cancer treatment due to lack of economic capital, but both support the doxa that the public sector is somewhat inattentive.

When asked about her preconceptions and previous experiences of the public sector Rose discussed her experience of having her appendix removed in the public hospital, the time it took to diagnose and the lack of support she received after the operation:

I had appendicitis [...] it was really painful and it took them something like four hours from the time they diagnosed me, late at night, half past 11, I finally went into theatre. [...] Nobody was around; I had no support team, coz everybody had 
been sent home basically. [...] It was pretty scary, I woke up, on my own and not able to move, [...] I was completely ignored, my existence was completely ignored, I was lying in immense pain, I couldn't move and I actually couldn't speak. [...] Nobody came to check on me, it was horrible; it was a pretty horrific experience. - Rose

This occurrence Rose detailed above aligns with another incident in the public sector she experienced after her breast cancer surgery. ${ }^{35}$ This experience had already provided her with some sort of anticipation of what the public sector could be like before her breast cancer treatment in a public hospital.

Rose also had experience of the private sector before her breast cancer treatment through visiting her partner when he had an operation:

My partner at the time, [...] a few years ago, had used that private system. He'd had a part of his lower leg amputated and I was pretty impressed [...] because there seemed to be a very like almost a one-to-one caring basis. --Rose

When asked about her past preconceptions and experiences of the public sector before her breast cancer Karen discussed her experience of her child having a procedure in the public system. Her narrative emphasises that the treatment and hospital were good, but highlights the delay in waiting for the procedure and the work that she had to do to get her daughter's operation performed:

I wouldn't say they were speedy. My child had her tonsils out but I had to keep ringing up to remind them when I was going to get in for her to have her tonsils out. And it took quite some time [...] staying on their back and then all of a sudden we had an appointment just out of the blue. That was going to [...] up to

\footnotetext{
${ }^{35}$ In this situation Rose detailed how she and another patient were left with no staff support post-surgery and how their requests for assistance were ignored. When asked about making a complaint Rose commented that she did not make one as she was too unwell after her surgery and was aware of the time involved in complaints procedures. Bourdieu comments how people invest in doxa even when they are suffering or unhappy as the field operating in other ways seems unthinkable and impossible (Webb et al. 2002). Rose's actions after her breast cancer surgery reflect this idea.
} 
three months and I think it was six months before we actually got an appointment. But the treatment was fine and the hospital was fine. - Karen

Doxa produces the common sense or natural belief that private sector health care is superior with classifications such as fast and personalised care associated with the private system and large-scale, inattentive care associated with the public sector. The illusio that private care is worth the investment is reinforced by participants' comments about different problems in the public sector and justifies their investment in the private sector. Bourdieu (1990) comments that dominant members of society produce doxa as their position in society means that they have the power in defining discourses and items of distinction. In the case of medical care, private care means the dominant class can use economic capital to access fast care, in nice facilities, at a time of their choice. This provides distinction as it means their health issues are addressed, having less impact on their life or employment. There seemed to be a doxa among the participants that the public sector is not meeting health needs on an individual level. Whether it was through not dressing Eleanor's mother-in-law or putting her teeth in, not reading about her father's health condition, not checking on Carol over a three-day period, not checking on Rose, and relying on Karen to negotiate her own daughter's entry into hospital. Participants' experiences discussed in this section help to support Eleanor and Carol's justification in belonging to the private health field. Rose and Karen's comments support the doxa that the public system is less attentive. Speed is an issue discussed by many of the participants particularly in relation to their understanding of the public and private sector. The next section explores the participants' preconceptions in relation to speed.

\section{Preconceptions associated with waiting lists and speed}

Speed seemed to be the most common adjective participants used associated with the private health sector. The link between speed and the private sector has been made in different studies. Research across five different countries has found that "New Zealand adults expressed some of the highest levels of dissatisfaction with their system overall, citing concerns with waiting times for hospitals care" (Blendon et al. 2003: 119). Howden-Chapman and Ashton (2000: 33) commented that New Zealand public patients have "significantly" longer waits for specialist appointments and hospital appointments 
than private patients do. Other authors such as Glied (2008) and Jacobson (2004) argue that dissatisfaction towards waiting times in the public health system is caused through the private sector increasing the public's expectations of reasonableness in relation to waiting lists. This section will discuss Bourdieu's notions of doxa and illusio to explore the participants' comments related to their preconceptions of health systems. It is argued that these comments provide support to Bourdieu's argument that access to capital gives individuals dominance and control over specific fields and manipulates societal values around issues and objects ${ }^{36}$ (Williams 1995).

Once many of the participants were diagnosed with breast cancer they wanted to have the cancer removed at the soonest possible date. This sense of urgency can be linked with societal understandings of cancer from medical science. Cancer spreads through normal bodily processes; normal body cells continually divide and replace themselves, and cancer cells work the same way, mimicking normal cells, tricking the body into reproducing them and spreading them throughout the body in a process where "death infects life" (Stacey 1997: 79). The association of cancer and death reflect in several of the participants choices as to why they chose private cancer care.

One of the participants, Eleanor, made specific reference to death when she discussed her reasoning behind going privately:

I wanted it done now. You know, once you know that something's there that could damage your lifespan. - Eleanor

Jan's decision was also based around making sure that the cancer specialists saw her promptly so that her cancer was dealt with quickly:

I chose the private because I didn't want to wait. - Jan

\footnotetext{
36 Williams (1995: 589) stated that "because of their greater access to and possession of capital the dominant classes are more likely to be in control of those fields which are invested with the power of bestowing value upon particular bodily forms and lifestyles. Indeed, central to the process involved in the search for social distinction is the ability of dominant groups to define their bodies and their lifestyles as 'superior'."
} 
I thought $[\ldots]$ I would get to the specialist quicker than going through the public hospital system. I thought I would go on a waiting list for the public and I didn't want to wait, I wanted to move fast, so I naturally thought the private way was the way to go. - Jan

Eleanor and Jan emphasise the importance of acting quickly when dealing with cancer, a disease that has been proven to move quickly.

Speed was an aspect that backed Carol's decision to have medical insurance. In her discussion of the public sector, Carol associates aspects such as uncertainty, bureaucracy, and risk with the public sector:

Every time we go to hospital [...] it's worth having medical insurance if you want to get it done quickly, which of course that's what I do. You can have the treatment, $[\ldots]$ there's no prick in Wellington telling you you're not serious, $[\ldots]$ there's no waiting lists. You decide whether you want to have treatment, you and your doctors, not some bureaucrat. [...]. I mean if you've got an acute problem the public system's great. But if you've got something you're not going to die from tomorrow [...] then some bureaucrat in Wellington decides whether you know you're a number one or a number two or whatever. - Carol

Linda, another participant that used the private sector, also had similar concerns around timeframes associated with the public system around rationing and waiting times and their association with risk:

I was concerned in the public sector I might have waited until you're basically not here. - Linda

In many occasions when you really need something to happen you wait a very, very long time in the public system to access. - Linda

Linda's understanding of the public system was that unless cancer was reaching critical stages it was not a priority in the public sector. This doxa associating the public sector 
with waiting gave the assumptions that early stages and symptoms of cancer could be overlooked for a period of time in the public sector bringing significant risks to lifespan.

Eleanor also emphasised how cancer patients in the public sector could have a potential wait and comments that she chooses to retain her medical insurance despite the significant increases in the cost.

But I'd like to have retained that opportunity to get something done quickly. [...] I think with cancer some people have to wait such a long time and you just don't know what's happening to their body while they're waiting, and if you haven't got those insurances you don't have the same opportunity unless you're earning good money. - Eleanor

Participants' doxa linking speed with the private sector is reinforced by the orthodoxy linked with general understanding of the market and rationing mechanisms. Hurley et al. (2002: 24) assert "unless there is perceived to be a quality difference between the public and private sectors, no economically rational person would choose private finance in the presence of a free alternative." Speed was something that Karen associated with the private sector before her cancer treatment:

I always thought the private sector would be quicker, more efficient and obviously staffed a lot better than public. Because you're paying. - Karen

The doxa that private system would be quicker was reinforced through the orthodoxy of market reasoning. The fact that people invested money for private treatment they could receive free of charge in the public sector meant that Karen reasoned that there had to be some benefits for going privately. The following section explores how physicians' statements either worked as an orthodoxy reinforcing some of the participants' doxa related to the public sector or how they worked in reverse as a heterodoxy exposing positive conflicting and contradictory discourses linked with the public sector.

Impact of physicians' statements on perceptions of speed and health sectors 
The previous section discussed the doxa (associating the public sector with waiting and the private sector with speed) that some of the participants highlighted during their interviews. This section explores how health professionals' statements either reinforce or oppose the doxa in society linked with health sectors and speed in relation to cancer. It does this through examining participants' comments about their health professionals' statements and how these either worked as an orthodoxy, reaffirming the doxa participants associated with the public field, or a heterodoxy, transforming their opinions through assisting them to see contradictory discourses.

The doxa surrounding the public and private sectors can be reaffirmed or discouraged through the comments of health professionals, who are dominant authorities in the medical field. As discussed earlier those with higher amounts of capital have more power in fields and defining fields. Physicians in the health field have high amounts of cultural and symbolic capital, which means their patients respect their opinions and they are "in a position to impose recognition" (Bourdieu 1989). In the next quotes, three of the participants discuss how their health professionals' comments helped to reaffirm their decision to go privately.

In this first quote, Patricia discusses how her physician showed signs of concern about the lump in her breast during their appointment and recalls their discussion about what the physician suggested she should do:

My doctor said that I should go and find out really quickly, so she sent me off really quickly, and she obviously thought there was something to be concerned about $[\ldots]$. She said 'if you can afford to pay for the [...] first x-ray [...] do that because then you'll get it like tomorrow and you'll know'. [...] She didn't really recommend going public. - Patricia $^{37}$

\footnotetext{
${ }^{37}$ This quote was particularly interesting as Patricia referred to it again later in the interview when discussing what health sector she would choose in the future based on her experiences: "I would probably do the same again [...], I would actually probably not go for a private x-ray, my guy could get a free one much quicker because I've got an existing history. So I would probably just go public again." This quote highlights the importance of physicians giving their patients information and choice rather than making decisions for them.
} 
In the next quote, Linda discusses how her physician associated speed and urgency with the private system:

I was actually referred straight to the private sector because they believed that I needed urgent immediate treatment. It was intimated to me that I would receive it more quickly. [...] Instead of coming into the public system we were immediately marching in through the private sector [...]. All we knew was that we had been told it had looked pretty serious from straight away [...] at that stage Dr X recommended that if I could afford to see Dr Y privately, that he was an excellent oncologist and what was it that I prefer to do. So really I was being led. [...] His message to me wasn't 'you will be well looked after in the public sector'. He was saying to me [...] 'can you afford to be looked after privately in this setting?' - Linda

Jan also comments that her physician influenced her understanding of the health systems in relation to speed:

The way that it is told to you, if you go through the private sector it's quick, you get in quick. - Jan

I thought I would go on a waiting list for the public and I didn't want to wait, I wanted to move fast. - Jan

The previous section discussed the doxa linking the public sector with waiting and the private sector with speed. The above quotes show how three of the participants' physicians' comments worked as an orthodoxy further reaffirming their taken for granted beliefs about the public and private sectors. In Patricia's consultation, her apprehension around waiting in the public sector was strengthened when her physician stated that something should be done quickly through the private sector if she could afford it because the lump looked like something to be concerned about. This statement strengthened the doxa linking the public sector with waiting lists for Patricia and made her book in for tests in the private sector. The doxa linking private sector with speed was also reinforced to Linda by her physician at the beginning of her cancer with him "recommending" that she went privately because of the serious nature of her cancer, not 
informing her of alternative discourses, which meant that, because of the acute stage of her cancer, the public system could have responded quickly.

Jan also had fear associated with waiting and the public system when she was diagnosed with breast cancer and her physicians' comments reinforced the orthodoxy that the private sector was fast, which by association reinforced the public sector as slow. The physicians' status, in all of these examples, which is linked with their symbolic capital related to their professional position and their embodied capital related to their knowledge of the sector acted as an orthodoxy reinforcing the doxa which aligned the private sector with speed and the public sector with waiting. Physicians' statements can also question doxa in society illuminating alternative discourses - this process is called heterodoxy. The next statements show how physicians' statements were positive about the public sector and in fact transformed the participants' habitus and understandings associated with the public sector.

Patricia had some concern about the waiting times through the public sector. This was because of conversations with individuals that had experienced the public sector "mostly with elective surgeries." Her physician reassured her of her concerns regarding timeframes:

My doctor assured me that if I actually did have cancer that they would [...] get right onto it. [...] The surgeon, when he told me that I had cancer, said there would be no advantage whatsoever in doing it privately. [...] Once it was confirmed he said that [...] all the care that I would get would be exactly the same under the public health system as I would get privately, except that I wouldn't be paying for it. - Patricia

Heather was initially apprehensive about having cancer treatment in the public sector due to the doxa associated with it, and she saw specialists in both sectors to try to decide what sector to choose. Heather's decision to use the public sector for her cancer treatment was influenced by a discussion that she had with a nurse at the public hospital about the reality of the actual time delays in the public sector for cancer patients: 
That was my main concern [waiting list] and overcrowded wards and [...] you're rushed out [...]. But then I was advised that the public system was as good as the private and there probably wouldn't be a big delay. - Heather

Susan discussed in her interview that she thought there would be waiting lists for everything in the public sector before her cancer treatment due to different comments that she had heard in the media. However, her physician's comments reassured her about the waiting times for cancer patients:

I said 'oh well put me on the waiting list', coz you hear about the waiting list. And he said 'there's no waiting list'. There's no such thing. [...] I thought there would be waiting lists for everything. Because that's what you hear about in the media. I didn't realise when you are very sick there is no such thing. [...] If you are seriously ill they take you straight away. - Susan

Patricia, Heather, and Susan's comments note that physicians can also use their position in society to expose heterodoxy or alternative discourses. Before discussions with their physicians, the doxa linking the public sector with waiting was reinforced to Patricia through conversations with friends about elective surgery as well as the previous conversation with her physician, to Susan through media reporting and to Heather as her generalised thoughts related to the sector. Waiting was Heather's biggest concern, and once a nurse who worked in the cancer area for the public sector informed her that both sectors were similar in terms of treatment and waiting times she was able to overlook her previous concerns. Susan was so sure about what she heard about waiting in the public sector she even joked about it with her physician after she was diagnosed with cancer. Her physician's comments and the subsequent actions in the public sector quickly transformed her opinion of public sector cancer care that she continually praised throughout the interview. In fact, the entire reason that Susan volunteered to be interviewed for this study was because she was aware of the bad reputation that the public health system had. She wanted to discuss the positive service and treatment that she had received.

Anspach's (1993) research on the dynamics between health professionals and parents in the intensive care ward for premature babies, discussed in the literature review, has a 
number of similarities to the interview material explored regarding physicians' statements. The research identified that health professionals' speech complexity had an effect on the nature of parent's decisions and the nuances of the decision (Anspach 1993). Intricate speech meant complexities came through, making parents aware of the multi-faceted nature of their decision whereas simple speech made a decision seem natural and as if there was only one "right" decision (Anspach 1993). Although Anspach does not specifically employ doxa, orthodoxy and heterodoxy to examine her narratives one can see how these concepts could be used to examine how physicians can choose to manipulate their advice.

This section discussed three situations where physicians reinforced participants' doxa related to their understandings of the public and private health sectors and three situations where they exposed alternative discourses relating to these sectors. Bourdieu's concepts of doxa, orthodoxy, and heterodoxy are useful for examining participant decisions and the control dominant members of society have in defining common sense understandings.

\section{Findings on participants' preconceptions of public and private health sectors}

The first half of this chapter explored narratives relating to participants' preconceptions of the public and private sectors before their breast cancer treatment to get some understanding of the reasoning behind their choice of health sector. It analysed some of the participants' previous experiences of the public and private sector using the concept of illusio. It also used the concept of doxa, specifically focusing on narratives which were based around ideas of either the private sector and speed or the public sector. It also used the concepts of orthodoxy and heterodoxy to show how physicians, dominant figures in both the public and private sectors, can reinforce or expose doxa in society. The second half of this chapter explores the participants' narratives about their experiences of the public and private sector during their breast cancer treatment.

\section{Experiences of health sectors}

This section examines the participants' comments about their experiences of the public and private health sectors based on their breast cancer treatment. It uses Bourdieu's 
concepts to explore and compare the participants' comments related to their experience of speed, staff, privacy and facilities, and after care to discuss similarities and differences between public and private sector care.

\section{Experiences of waiting lists and fast service}

The participants placed an emphasis on the importance of speed in the previous section and fast treatment was one of the main justifications for them choosing to go privately for their treatment. Other studies note that although patients liked aspects such as a nice room, good food or empathetic staff their main concern regarding their hospital care was to "successfully treat a medical condition" (Clemes et al. 2001). Successfully treating cancer means dealing with the condition as quickly as possible and this is perhaps the reason for such a significant emphasis on the importance of speed in participants' comments. The strong doxa among many of the participants before their cancer treatment, which associated the public sector with waiting and the private sector with speed has been outlined. This section will detail and compare the participants' experiences associated with speed and waiting times using the public sector participants' comments to show a heterodoxy, or alternative reality experienced by participants' in this study.

The preconceptions the participants had discussed, linking the private sector with speed, were mirrored in the participants' experiences:

Jan's expectation of speed in the private sector was met when she had an appointment with a specialist less than a week after she was diagnosed with cancer:

I had private insurance and [...] I would like to go to him as soon as possible [...] within a week I had an appointment. - Jan

Mary, after waiting for several weeks in the public sector to get tested for breast cancer, decided to go privately and recalled instant after-hours service and having surgery a few days later: 
I went to Auckland [...] he came after work to see me, so it was absolutely instant and within two days I'd had the surgery done. [...] I had waited so long and there boom, boom [...] I was booked in to see him. He came and saw me after-hours and spent [...] several hours with both of us. Had all sorts of people running round, staff staying on to do an extra mammogram, this kind of thing. So it was pretty impressive $[\ldots]$ and then surgery was all booked, nice private hospital, done and dusted. - Mary

Linda used the term immediate to describe the nature of her private sector care:

Not waiting for somebody to decide that they may or may not be seen by someone in the next week or two. It was a case of [...] because our medical insurance was prepared to pay up if something was needed for me it was immediate. - Linda

Immediacy was something that Carol also emphasised in her description of her private sector care:

I made an appointment with the GP [...]. That afternoon [...] I went in and had a mammogram. So that was the same day $[\ldots]$ and then they found something. So they made an appointment, at eight o'clock the next morning I returned for an ultrasound and core biopsy and that same day I had an appointment with the surgeon [...] then I got a call and I had another appointment Friday afternoon with the surgeon to tell me that the biopsy had come back [...] Monday morning I was in the operating theatre. - Carol

The doxa linking the private sector with speed that was discussed in the previous chapter is reaffirmed through the participants' experiences that used the private sector for their breast cancer treatment. As discussed in the previous section many of the participants associated the public sector with waiting. These next quotes expose a heterodoxy in relation to timeframes for the public sector breast cancer participants interviewed in this research and how treatment was performed in similar timeframes to the private sector for participants. 
Rose recalled how quickly her public sector surgeon operated on the lump in her breast, even though it initially showed through as negative:

Found the lump went to my local doctor, was sent immediately, [...] they gave me a mammogram, and a sound thing ultrasound, and it showed up as a peasized black area in my breast. The surgeon said he would he wanted to take a biopsy [...] I was called back, and this would have been within a week, the results of these core biopsies were negative. [...] He said 'but I don't trust them' $[\ldots]$ he said 'I want to just remove the lump' [...]. Within a week [...] took the lump out $[\ldots]$, he said 'no the lump was this cancer $[\ldots]$ and I want to remove more'. [...] I was kind of grateful that he'd pushed for this so then they did the bigger operation [...] the decisions are made so quickly, you're not given a chance to say well you know what other options are there? - Rose

When Karen found a lump, she got an appointment in the public sector within a week, in the next few days she was informed about her results and the following week she was booked in for surgery:

Within the week I had an appointment to see a surgeon at the hospital, [...] he did a biopsy, $[\ldots]$ straight away they sent me round and I had $[\ldots]$ a scan $[\ldots]$ on that same morning and he said there would be three days for the biopsy to come back. [...] Friday seven o'clock he rang and unfortunately the hospital had lost the biopsy. So I had to go again he said on Monday. To do another one I was petrified and said no I didn't want to do that because it was painful, he said I had no choice but to do it and he would do it privately in his own private surgery, at no cost. [...] Went back on the Monday, [...] he said he could try and ring the hospital and see if they could find them, they'd found it, he said 'unfortunately, yes it is breast cancer'. [...] I was booked in within the week. - Karen

Karen also commented during her interview that there was no waiting in between her different types of treatment in the public sector:

I don't think there was a wait, we just kept rolling, they were really awesome. Karen 
Heather discussed how there was a few weeks wait for her treatment in the public sector and she thought her surgeon made sure that she got her booked in for her operation:

I think it was two to three weeks [wait]. This nice surgeon could see that I was upset. And I'm sure he pulled a few strings. - Heather

When Susan was asked why she chose the public sector for her cancer treatment her answer was different to the other participants. She did not get a choice. Susan's cancer was so serious she was referred straight into the public sector for immediate treatment. Her next quote reflects the same urgency that the participants above used to discuss the private sector experiences:

I went to the doctors, they sent me to the hospital for some tests. [...] They just took me straight away; [...] they sent me to the hospital the next day for tests. They tested me basically nearly every day for three weeks. [...] I got the news on the Tuesday that yes you've got breast cancer, see you Friday for surgery. [...] He said, 'yes you've got breast cancer we need to have a mastectomy'. - Susan

The above experiences from participants who used the public sector show that their breast cancer treatment in terms of time and waiting was very similar to the participants who used the public sector.

Not all of the participants' experiences were the same in the public and private sectors. Mary had significant delays using the public system, as mentioned in Chapter 4, both to test whether she had breast cancer and again when she had her radiotherapy. She comments:

I waited a long time to be seen, [...] in the public system, I waited six weeks from my doctor suspecting something to being seen at a breast clinic. - Mary

Mary also discussed in her interview that she recognises how public sector breast cancer care has improved for women in her area since she had her issues: 
From [...] my experience wasn't great from my being diagnosed with cancer because I waited so long and I was low priority. [...] I felt I was high priority, I was a youngish vital mother working in society, more so than somebody in their 70's, but who am I to say [...]. I felt I was unfairly treated by the public system [...]. I didn't find the surgeon particularly good with having to wait and that's basically why I went private as well. But I think that the care that the breast care nurse is giving in the clinics is all excellent and the follow-up is excellent, they go beyond the pale actually, [...] that's all followed-up through beautifully now, women there's very little chance for them to slip through the cracks. - Mary

Jan, who had her treatment through the private sector, gained knowledge surrounding the public sector timeframes and treatment from watching her friend go through breast cancer. This knowledge led to her decision of cancelling her medical insurance:

From what Dr X has explained to me is that the difference between the public and the private is if it's urgent in public it will get done quickly, you go to the top of the priority list. If it's not it's a bit like, you know, they prioritise what is urgent and what is non-urgent so that's why the waiting list. A lot of people get upset about it but if they are on a waiting list, they're on it for a reason because there are people that are more urgent than them. - Jan

So now I have cancelled my Southern Cross. So it was just the fact that I made the decision well the premiums kept going up. And you go oh here we go. And what did the private do for me compared to what I've heard the public, well I'm prepared to take the risk and wait. - Jan

Jan cancelled her private health insurance and has witnessed her friend's public sector breast cancer treatment. But at the same time, Jan still highlights the doxa associating the public sector with risk and waiting.

These experiences of the private and public sectors show many similarities. Participants in both sectors were seen quickly, within a week in a few cases. The private sector participants' breast cancer accounts are an orthodoxy, reinforcing their previous views that link the private sector with speed. The public sector participants' breast cancer 
accounts, in comparison, are a heterodoxy, exposing that the public sector does move quickly. Although, private sector patients pay for private sector treatment, and this somewhat validates the illusio that their treatment is faster. On the other hand, the public sector participants' accounts are an alternative discourse providing a lived experience of the public sector. Some of the public sector participants, however, question the quality of their care.

Staff

Personal service was something that the participants emphasised was important in relation to their breast cancer care. This has also been shown in other breast cancer studies noting the importance of non-treatment related conversations, making extra effort with patients and respecting differences (Ashing-Giwa et al. 2004; Burkitt Wright et al. 2004). This section first explores private and public sector participants' comments regarding staff, and it then examines their comments about breast cancer nurse support. Finally this section uses narratives from Linda (a private sector patient) and Karen (a public sector patient). This is a way of showing that the public and private sectors for breast cancer patients differ very little in terms of the way they are treated by staff and the personalised extra effort staff make for patients in both sectors.

The participants who received their treatment in the private sector were very positive about the staff. There was an emphasis among many of these participants about how medical staff went beyond their call of duty providing extra time, reassurance and more personalised care during their time in hospital:

Nursing and specialist time in the hospital was very good in your own room. Mary

They were fantastic. Couldn't fault them there. - Jan

The doctor [...] came back in the next morning, he came that night. He visited me [a] couple of times a day. And he kept telling me I was brave and got an awesome you know way I'd approached it, the nurses everyone were just yeah amazing. - Eleanor 
Dr X especially always runs over time [...] he just sits and chats to you, you never feel under pressure, in fact I'm the one who sort of starts standing up coz I'm thinking there must be somebody else waiting out there. - Carol

They were brilliant [...] the treatment there was fantastic, saw a fantastic [...] radiotherapy oncologist she spent heaps of time with us probably more coz it was private. - Mary

I was in the operating theatre, shaking unbelievably, just beside myself with nerves. But they were lovely. I had a nurse beside me the whole time. - Carol

Not all experiences of staff service in the private sector were positive. Jan's experience of the private sector, particularly the impersonal service she received at the private breast screening, was a catalyst in her decision to cancel her health insurance:

I asked Dr X whether I could go back through the [public] breast screening [...] because they are just absolutely amazing. It's no disrespect to the private radiographers down the road here but every time you go in the same thing is said, they're not as sensitive as the women at the [public] place. Because I guess that's what they're [public screening] dealing with all time. Whereas they're [private screening] dealing with everybody that comes in with all types of injuries with all types of illnesses, so they're a busy place [...] the private one. Because you've gone private you have to go private [...] I don't have a choice. [...] [...] I've found them really impersonal and I've dreaded going every time. I'm paying good money but I'm not getting that personal touch. - Jan

Jan's experience with the public breast-screening clinic before her cancer had been positive and she appreciated the female environment, the specialised staff dealing only with breast screening and the personalised sensitive manner in which she was treated. Once Jan used the private sector she emphasised that she had to go privately, that she was no longer allowed to use the public breast screening system, despite the negative experiences she had through the private breast-screening clinic. Her experiences of 
private sector screening staff as well as watching her friend's treatment in the public sector were both catalysts towards her cancellation of her medical insurance.

Karen's received most of her care in the public hospital and only went privately for her Taxotere, because it was not funded by the public sector. When she discusses the care in the private sector, she emphasises that staff have just as many demands upon them in the private sector as those in the public sector:

I had lovely nurses and I think [...] they [did] a great job and they'd probably do just as good job in the public system it's just that they're in the private system. $[\ldots]$ It is nice and the nurses are lovely [...] everything is taken care of [...] like anywhere [...] staff are stretched. [...] Paying privately gets you [...] I thought basically a one-on-one nurse that doesn't happen but [...] they were very good but saying you're paying [...]. - Karen

Regarding the quality of treatment, staff and the different services that were available Karen comments that she believes the quality in the public and the private sectors are the same:

Yeah, yeah, and I don't think that going private would have made any difference. - Karen

Karen's comments about the quality of staff in the public sector are emphasised when compared alongside many of the participants' comments about their experiences of the staff in the public sector. Participants commented about the kindness, help, warm personalities, and personalised service they received during their breast cancer treatment:

Everybody was so nice. So honest and so helpful. - Susan

Yeah I like Dr X, he's a lovely man, the staff were fine. - Karen

Oh they were tremendous, they were outstanding, they really were. They were so caring. [...] They were just there for you. [...] Whatever you wanted. - Nancy 
He talked to me as a human being. And he saw me at my worst. [...] His bedside manner was just so lovely. Whenever it got really bad he just held my hands. Susan

The theatre staff were just wonderful, they were really, really neat. You know there's something about the personality of the people in the theatre that puts you, well put me at ease. You know joking and laughing and you know. It was really nice that. I must admit that putting me quite at ease and joking [...] they make, they help you relax. - Rose

Two of the participants who used the public sector noted situations where staff were not meeting their needs. Rose had some problems with the support (or lack of support) that she received from staff in the public sector when she first came out of surgery:

I came into recovery pretty slowly [...] I just couldn't move, I was in a lot of pain. I think because they put the saline solution through your body, my bladder it was just continually, just kind of like you know. Oh I couldn't get out of bed. I couldn't and there was nobody around I needed to have a bed pan. [...] A lady across the way I heard her moaning she needed a bed pan. And there were no nurses around. [...] I felt like it was awful, I felt I was in their way and I was taking up their time. [...] It was really, really embarrassing. And the attitude of the nurse when she finally came was if oh you know it was like I was making a fuss. [...] There was some later on who came on who were far more caring. Rose

This situation with staff, as well as her previous experience of the service that was noted in the first half of the chapter, help to explain Rose's apprehension in relation to public sector health care.

Patricia commented how perhaps in the public sector that doctors could receive some training about how to deal with younger patients with breast cancer: 
The surgeons [...] I think they are more used to dealing with like women in their 60s [...]. When I said, 'so how long before you think I can take up karate?' They were like 'why would you want to do that?' and Dr X, I said to him, 'so when can I start running again?', and he's like 'running, running we don't want you running'. Ok so I walked. [...] The registrars would have been probably a bit better because they were younger. The older guys [...] I found I they were very anti-exercise and if you asked them about diet and about alternative stuff I think they would have just poo-hooed all of that completely. But you know, I know a lot of people who are younger women who are much younger than me who've had breast cancer. - Patricia

This comment from Patricia resonates with the issues discussed by other younger women with breast cancer in research by Thewes et al. (2004) which found that services and staff in Sydney, Australia were not addressing young breast cancer patients' needs.

Patricia also commented in detail about her negative experience with administration staff whilst waiting for appointments during her breast cancer treatment. But she also described how in her area a special clinic in the public sector has now been built specifically for breast cancer patients and the efficiency and kindness of staff members in the new clinic:

They're all really good nurses [...]. As opposed to the woman who they had when they had the general waiting room, and the woman there was just appalling [...] she would give you no information about how long people were going to be, she just really unhelpful attitude like 'why are you asking me these things?', 'why don't you just go and sit down with everyone else?', 'who cares how long you have to wait?', [...] that kind of attitude. But the last time I went out to the breast centre, I walked in because the bus times, I was about 20 minutes early, I walked in and she said 'oh the bus must have come in, [...] we'll just start now'. And then when I finished she said 'oh you just sit there sit there and have a coffee while you wait til you go back over to the bus it'll be fine'.Patricia 
Although there were a few issues with staff discussed by participants in both public and private sectors, overall feedback about hospital staff was positive with participants reflecting on their experiences with praise and the personalised service and care they provided. The next part of this section explores participants' comments about specific staff support from breast cancer nurses. ${ }^{38}$ The participants were not specifically questioned about the involvement of breast cancer nurse support during their breast cancer treatment. However eight of them discussed breast cancer nurse support during their interviews and the following quotes detail their comments about this.

Carol found the support from the breast cancer nurse in the private sector very helpful:

Lovely. [...] You have this person who is in charge of you. Who basically sat and held your hand if you wanted to. Who was always available, she gave her phone number out as soon as she met me. - Carol

Eleanor, who went through the private sector, specifically stated that although it was nice support offered from the breast cancer nurse, it was not at a particularly good time, just before she went into theatre. She also felt she was getting good support from her partner, family, and specialist and did not need the extra support from the breast cancer nurse:

This woman arrived [...] and introduced herself. [...] One of the nurses came in soon after [...] she was nice but I just didn't need that. [...] But she was just there and some people would have probably loved it [...] saying 'look I'm here, we'll be there to hold your hand' [...] but I had my support with Dr X and the family. [...] She came to my house. [...] It's sort of good, but you see we're all different aren't we? - Eleanor

Mary specifically mentioned during her interview that she did not receive support from the breast cancer nurse in the private sector:

\footnotetext{
${ }^{38}$ A breast cancer nurse is a special nurse who provides breast cancer patients with information about different services, answers questions, provides support and helps them with different queries (Marsh et al. 2010).
} 
I know [...] our breast cancer nurse really well now. [...] I never got any information about subsidies for prosthetics and bras or anything. It was never given to me through the private system. - Mary

Four of the public sector participants mentioned the support they received from the breast cancer nurse during their interviews and this ranged from information about services and entitlements, answering questions and providing advice through to support for different breast cancer-related issues:

The nurse, $[\ldots]$ when the surgeon told me [...] that I had breast cancer, [...] she was really, really nice. She gave me all the information I needed. [...] Just covers everything about what's available [...] the whole processes. [...] Yeah [...] she was really lovely, $[\ldots]$ she was neat. $[\ldots]$ I think [...] it's really important to have women $[\ldots]$ as support professionals, $[\ldots]$ only a woman knows what it feels like to be a woman. [...] A few weeks after I had to go back and they checked to see how I was. [...] My arm was swollen, I'd actually got frozen shoulder. [...] I went $[\ldots]$ to the breast nurse [...]. She said, oh she said 'there's a lady who did lymphatic massage out of $X^{\prime}$. So I was sent to her a couple of times and she helped. - Rose

Everything explained to the detail which was really good. [...] The breast nurse [...] she comes and talks to you as well, [...] if you have any questions you go to her. [...] She was there the day that he came in and said to me that the breast had to come off [...] she said 'oh you'd need such and such a treatment' [...] she was always there, she's great, [...] you could phone her any time you liked and any appointment I went to with the surgeon she was there. [...] I think most people know her and she's the one that gives you all the information on $[\ldots]$ the wigs, the funding. - Karen

Very nice breast nurses came and I had to have a drain in to take the fluid off. [...] The breast care nurse, [...] one in particular who came and fitted the prosthesis. She had the breast cancer herself and she was extremely nice and approachable and just wonderful. Yes and she said if there were any problems to ring her up [...]. Having back-up contact like that was invaluable. - Heather 
She was wonderful. She was absolutely outstanding. - Nancy

Only two of the private sector participants in comparison to four of the public sector participants mentioned support from the breast cancer nurse during their interviews. This seems to align with the Marsh et al. (2010: 144) research on New Zealand and Australia breast cancer patients' access to a breast cancer nurse which found "more public practices have access to a breast cancer nurse than private practices." This could also highlight an area in the private sector that needs to be addressed further. However, in relation to the results from this study it is important to emphasise that the participants were not specifically questioned about breast cancer nurse support during their interviews.

The final part of this section on staff compares two of the participants' experiences in terms of staff and choice. The following two narratives, discussed by Linda and Karen, emphasise the exceptional care and services that they received. Linda had surgery, chemotherapy, and radiotherapy in the private sector. Karen had surgery, chemotherapy, and radiotherapy in the public sector, and Taxotere and a reconstruction done in the private sector. These participants received very similar care in terms of the special scans and personal contact with their specialists throughout their breast cancer treatment and these narratives show that in these cases, cancer services were exceptional in both sectors.

During both of their interviews, they refer to their personal contact with their specialists:

I had additional and more access given to me, $[\ldots]$ more choice given to me. [...] My experience with the oncologist was that $[\ldots]$ he was more accessible $[\ldots]$ because we were paying for that access. That included the fact that he had said to me if at any point of my treatment I was really unwell I had access to him by cell phone, he'd even come to my home. [...] I'm really not sure at all that that would have happened for me in the public system. I believe that I would have had to have gone out there. - Linda 
Linda had the assumption that she was getting extra contact with her specialist because her treatment was through the private sector. Karen also had 24-hour access to her specialist in the public sector. This meant when she was having serious health issues related to her cancer there was fast treatment in the public health system for her:

If you know have a temp [...] don't hesitate to ring me. I have Dr X's cell phone. I could ring him immediately if I needed. [...] Three o'clock in the morning I rang him, $[\ldots]$ the minute I rang $[\ldots]$ he said 'what's wrong?' and I said 'oh I've got a temp 38'. He said 'they will know you're coming [...]'. Pulled up outside the front of A \& E this orderly came out [...]. [Dr X] just spoke and I tell you what I had the whole of the A \& E racing around like lunatics. [...] Well I tell you what that man has got some power. - Karen

Linda when discussing her experiences emphasises the extra services, choices as well as the speed in the private sector:

Not waiting for somebody to decide that they may or may not be seen by someone in the next week or two. It was a case of, you know, [...] our medical insurance was prepared to pay up. So if I had pain in my hands it was organised for me to have my hands X-rayed, if I suspected that I had pain behind my eye that wouldn't go away, I was given a brain scan. [...] I don't believe that I would have got that in the in the public system. It would have had to have had huge justification. [...] One of the other things that I'm not sure whether other people got it [...] I had a full body scan I paid for. Once again, [...] pretty quickly. [...] He said to me 'I believe you need to do this, if you can afford to do it do it'. Because he said 'what it's going to do straight away is tell us what the real true picture is'. [...] I felt quite nervous in my head at that time that other women [in the public sector] weren't offered that. - Linda

Linda comments at the end of the quote her concerns that public sector patients did not get the same sorts services and choices. However, Karen emphasised she received similar scans in the public sector: 
So when you first go in they do a full body scan. [...] I said, 'I want a brain scan', and they said, 'well it's very unlikely', and I said 'well you're doing the rest of me'. [...] So they did. [...] I think we're very lucky to have the system that we've got. And I certainly wouldn't have any qualms to have to go back through the same system if something was wrong. - Karen

This section has explored positive and negative aspects of the participants' breast cancer experiences in terms of the treatment of the participants by staff in the public and private sectors. The predominantly positive experiences of the participants emphasises the quality of staff in both public and private sectors and exposes an alternative discourse or heterodoxy in relation to the doxa in society often associating the public health sector with being short of staff.

\section{Privacy and facilities}

Privacy was one aspect in this study where the participants' comments made the private sector appear better than the public sector. There is a doxa that naturally links privacy in health care as something that is positive and optimal for individual recovery. This doxa was drawn upon with many of the participants mentioning privacy when discussing their experiences.

Some of the private sector participants mentioned the importance of privacy in terms of their recovery with this aspect working as an orthodoxy in their narratives, further reaffirming their view of the private and public sectors, and validating their choice of health sector:

I was exceptionally well cared for within that within that setting, [...] I was afforded privacy, I didn't have to have people coming into see me. I didn't have to have people coming in from other rooms wanting to know what I was in that public setting for. For me that was terribly important that it was a private time because I think at that time there was a fair amount of grief wrapped around it as well. - Linda 
It's lovely to have your own room [...] [and] ensuite. Your family can come and go, [...] you haven't got a patient next door where there's a curtain pulled and there's a doctor telling someone that they're unwell or, you know, that they can't have an operation for whatever reason and they burst into tears. - Eleanor

As noted earlier, Karen has experienced both sectors. She emphasised that there was little difference between her public and private sector care apart from the privacy that comes with private sector care.

With my husband they put a bed in the room because you pay the extra so much for them to be down there with you. I guess being in a private room the bonus is of course you can have your husband right next to you so if you need anything you know he's there as well so you probably do get more attention [...] in the private $[\ldots]$ I mean they've got lots of people to manage where privately not so many people. The only difference I guess would be that the private it is private. It's you in a little room and it's only you. - Karen

The next quote describes the differences between her public sector chemotherapy care and her private sector Taxotere care:

You're sitting in with a group of people, so it's not so private. [...] So you've got the guy next to you, you're here, you're over there, and you're your sort of lined up like little sheep. And I know they can't probably give you individual rooms but certainly doing the private's better, you go in there, my husband my two girls $[\ldots]$ they sat over there and away you go and you just carry on yapping and a bit more casual. [...] there's no machines beeping [...] I remember I think there's one room you know the chemo room and it's in the corridor and I basically was sitting in the corridor getting chemo because there's just not enough room. It really didn't bother me, I just wanted to get it and get out. Karen

Heather, who had her treatment in the public sector, made a few comments in relation to sharing a room with four people: 
I was in the ward with four others [...] because it was such a short time in there, it didn't really worry me. But had it been for longer I would have appreciated having my own space. - Heather

There was a $[\ldots]$ woman in one bed and her whanau were all coming in, traipsing in past me. - Heather

Patricia spent some time during her interview discussing the facilities at the public hospital and the changes that she has seen for breast cancer patients in the public sector since she started her treatment:

When I first started going to the hospital there was the general outpatient's waiting room and there was this nasty little room with kind of benches and formica chairs and kids running everywhere. People that were really, really sick in there and horrendous waiting times. [...] Now they've actually got a little centre out [...] where you go in and it's all nice and clean and bright and shiny and it's only for breast screening [...] patients [...] there's no one actually there that's really sick [...] you really just don't kind of want to be in a room full of sick people [...] It's just in terms of getting moving on and getting back on with your life and things. It's actually much nice to just whip [...] go during a special little centre $[\ldots]$ where everyone's kind of moving on from it. - Patricia

At first yes I think the treatment in the hospital in the radiotherapy was all pretty good [...] you were probably getting all the same sorts of care although I think privately. [...] When I was having to traipse out to X Hospital and hang around for hours in sub-standard waiting rooms with zillions of other people I think I was regretting not going private and thinking there probably was quite a bit of difference. But I think [...], if I went through now, where they actually had [...] the centre separate from the actual hospital I think would be seeing very little difference between the two. [...] They seem to making quite an effort to have special gowns and things to $[\ldots]$ make it nice. - Patricia 
Privacy was initially an issue for Patricia, with her making similar comments to Karen regarding the crowded areas of the public hospital when she went for appointments. However, she does note that there has been a change.

Privacy is a doxa strongly associated with the private sector - as Karen states "the private, it is private."

\section{After care and services}

After care and services was one area where public sector participants' had more positive experiences than private sector participants' did. This section discusses public and private sector participants' comments about their after care and access to services.

There seemed to be a difference in support services for lymphoedema. Participants in the public system received district nursing follow through after their operations and information about lymphoedema services. All of the public system patients received district health nurse care in their homes:

I had a district nurse, local district nurse [...], she's lovely I think she's retired now, but she was good she came every day. - Rose

Yes very nice breast nurses came and I had to have a drain in to take the fluid off. They came everyday and changed that. They said I could of changed it myself but they'd continue to come so long as I felt I preferred them to do it and they did it. - Heather

I had the district nurse everyday [...] they came twice I think, or might have been three times, and then they rang me [...] they heard that I still drove a car and I had to go down to the health centre. - Nancy

Whenever I wasn't in hospital I always had district health nurses coming in and out. I had the oncology nurse coming in and out. She became the part of the family, sort of thing. - Susan 
Then after you leave when you have a chest drain a district nurse comes every day. [...] They're supposed to come and empty it and after the first couple of times they said 'we'll show you how to empty it,' and I said yeah that'll be good so everyday I'd empty it, ring them up and tell them how much was in it and get on with my day which was much better for everyone really. [...] That was another situation where I felt like I had a lot more control because [...] I could do it myself instead. - Patricia

In comparison, some of the private sector participants had no district nursing follow-up after their operation and were sent home without assistance or warning regarding the issues that could arise with their surgical wounds:

The private system was absolutely hopeless and I think because I was out of area too. - Mary

The after care was possibly a bit shoddy now I realise what can be done. No district nursing follow-up, no travel an hour to see them. - Mary

I think I was there for two nights maybe three days you know the Monday, Tuesday, Wednesday, I think I went home could have been the Thursday. The drains came out. Because they weren't draining much but then I went home [...]. When I got home after about three days I think I rang her and said, how sore should my breast be you know because it was blowing up like a balloon. [...] She said oh well you know reasonably sore mmm why what's happening? [...] I sat around for another day and then it was just beyond belief. [...] I came in and I think they drained about a pint of fluid off about $600 \mathrm{ml}$ of fluid came off the first time [...] So all week I went in each day and then it came out just every second day for you know it might have gone on for eight days I think just getting it drained out. - Carol

We just went back to [...] the specialist and he had to drain fluid off my back he took about a cup out once one time. [...] I had a number of visits to him. Eleanor 
Carol and Eleanor gave detailed explanations about the issues that they confronted with the after care of their operation wounds. However, neither of them criticised their private sector care. This emphasises the strength of their illusio and belief in the private sector due to their participation in this sector for their breast cancer treatment and their continued participation in this sector.

Linda also mentioned several issues that she experienced through the private sector after her operation in terms of problems with her arm. The privacy she referred to earlier as something positive in relation to her care and treatment emerged as an issue in other areas. Linda discusses the problems with the private sector as disconnected and isolated from other rehabilitation services:

The disconnectiveness of the private sector meant that you were reliant on your own ability to access. - Linda

Some of the difficulties I did think that were there with the private sector, particularly around the surgeons as opposed to the oncologists, were the lack of connectional follow through to things such as physiotherapy. So I felt that that was a component that was a concern or a worry. - Linda

So you know the extension of any other things you might have needed like physiotherapy and that type of thing actually in the private sector you would have been pursuing it yourself and there didn't seem to be any other way to connect you back into the public system so you found yourself constantly paying for everything you got. - Linda

Linda's comments show how aspects of care such as speed and privacy are "most important" in terms of cancer care causing other issues such as access to after care or facilities to be overlooked.

This section explored the participants' experiences of after care and rehabilitation in the public health sector and showed the strength of public sector services for these aspects.

Findings on participants' experiences of public and private health sectors 
Using Bourdieu's concepts of doxa and illusio provided a different perspective to analyse some of the interview material in this chapter, opening up questions relating to natural assumptions in society and alternative discourses that can be exposed through lived experiences. The second half of this chapter identifies that some for some services (speed, staff help and general information) the participants felt there was very little difference between the public and private sectors. Overall, the private sector provided more privacy and better facilities for patients in secondary hospital facilities during surgery and treatment. The public sector provided better information and services related to post-surgical district nursing care and lymphoedema, physiotherapy and prosthesis and bra services. The comments related to positive experiences of the public sector participants in this chapter could potentially provide a patient voice for studies, such as Cancer Control New Zealand's research exploring public sector patients' satisfaction with services.

\section{Summary}

This section provided an overview of participants' preconceptions and experiences of the public and private health sectors. The first part explored different aspects of their preconceptions of these health systems before their breast cancer treatment. It used Bourdieu's concept of illusio to analyse some of the participants' narratives about their previous experiences of health sectors, commenting on how these narratives helped to validate and justify their reasoning behind their choice of health system. It used Bourdieu's concept of doxa to examine participants' preconceptions linking natural beliefs to specific sectors. Finally, it examined the impact of physicians' statements on participants' choice of health system, commenting on how these worked as either an orthodoxy reinforcing participants' beliefs, or as a heterodoxy highlighting alternative ideas. The second part of the chapter explored participants' experiences of the public and private sectors in relation to their breast cancer treatment. It uses the participants' narratives to emphasise that these sectors have very little differences in terms of waiting times and staff. It then uses the participants' narratives to show how the private sector has better privacy and facilities and the public sector has better after care and services. This chapter emphasises the power of the doxa associating positive attributes such as 
speed with the private sector and waiting with the public sector and highlights the need for considerations in exposing alternative discourses about public sector care. 


\section{6) Conclusion}

The purpose of this thesis was to investigate the impact of cultural capital on breast cancer patients' perceptions and experiences of the public and private health sectors. Using semi-structured interviews meant that there was some flexibility for the participants and the researcher to address other issues during the interviews. This led to an exploration into the impacts of social capital and the use of the other Bourdieuian concepts, doxa and illusio, to investigate the participants' perceptions and experiences of the public and private health systems. This chapter reviews the main findings of this research and some merits and limitations of the study. It then proposes some recommendations based on the findings and provides some suggestions for further research expanding on this work.

Bourdieu's theory of practice provided the framework for this thesis. The interconnected concepts of capital, habitus, field, and the wide range of work using Bourdieu's theory of practice to describe different processes in society provided a strong theoretical base for this thesis including planning, interviewing, and analysis. This research suggests that in New Zealand, cultural and social capital can be useful for breast cancer patients in their negotiation of the public and private health sectors providing participants with access to health services and information. This research also found that participants' preconceptions of the private sector were positive. The general reasoning behind paying for this service was mainly because of the speed, which made it seem more appealing. Bourdieu's notions of doxa provided a way of critically examining these preconceptions and their effect on the public sector. The participants' experiences in the public and private sectors were similar in relation to access and staff although many of the participants who used the private sector held an illusio that their services were better, particularly in relation to speed. The private system generally offered better privacy and facilities for participants. The public system offered better assistance generally in terms of after care and connection through to after care services.

The concept of capital was useful in examining how the participants drew upon their embodied knowledge or cultural capital. In a similar nature to Noissen et al. (2004), Grineski (2009) and Anspach's (1993) research, cultural capital assisted participants in 
this study by shaping their information seeking behaviour and their way of approaching their illness. Shim's (2010) concept of cultural health capital has not been tested by her own personal research in the same thorough manner that Bourdieu tested his concepts. The concept of cultural health capital could benefit from research investigating its claims to strengthen the concept. One aspect of cultural health capital Shim touches on is the role of the physicians through encouragement in building, maintaining or discouraging a patient's cultural health capital. This aspect had mixed results in this research with Mary, Susan and Jan's experiences showed the importance of provider encouragement and Barbara and Rose's experiences showed that participants could draw on cultural health capital without encouragement from their provider.

Flexibility surrounding the definition of social and cultural capital in the work was useful as it enabled an exploration into the nature of these concepts. For example, in the interviews some participants' detailed the lack of assistance they experienced, or help that they received from others, as well as help that they have since given to other cancer patients. There seemed to be a general sense that these women wanted to help others going through similar treatment in order to prevent other people from experiencing issues they had experienced. These discussions which encompassed elements of social interdependence and philanthropy touched on by Coleman (1990) and Putnam (2000) descriptions of social capital.

The participants' comments in this study about social capital, even when questions around this concept were not specifically asked, further demonstrates the strength of Williams and Robinson (2002), Meinert (2004), Abel (2007) and Stuber's (2009) arguments and the need to explore multiple forms of capital in research. Many participants in this study seemed to draw upon the importance of networks outside of their family in their negotiation of their breast cancer. This would likely differ if there was a wider range of participants of different ethnicities as Meinert (2004) and Williams and Robinson (2002) comment that different cultures emphasise the importance of family networks.

Investigating the participants' narratives using Bourdieu's theory of practice allowed an exploration of the positive manner in which the private sector is construed and the effect of these positive associations on the public sector. Bourdieu's concepts illuminated the 
doxa surrounding the participants' perceptions of the public and private health systems and the illusio the private system maintains, even after participants experience positive public service and negative private service. Bourdieu's concept of doxa allowed an indepth investigation of the "taken for granted" ideas participants associated with the public and private health sectors and the concept of illusio provided a way to consider participants justifications that validate their investment and participation in the private health sector.

The flexibility of semi-structured interviews emphasised by Crouch and McKenzie (2006) were useful in this research because they allowed for the pursuit of other issues that the participant brought up. This style of interviewing for this project maximised "discovery and description" particularly in the exploration of capital (Reinharz and Davidman 1992: 18). This is because many of the participants' discussed the importance of social connections or social capital during their interviews bringing another dimension into the research that was not in the initial interview guide. As emphasised by Wengraf (2001), semi-structured interviews were also a useful method to investigate theory, or in this case Bourdieu's theory of practice, allowing for an indepth examination of his concepts in public and private health fields.

The New Zealand research community has a number of breast cancer studies exploring breast cancer, ${ }^{39}$ some of which were mentioned in the introduction, but limited research about breast cancer patients' personal opinions and experiences. Interviewing participants with high levels of cultural and social capital provided insight into issues that occurred for these women, identified strategies they took to address these issues as well as allowed for an exploration into their perceptions and experiences of public and private health sectors.

This research is based around findings from interviews with 11 participants that are predominantly of New Zealand Pakeha ethnicity, which is a small sample. The size of the sample, the method of recruitment, and ethnicity ${ }^{40}$ of the participants, are a limited

\footnotetext{
39 Studies are a combination of both statistical analysis of breast cancer information from National Databases as well as surveys performed on patients.

${ }^{40}$ Particularly in relation to the recent findings of Cunningham et al. (2010) which highlight that Maori women have significantly higher incidences of breast cancer.
} 
factor in considering the broader relevance of the research in the New Zealand population. It is likely that other issues highlighted by Grineski (2009), such as language and literacy proficiencies as well as nuances described by Yosso (2005) regarding the racism entrenched within cultural capital, could arise in research undertaken with different ethnic groups. In addition, the semi-structured interview style meant questions varied to some extent for the different participants. For example, some of the participants discussed their breast cancer nurse care, this was not a specific question, but the participants that mentioned it were questioned about their experiences. This goal of the research was to explore the effects of capital on breast cancer patients' negotiation of health systems rather than to make generalisations and despite the limitations this research has provided insight into breast cancer care, particularly regarding access to entitlements and general perceptions of the health sectors (Gubrium and Holstein 2002; Hesse-Biber and Leavy 2006).

This research highlights that the breast cancer patients interviewed were reliant on cultural and social capital when their health providers did not address issues such as giving information or access to services. This study emphasises the relevance of concepts from Bourdieu's theory of practice for investigating health with Chapter 4 noting the impact of cultural and social capital on participants receiving different resources and information in the public and private health fields and highlighted the importance of these forms of capital for the participants. This section discusses suggestions to address inequalities caused by social and cultural capital including case management of cancer patients and improvements to breast cancer nurse services. It also emphasises the importance in the continuation of Government initiatives supporting individuals of different ethnicities, cultures and literacy levels and on CCNZ's (2009) recommendations for a hui and continued professional debate in the area which will assist in building social capital among different individuals and organisations involved in breast cancer. Finally, it recommends the implementation of a widespread public campaign celebrating the successes of public sector cancer services in New Zealand.

Rankin et al. (2004: 145) comment that uptake of services for breast cancer is determined by how informed women are rather than demographic characteristics. Case management of cancer patients would assist in addressing the resource inequalities 
caused by the individual's possession of different forms of capital. Case management is when a professional works with a client to coordinate their health needs through providing them with advice, organising assessments and linking them with other health services and groups (Lantz et al. 2004). This service has already proven to be positive for breast cancer patients in the United States. ${ }^{41}$

Case management of cancer services by breast cancer nurses would address inequalities caused by social and cultural capital by allowing each cancer patient to get the information and advocacy they need from an individual with intensive knowledge of cancer services, resources, entitlements, and cancer organisations. Breast cancer nurses are professionals with high cultural capital in terms of their knowledge of health, breast cancer, breast cancer services, and organisations. Breast cancer nurses also have high social capital as their role means they have connections with different breast cancer organisations. Breast cancer nurses are already working to support women across New Zealand providing a personal one-on-one approach for patients. However, the number ${ }^{42}$ of breast cancer nurses needs to be increased so they have more time to provide support and advice to women throughout their treatment so they do not have to rely on their own social and cultural capital. There needs to be a focus on the training and recruitment of Maori breast cancer nurses because as mentioned in Chapter 1, studies in New Zealand continue to disclose the large number of Maori women diagnosed with breast cancer and other studies also emphasise the importance of an increased Maori health workforce (Walker et al. 2008). More breast cancer nurses would allow these individuals to provide more of a case management role for breast cancer patients, helping to coordinate treatment, providing them advice and linking patients with other breast cancer services and organisations.

Findings from this thesis suggest that the private sector needs to work on developing their after care services for their patients and establish strategies to inform them about

\footnotetext{
${ }^{41}$ Goodwin et al. (2003) has already completed a trial on 335 older women with breast cancer in Texas and found that higher percentages of the 169 women that were case managed got back their normal arm function and felt they had choices regarding their treatment. Lantz et al. (2004: 554) reviewed case management of cancer screening services in America commenting that "case managers play an important and integral role in the transition between diagnosis in the National Breast and Cervical Cancer Early Detection Program and enrolment in Medicaid for treatment services."

${ }^{42}$ In 2008 there were 25-30 breast nurses in New Zealand with 14 located in the Auckland area (Breast Cancer Aotearoa Coalition 2008).
} 
services they are entitled to through the public sector. This is because all five of the participants in this study who used the private sector had issues regarding access to services in one way or another. ${ }^{43}$ Marsh et al. (2010) identified that there is less breast cancer nurse support in New Zealand and Australia for patients in the private sector. This thesis shows some of the implications of reduced breast cancer nurse support for private patients, showing how participants instead had to use personal social and cultural capital for assistance with cancer-based issues. Private services need to make breast cancer nurse support a priority due to their knowledge about the health system and information and support they provide for patients. An onsite breast cancer nurse, similar to some private clinics ${ }^{44}$ in Auckland, should be investigated for other private clinics across New Zealand.

The results in this study suggest relationships or social capital formed between the public and private health sectors as well as between different cancer services and organisations need to be further strengthened. Such relationships would assist providers in attending to patient requirements and needs throughout their cancer, meaning that patients would have less reliance on cultural and social capital. As highlighted by Grineski (2009: 128), giving more money to individuals cannot properly address health inequalities created by social and cultural capital. Instead, the situations and reasoning behind why patients access these forms of capital need to be addressed. Gillon's (2002) paper documents the success of developing relationships between different health organisations in Porirua. Different breast cancer charities combined to form The Breast Cancer Aotearoa Coalition (BCAC) in 2004 to work as advocates for women with breast cancer and to bring concerns to the Ministry of Health, some of which have already been addressed in CCNZ's Action Plan ${ }^{45}$. BCAC's work could be further strengthened through inclusion of health organisations and health professionals. Following on from CCNZ's (2009) suggestions a workshop, conference or hui at least yearly at a local level between breast cancer health organisations would develop relationships in the breast cancer community. This event would assist individuals within

\footnotetext{
${ }^{43}$ Linda, Eleanor, Mary and Carol had different issues regarding access to surgical after care and follow through with lymphoedema services and Jan had issues with receiving information and support.

${ }^{44}$ Breast Associates (2010) and Mercy Breast Clinic (2011) both employ their own breast nurses.

${ }^{45}$ These include waiting times for treatment, access to innovative medicines, inconsistent cancer services across different health boards, a lack of comprehensive cancer data, poor outcomes for Maori and Pacific women, low uptake of screening, no consumer representation in government cancer organisations and lack of psychological support for patients (Breast Cancer Aotearoa Coalition 2009).
} 
organisations in understanding the role of other organisations and the services and resources other organisations provide. This corresponds with similar recommendations by Simmonds and Robson (2008: 12) for providers and service providers "to increase and strengthen collaboration and coordination" with one another. Developing these connections builds social capital between organisations and ultimately could benefit patients as knowledge and connections between organisations can lead to faster institutional processes and more information for patients.

This research and other research continues to celebrate the successes of the public sector in New Zealand for cancer patients and Cancer Control New Zealand's (2009: 29) report indicated that sharing information about positive achievements in the public sector can help build the service's reputation. This study found that many of the participants' opinions of the public health drastically changed after their cancer treatment. The Public Service Association of New Zealand (1985: 8) stated over 25 years ago that there was "failure to promote the strength and competence of the public system." When looking at the comments from many of the participants in this study surrounding their preconceptions of the public system before their cancer treatment it appears that 25 years later this is still the case. The Cancer Control New Zealand's (2009: 5) study reported 97\% of people report being very satisfied with the publiclyfunded outpatient cancer care system. Other studies report that in New Zealand and Australia there is better access to breast cancer nurses for patients in the public sector (Marsh et al. 2010). There needs to be a positive campaign celebrating public sector success in responding to breast cancer and other forms of cancer.

The results from this project show how preconceptions about public cancer services align these services alongside their understandings of general public hospital services. Crossley et al. (1999; 2001) used Bourdieu's concepts to investigate social movements addressing issues surrounding the care, treatment, and rights of mental health patients. Habitus is a product of time and experience, and the analysis in this research shows the change in habitus over time and how there can be a positive transformation of the assumptions informing habitus which structure preconceptions. "The personal voice of the mental patient is formulated in dialogical relation to wider public and collective movements" (Crossley and Crossley 2001: 477). 
This thesis identifies the assumptions and preconceptions informing the collective habitus and views around the public sector cancer treatment that are negative and uncertain in relation to timeframes. To address the general preconceptions about the public sector that were discussed by the participants this research suggests that the CCNZ's next Action Plan for 2012 include a target related to a public cancer services promotion campaign. This campaign would focus on the positive outcomes of research as well as positive personal accounts from cancer patients. There would also be a strong focus in this campaign on the health sector both celebrating and informing health professionals about the successes in the public sector for cancer. Private health companies celebrate by advertising their merits publically. For example, Sovereign insurance previous advertising campaigns emphasised trust, their $\mathrm{A}+$ rating, and their recent television advertisements state that they use the "best" doctors internationally giving patient testimonials of their services (Sovereign Services Limited 2010). A similar campaign celebrating public sector cancer successes and patient feedback is required.

Initially there was an interest in using critical discourse analysis to analyse media articles surrounding public and private health sectors in New Zealand alongside the interview material. Unfortunately, time constraints meant this aspect of the research was not pursued. Future research following on from this topic could also investigate media articles in New Zealand reporting on public and private health services and analyse the articles using Bourdieu's theory of practice. Critical discourse analysis, which explores how language reproduces power relations in society, would provide insight to how the media works as an orthodoxy or heterodoxy, reinforcing or questioning classification systems surrounding public and private health sectors which appear to be grounded in reality.

There is a call for more research exploring how poverty and ethnicity shape social capital and an emphasis that social capital is "shaped and constrained by factors such as gender, ethnicity and social class" (Campbell and McLean 2002: 655). New Zealand studies show ethnicity is a particularly important factor needing further investigation for breast cancer patients (Cunningham et al. 2010; Jeffreys et al. 2009; Sarfati et al. 2006). Future research needs to include a wider range of women to enable further insight into 
aspects such as ethnicity, age, and rural $^{46}$ and urban location. Walker and colleagues (2008) in their investigation of 44 Maori experiences of cancer provide a solid framework to ground future research. Research combining ideas from Walker et al. (2008) and Grineski's (2009) encompassing a range of breast cancer patients in different ethnic and socio-economic groups would provide further insight into the impact of social and cultural capital.

This study provides a voice to the New Zealand women discussed in the many quantitative breast cancer studies undertaken in this country, giving insight into hidden power dynamics in both participants' access to services and between the public and private health sectors. This study highlighted issues breast cancer patients experienced in receiving services they are entitled to, the lack of information they received from their health professionals about these services and their methods of accessing this support. Bourdieu's theory of practice in relation to his concept of capital shows that aspects relating to information and entitlements need improvement to ensure that breast cancer patients do not have to work as hard to access these basic needs and entitlements. Bourdieu's concepts of doxa and illusio also emphasised the need for promotion of public sector cancer services in New Zealand.

\footnotetext{
${ }^{46}$ Gollop et al. (2009) has already begun investigating breast cancer issues for rural and urban Taranaki women, exploring reasoning behind choosing a mastectomy when they could have kept their breast. Professor Susan Dovey at the Otago School of Medicine is also investigating treatment choices among New Zealand rural and urban breast cancer patients (The New Zealand Breast Cancer Foundation 2009).
} 


\section{Bibliography}

Abel T. (2007). Cultural Capital in Health Promotion. In Health \& Modernity, edited by McQueen D, Kickbusch I, Potvin L, Pelikan J, Balbo L and Abel T. New York: Springer, 43-73.

Abel T. (2008). Cultural capital and social inequality in health. Journal of Epidemiology \& Community Health, 62(13), 1-5.

Allmark P, Boote J, Chambers E, Clarke A, McDonnell A, Thompson A, and Tod A. (2009). Ethical issues in the use of in-depth interviews: literature review and discussion. Research Ethics Review, 5(2), 48-54.

Angus J, Rukholm E, St. Onge R, Michel I, Nolan R, Lapum J, and Evan S. (2007). Habitus, Stress, and the Body: The Everyday Production of Health and Cardiovascular Risk. Qualitative Health Research, 17, 1088-1102.

Anspach R. (1993). Deciding Who Lives: Fateful Choices in the Intensive-Care Nursery. Berkerley: University of California Press.

Ashing-Giwa K, Padilla G, Tejero J, Kraemer J, Wright K, Coscarelli A, Clayton S, Williams I, and Hills D. (2004). Understanding the breast cancer experience of women: a qualitative study of African American, Asian American, Latina and Caucasian Cancer survivors. Psycho-Oncology, 13, 408-428.

Ashton T, Mays N, and Devlin N. (2005). Continuity through change: The rhetoric and reality of health reform in New Zealand. Social Science \& Medicine, 61(2), 253262.

Auckland Radiation Oncology. (2008). Auckland Radiation Oncology. MercyAscot \& South Cross Hospitals [cited 28 March 2011]. Available from http://www.aro.co.nz/.

Balka E, Krueger G, Holmes B, and Stephen J. (2010). Situating Internet Use: Information-Seeking Among Young Women with Breast Cancer. Journal of Computer-Mediated Communication, 15(3), 389-411.

Barnball L, and While A. (1994). Collecting data using a semi-structured interview: a discussion paper. Journal of Advanced Nursing, 19(2), 328-335.

Besley T, Hall J, and Preston I. (1999). The demand for private health insurance: do waiting lists matter? Journal of Public Economics, 72(2), 155-181.

Bhasale A, Miller G, Reid S, and Britt H. (1998). Analysing potential harm in Australian general practice: an incident-monitoring study. The Medical Journal of Australia, 169, 73-76.

Birks M, Chapman Y, and Francis K. (2007). Breaching the Wall. Journal of Transcultural Nursing, 18(2), 150-156. 
Blauner B. (1987). Problems of Editing First Person Sociology. Qualitative Sociology, 10(1), 46-64.

Blendon R, Schoen C, DesRoches C, Osborn R, and Zapert K. (2003). Common Concerns Amid Diverse Systems: Health Care Experiences in Five Countries. Health Affairs, 22(3), 106-121.

Bourdieu P. (1977). Outline of a Theory of Practice. Translated by Nice R. Cambridge: Cambridge University Press.

Bourdieu P. (1979). Distinction: A Social Critique of the Judgment of Taste. Translated by Nice R. London: Routledge \& Kegan Paul.

Bourdieu P. (1985). The Social Space and the Genesis of Groups. Theory \& Society, 14(6), 723-744.

Bourdieu P. (1986). The Forms of Capital. In Handbook of Theory of Research for the Sociology of Education, edited by Richardson J. New York: Greenwood Press, 241-258.

Bourdieu P. (1989). Social Space and Symbolic Power. Sociological Theory, 7(1), 1425.

Bourdieu P. (1990). The Logic of Practice. Translated by Nice R. Stanford: Standford University Press.

Bourdieu P. (1998). Practical Reason. Cambridge: Polity Press.

Bourdieu P. (2005). The Social Structures of the Economy. Cambridge: Polity Press.

Bourdieu P, and Passeron J-C. (1965). Introduction: Language and Relationship to Language in the Teaching Situation. In Academic Discourse: Linguistic Misunderstanding and Professorial Power. Stanford: Stanford University Press, $1-34$.

Bourdieu P, and Wacquant L. (1992). An Invitation to Reflexive Sociology. Chicago: University of Chicago Press.

Breast Associates. (2010). Breast Associates: For Complete Breast Care. Breast Associates [cited 3 April 2011]. Available from http://www.breastassociates.co.nz/breast-nurse-jan-munro.htm.

Breast Cancer Aotearoa Coalition. (2008). All about breast nurses. Breast Cancer Aotearoa Coalition [cited 3 April 2011]. Available from http://www.breastcancer.org.nz/BreastNurses.htm.

Breast Cancer Aotearoa Coalition. (2009). BCAC briefing for the Minister of Health, Tony Ryall, June 2009. Breast Cancer Aotearoa Coalition [cited 3 April 2011]. Available from http://www.breastcancer.org.nz/Healthministerbriefing.htm. 
Briggs C. (2002). Interviewing, Power/Knowledge and Social Inequality. In Handbook of Interview Research, edited by Gubrium J and Holstein J. California: Sage Publications, 911-922.

Britt H, Miller G, Steven I, Howarth G, Nicholson P, Bhasale A, and Norton K. (1997). Collecting data on potentially harmful events: a method for monitoring incidents in general practice. Family Practice, 14(2), 101-106.

Brown M, Koch T, and Webb C. (2000). Information needs of women with noninvasive breast cancer. Journal of Clinical Nursing, 9(5), 713-722.

Brunton M, Jordan C, and Campbell I. (2005). Anxiety before, during, and after participation in a population-based screening mammography programme in Waikato Province, New Zealand. New Zealand Medical Journal, 118(1209).

Burkitt Wright E, Holcombe C, and Salmon P. (2004). Doctors' communication of trust, care, and respect in breast cancer: qualitative study. British Medical Journal, $328,864-867$.

Calhoun C. (1993). Habitus, Field, and Capital: The Question of Historical Specificity. In Bourdieu: Critical Perspectives, edited by Calhoun C, LiPuma E and Postone M. Chicago: Chicago University Press, 61-88.

Calhoun C. (2003). Pierre Bourdieu. In The Blackwell Companion to Major Contemporary Theorists, edited by Ritzer G. Malden: Blackwell Publishing, 274-309.

Callaghan G, and Wistow G. (2006). Publics, patients, citizens, consumers? Power and decision making in primary health care. Public Administration, 84(3), 583-601.

Campbell C, and McLean C. (2002). Ethnic Identities, Social Capital and Health Inequalities: Factors Shaping African-Caribbean Participation in Local Community Networks in the UK. Social Science \& Medicine, 55(4), 643-657.

Cancer Control New Zealand. (2009). The Voice of Experience. Part One. National Report: Preliminary Results from the 2009 Cancer Care Survey, December 2009. Wellington: Cancer Control New Zealand.

Caplan L, Helzlsouer K, Shapiro S, Wesley M, and Edwards B. (1996). Reasons for Delay in Breast Cancer Diagnosis. Preventive Medicine, 25, 218-224.

Carpiano R. (2008). Actual or Potential Neighbourhood Resources for Health: What Can Bourdieu Offer for Understanding Mechanisms Linking Social Capital to Health. In Social Capital and Health, edited by Kawachi I, Subramanian SV and Kim D, 83-93.

Cancer Control New Zealand. (2009). The Voice of Experience. Part One. National Report: Preliminary Results from the 2009 Cancer Care Survey, December 2009. Wellington: Cancer Control New Zealand. 
Chirnside J. (2006). Access and Participation in Tertiary Education: A study of students from low decile schools attending the University of Canterbury. Master of Arts, Department of Sociology, University of Canterbury, Christchurch.

Clemes M, Ozanne L, and Laurenson W. (2001). Patients' perceptions of service quality dimensions: an emperical examination of health care in New Zealand. Health Marketing Quarterly, 19(1), 3-22.

Cockerham W, Rutten A, and Abel T. (1997). Conceptualizing Contemporary Health Lifestyles. The Sociological Quarterly, 38(2), 321-342.

Codd J. (1990). Making Distinctions: The Eye of the Beholder. In An Introduction to the Work of Pierre Bourdieu: The Practice of Theory, edited by Mahar C, Harker R and Wilkes C. Hampshire: The MacMillan Press, 132-159.

Coleman J. (1990). Foundations of Social Theory. Cambridge: The Belknap Press of Harvard University Press.

Coradini O. (2010). The divergences between Bourdieu's and Coleman's notions of social capital and their epistemological limits. Social Science Information, 49, 563-583.

Crossley N. (1999). Working Utopias and Social Movements: An Investigation Using Case Study Materials from Radical Mental Health Movements in Britain. Sociology 33, 809-830.

Crossley N, and Crossley M. (2001). 'Patient' voices, social movements and the habitus; how psychiatric survivors 'speak out'. Social Science \& Medicine, 52, 14771489.

Crouch M, and McKenzie H. (2006). The logic of small samples in interview-based qualitative research. Social Science Information, 45(4), 483-499.

Cunningham R, Shaw C, Blakely T, Atkinson J, and Sarfati D. (2010). Ethnic and socioeconomic trends in breast cancer incidence in New Zealand. BMC Cancer, $10,674-684$.

Curtis E, Wright C, and Mall M. (2005a). The epidemiology of breast cancer in Maori women in Aotearoa New Zealand: implications for ethnicity data analysis. New Zealand Medical Journal, 118(1209).

Curtis E, Wright C, and Mall M. (2005b). The epidemiology of breast cancer in Maori women in Aotearoa New Zealand: implications for screening and treatment. New Zealand Medical Journal, 118(1209).

Das J. (2007). Sydney freelance journalists and the notion of professionalism. Pacific Journalism Review, 13(1), 142-160.

David M, and Sutton C. (2004). Social Research the basics. London: Sage Publications. 
Denzin N, and Lincoln Y. (2008). Introduction: The Discipline and Practice of Qualitative Research. In Collecting and Interpreting Qualitative Materials, edited by Denzin N and Lincoln Y. California: Sage Publications, 1-43.

Devault M. (1990). Talking and Listening from Women's Standpoint: Feminist Strategies from Interviewing and Analysis. Social Problems, 37(1), 96-116.

Dougherty E. (2011). The Balance of Practice [cited 30 March 2011]. Available from http://www.elizd.com/website-LeftBrain/essays/practice.html.

Drevdahl D, Kneipp S, Canales M, and Dorc K. (2001). Reinvesting in Social Justice: A Capital Idea for Public Health Nursing? Advanced Nursing Sciences, 24(2), 1931.

Ferguson B. (2003). What does Private Health Care Really Mean? Saskatchewan Law Review, 66, 597-613.

Fine B. (2010). Theories of Social Capital: Researchers Behaving Badly. London: Pluto Press.

Flere S, Tavar Krajnc M, Klanjek R, Musil B, and Kirbis A. (2010). Cultural capital and intellectual ability as predictors of scholastic achievement: a study of Slovenian secondary school students. British Journal of Sociology of Education, 31(1), 4758.

Fontana A, and Frey J. (2008). The Interview. In Collecting and Interpreting Qualitative Materials, edited by Denzin N and Lincoln Y. California: Sage Publications, 115-159.

Fukuyama F. (2000). Social Capital. In Culture Matters: How Values Shape Human Progress, edited by Harrison L and Huntington S. New York: Basic Books, 98111.

Gatrell A, Popay J, and Thomas C. (2004). Mapping the determinants of health inequalities in social space: can Bourdieu help us? Health \& Place, 10, 245-257.

Gerson K, and Horowitz R. (2002). Observation and Interviewing. In Qualiative Research in Action, edited by May T. London: Sage Publications.

Gillham B. (2000). The Research Interview. London: Strand.

Gillon M. (2002). Terms of Engagment in Porirua - A Case Study for Civic Action on Health. In Building Social Capital, edited by Robinson D. Wellington: Victoria University of Wellington, 67-74.

Glaser G, and Strauss A. (1967). The Discovery of Grounded Theory. Chicago: Aldine de Gruyter.

Glied S. (2008). Universal Public Health Insurance and Private Coverage: Externalities in Health Care Consumption. Canadian Public Policy, 34(3), 354-357. 
Gollop S, Kyle S, Fancourt M, Gilkinson W, and Mosquera D. (2009). Why Taranaki women choose to have a mastectomy when suitable for breast conservation treatment. Australia New Zealand Journal of Surgery, 79(9), 604-609.

Goodwin J, Statish S, Anderson E, Nattinger A, and Freeman J. (2003). Effect of Nurse Case Management on the Treatment of Older Women with Breast Cancer. Journal of the American Geratrics Society, 51(9), 1252-1259.

Gordon H, Street R, Sharf B, and Soucheck J. (2006). Racial differences in doctors' information-giving and patients' participation. Cancer, 107(6), 1313.

Greenslade V, Elliot B, and Mandville-Antsey S. (2010). Same-Day Breast Cancer Surgery: A Qualitative Study of Women's Lived Experiences. Oncology Nursing Forum, 37(2), E92-E97.

Grineski S. (2009). Parental Accounts of Children's Asthma Care: The Role of Cultural and Social Capital in Health Disparities. Sociological Focus, 42(2), 107-132.

Gubrium J, and Holstein J. (2002). From the Individual Interview to the Interview Society. In Handbook of Interview Research, edited by Gubrium J and Holstein J. California: Sage Publications, 3-32.

Guest G, Bunce A, and Johnson L. (2006). How Many Interviews Are Enough? Field Methods, 18(1), 59-82.

Gunaratnam Y. (2003). Messy Work: Qualitative Interviewing Across Difference. In Researching 'Race' and Ethnicity: Methods, Knowledge and Power. London: Sage Publications, 79-105.

Harker R. (1990). Bourdieu - Education and Reproduction. In An Introduction to the Work of Pierre Bourdieu: The Practice of Theory, edited by Mahar C, Harker R and Wilkes C. Hampshire: The MacMillan Press, 86-108.

Healy T. (2005). In Each Other's Shadow:What has been the impact of human and social capital on life satisfaction in Ireland? Doctor of Philosophy, Department of Sociology, National University of Ireland, Dublin.

Herzog H. (2005). On Home Turf: Interview Location and Its Social Meaning. Qualitative Sociology, 28(1), 25-46.

Hesse-Biber S, and Leavy P. (2006). The Practice of Qualitative Research. Thousand Oaks: Sage Publications.

Howden-Chapman P, and Ashton T. (2000). Public purchasing and private priorities for healthcare in New Zealand. Health Policy and Planning, 54, 27-43.

Hurley J, Vaithianathana R, Crossley T, and Cobb-Clark D. (2002). Parallel Private Health Insurance in Australia: A Cautionary Tale and Lessons for Canada Australia National University: Centre for Economic Policy Research.

Jabnoun N, and Chaker M. (2003). Comparing the quality of private and public hospitals. Managing Service Quality, 13(4), 290-300. 
Jacobson P. (2004). Health care markets and the health care guarantee: baking a better loaf, or baking enough bread. Policy Options, 50-59.

Jeffreys M, Sarfati D, Stevanovic V, Tobias M, Lewis C, Pearce N, and Blakely T. (2009). Socioeconomic Inequalities in Cancer Survival in New Zealand: The Role of Extent of Disease at Diagnosis. Cancer Epidemiological Biomarkers Prevention, 18(3), 915-921.

Jeffreys M, Stevanovic V, Tobias M, Lewis C, Ellison-Loschmann L, Pearce N, and Blakely T. (2005). Ethnic Inequalities in Cancer Survival in New Zealand: Linkage Study. American Journal of Public Health, 95(5), 834-837.

Jenkins R. (2002). Pierre Bourdieu. Edited by Hamilton P, Key Sociologists. London: Routledge.

Johnson R. (1993). Editor's Introduction: Pierre Bourdieu on Art, Literature and Culture. In The Field of Cultural Production: Essays on Art and Literature, edited by Johnson R. Cambridge: Polity Press, 1-23.

Jones A. (1991). At School I've Got a Chance - Culture/Privilege: Pacific Islands and Pakeha Girls and Schools. Palmerston North: Dunmore Press.

Juraskova I, Hegedus L, Butow P, Smith A, and Schofield P. (2010). Discussing Complementary Therapy Use With Early-Stage Breast Cancer Patients: Exploring the Communication Gap. Integrative Cancer Therapy, 9(2), 168-176.

Khawaja M, and Mowafi M. (2006). Cultural Capital and Self-Rated Health in Low Income Women: Evidence from the Urban Health Study, Beirut, Lebanon. Journal of Urban Health, 83(3), 444-458.

Kvale S. (1996). Interviews: An introduction to qualitative research interviewing. Thousand Oaks: Sage Publications.

Kvale S. (2006). Dominance Through Interviews and Dialogues. Qualitative Inquiry, 12(3), 480-500.

Labisch A. (1992). The Social Construction of Health. In The Social Construction of Illness, edited by Lacmund J and Stolberg G. Stuggart: Frans steiner verlag.

Lamont M, and Lareau A. (1988). Cultural Capital: Allusions, Gaps and Glissandos in Recent Theoretical Developments. Sociological Theory, 6(2), 153-168.

Lantz P, Keeton K, Romano L, and DeGroff A. (2004). Case Management in Public Health Screening Programs: The Experience of the National Breast and Cervical Cancer Early Detection Program Journal of Public Health Management \& Practice, 10(6), 545-555.

Little M, Jordens C, Paul K, and Phillipson B. (1998). Liminality: a Major Category of the Experience of Cancer Illness. Social Science \& Medicine 47(10), 1485-1494.

Lo M-C, and Stacey C. (2008). Beyond cultural competency: Bourdieu, patients and clinical encounters. Sociology of Health \& Illness, 30(5), 741-755. 
Lovell T. (2000). Thinking Feminism with and against Bourdieu. In Reading Bourdieu on Society \& Culture, edited by Fowler B. Oxford: Blackwell Publishers, 27-48.

Lutfey K. (2005). On Practices of 'Good doctoring': Reconstructing the Relationship between Provider Roles and Patient Adherance. Sociology of Health \& Illness, 27, 421-447.

Lutfey K, and Freese J. (2005). Toward Some Fundamentals of Fundamental Causality: Socioeconomic Status and Health in the Routine Clinic Visit for Diabetes. American Journal of Sociology, 110, 1326-1372.

Mahar C, Harker R, and Wilkes C. (1990). The Basic Theoretical Position. In An Introduction to the Work of Pierre Bourdieu: The Practice of Theory, edited by Mahar C, Harker R and Wilkes C. Hampshire: The MacMillan Press, 1-25.

Malat J. (2006). Expanding Research on the Racial Disparity in Medical Treatment with Ideas from Sociology. Health, 10, 303-321.

Marsh C, Wang J, Kollias J, Boult M, Rice J, and Maddern G. (2010). Disparities in access to breast care nurses for breast surgeons: A National Breast Cancer Audit survey. The Breast, 19, 142-146.

McCredie M, Paul C, Skegg D, and Williams S. (1999). Breast cancer in Maori and non-Maori women. International Journal of Epidemiology, 28, 189-195.

McKenzie F, Ellison-Loschmann L, and Jeffrey M. (2010). Investigating reasons for socioeconomic inequalities in breast cancer survival in New Zealand. Cancer Epidemiology, 34, 702-708.

Meinert L. (2004). Resources for health in Uganda: Bourdieu's concepts of capital and habitus. Anthropology \& Medicine, 11(1), 11-26.

Mercy Breast Clinic. (2011). Mercy Breast Clinic - Breast Care. Healthpoint [cited 2 April 2011]. Available from http://www.healthpoint.co.nz/default,32117.sm;jsessionid=16765384DA7B8540 52A29592ECCA780C.

Miller R. (2008). What is the added value of coordination? An institutional analysis of the United Nations' response to national and regional coordination of human trafficking in the Greater Mekong Subregion. Doctor of Philosophy, Development Studies, The University of Auckland, Auckland.

Ministry of Health. (2010a). Cancer Control in New Zealand: New Zealand Cancer Control Strategy and Action Plan. Wellington: Ministry of Health.

Ministry of Health. (2010b). National Cancer Programme Work Plan 2010/11. Wellington: Ministry of Health.

Ministry of Health. (2010). Cancer: New Registrations and Deaths 2007. Wellington: Ministry of Health. 
Montazeri A, Milroy R, Gillis C, and McEwen J. (1996). Interviewing cancer patients in a research setting: the role of effective communication. Supportive Care in Cancer, 4(6), 447-454.

Moore S, Haines V, Hawe P, and Shiell A. (2006). Lost in translation: a geneaology of the "social capital" concept in public health. Journal of Epidemiology \& Community Health, 60, 729-734.

National Health Board. (2009). Breastscreen Aotearoa. Wellington: National Health Board.

New Zealand Public Service Association. (1985). Private medicine: The origins, growth \& effects of private medical insurance \& private hospitals in New Zealand. Wellington: New Zealand Public Service Association.

Noiesen E, Larsen K, and Agner T. (2004). Compliance in contact allergy with focus on cosmetic labelling: a qualitative research project. Contact Dermatitis, 51(4), 189-195.

Page A, and Taylor R. (2008). BreastScreen Aotearoa Independent monitoring report: screening and assessment report of women attending BSA (women screened July 2006 to June 2008). Wellington: National Screening Unit.

Parsons J K, Kwan L, O’Connor S, Miller D, and Litwin M. (2010). Prostate cancer treatment for economically disadvantaged men: a comparison of county hospitals and private providers. Cancer, 116(5), 1378-1384.

Patton M. (2002). Qualitative Interviewing. In Qualitative Research \& Evaluation Methods. Thousand Oaks: Sage Publications, 339-427.

Pearce N, and Davey-Smith G. (2003). Is Social Capital the Key to Inequalities in Health? Amercian Journal of Public Health, 93(1), 122-129.

Pieters H, Heilemann M, Grant M, and Maly R. (2011). Older Women's Reflections on Accessing Care Across Their Breast Cancer Trajectory: Navigating Beyond the Triple Barriers. Oncology Nursing Forum, 38(2), 175-184.

Prieur A, Rosenlund L, and Skjott-Laresen J. (2008). Cultural capital today: A case study from Denmark. Poetics, 36, 45-71.

Putnam R. (2000). Bowling Alone: the Collapse and Revival of American Community. New York: Simon and Schuster.

Rabiee F. (2004). Focus-group interview and data analysis. Proceedings of the Nutrition Society, 63, 655-660.

Rankin N, Williams P, Davis C, and Girgis A. (2004). The use and acceptability of a one-on-one peer support program for Australian women with early breast cancer. Patient Education \& Counseling, 53, 141-146.

Reinharz S, and Davidman L. (1992). Feminist Methods in Social Research. New York: Oxford University Press. 
Remmers H, Holtgrawe M, and Pinkert C. (2010). Stress and nursing needs of women with breast cancer during primary treatment: A qualitative study. European Journal of Oncology Nursing, 14(1), 11-16.

Retsikas K. (2010). Unconscious culture and conscious nature: exploring East Javanese conceptions of the person through Bourdieu's lens. Journal of the Royal Anthropological Institute, 16, s140-s157.

Richardson A, Cox B, Brown T, and Smale P. (2005). The impact of breast cancer screening on breast cancer registrations in New Zealand. New Zealand Medical Journal, 118(1209).

Robinson B, and Robinson D. (2002). Possible Aids from Physic and Engineering to Assist Understanding Social Capital. In Building Social Capital, edited by Robinson D. Wellington: Victoria University of Wellington, 41-66.

Robinson D. (2002). Introduction. In Building Social Capital, edited by Robinson D. Wellington: Victoria University of Wellington, 1-13.

Rosenblatt P. (2002). Interviewing at the Border of Fact and Fiction. In Handbook of Interview Research, edited by Gubrium J and Holstein J. California: Sage Publications, 893-909.

Rubin H, and Rubin I. (2005). Qualitative Interviewing: The Art of Hearing Data. 2 ed. Thousand Oaks: Sage Publications.

Samuelsen H, and Steffen V. (2004). The relevance of Foucault and Bourdieu for medical anthropology: exploring new sites. Anthropology \& Medicine, 11(1), 310 .

Sarfati D, Blakely T, Shaw C, Cormack D, and Atkinson J. (2006). Patterns of disparity: ethnic and socio-economic trends in breast cancer mortality in New Zealand. Cancer Causes \& Control, 17, 671-678.

Schmidt J. (2005). Migrating Genders: Westernisation, Migration and Samoan Fa'afafine. Doctor of Philosophy, Department of Sociology, The University of Auckland, Auckland.

Seidman I. (2006). Interviewing as Qualitative Research: A Guide for Researchers in Education \& the Social Sciences. 3 ed. New York: Teachers College Press.

Shank G. (2002). Qualitative Research: A Personal Skills Approach. New Jersey: Pearson Education.

Sharp G, and Kremer E. (2006). The Safety Dance: Confronting Harassment, Intimidation, and Violence in the Field. Sociological Methodology 36, 317-327.

Shilling C. (2002). Culture, the 'sick role' and the consumption of health. British Journal of Sociology, 53(4), 621-638. 
Shim J. (2010). Cultural Health Capital: A Theoretical Approach to Understanding Health Care Interactions and the Dynamics of Unequal Treatment. Journal of Health \& Social Behavior, 51(1), 1-15.

Shulz W, and Brese F. (2008). Assessing Student Knowledge, Background and Perceptions in the International Civic and Citizenship Study. In Annual Meetings of the American Educational Research Association New York.

Siminoff L, Graham N, and Gordon H. (2006). Cancer communication patterns and the influence of patient characteristics: Disparities in information-giving and affective behaviors. Patient Education \& Counseling, 62(3), 355-360.

Te Rapu Rangahau Hauora a Eru Pamare. (2008). Independent Maori monitoring report BreastScreen Aotearoa July 2004 to June 2006 50-64 years. Wellington: Te Rapu Rangahau Hauora a Eru Pamare.

Singh-Manoux A, and Marmot M. (2005). Role of socialisation in explaining social inequalities in health. Social Science \& Medicine, 60, 2129-2133.

Sovereign Services Limited. (2010). Best Doctors. Helping you find the thing you need most. Answers. Sovereign Services Limited [cited 7 April 2011]. Available from https://www.sovereign.co.nz/bestdoctors/default-v2.html?gclid=CPuGtGgiqgCFQTabgodFV0aCg.

St George's Hospital. (2010). St George's Cancer Care Centre. St George's Hospital [cited 28 March 2011]. Available from http://cancercarecentre.co.nz/Cancer\%20Care.

Stacey J. (1997). Teratologies: A cultural study of cancer. London: Routledge.

Stimson G, and Webb B. (1975). Going to See the Doctor: The Consulation Process in General Practice. London: Routledge and Kegan Paul.

Stoebenau K. (2009). Symbolic capital and health: The case of women's sex work in Antananarivo Madagascar. Social Science \& Medicine, 68, 2045-2052.

Street R, Gordon H, and Haidet P. (2007). Physicans' communication and perceptions of patients: Is it how they look, how they talk, or is it just the doctor? Social Science \& Medicine, 62, 586-598.

Stuber J. (2009). Class, Culture, and Participation in the Collegiate Extra-Curriculum. Sociological Forum, 24(4), 877-900.

Sullivan A. (2002). Bourdieu and Education: How Useful is Bourdieu's Theory for Researchers? The Netherlands Journal of Social Sciences, 38(2), 144-166.

Swartz D. (1997). Culture \& Power. Chicago: University of Chicago Press.

The New Zealand Breast Cancer Foundation. (2009). NZBCF Research Grants. The New Zealand Breast Cancer Foundation, 23/03/2010. Available from http://www.nzbcf.org.nz/index.php/funding-and-grants/nzbcf-research-fund. 
Thewes B, Butlow P, Girgis A, and Pendlebury S. (2004). The psychological needs of breast cancer survivors; a qualitative study of the shared and unique needs of younger versus older survivors. Psycho-Oncology, 13, 177-189.

Thompson J. (1991). Language and Symbolic Power, edited by Thompson J. Cambridge: Polity Press.

Thorpe H. (2009). Bourdieu, Feminism and Female Physical Culture: Gender Reflexivity and the Habitus-Field Complex. Sociology of Sport Journal, 26, 491516.

Trueba H. (2002). Multiple Ethnic, Racial, and Cultural Identities in Action: From Marginality to a New Cultural Capital in Modern Society. Journal of Latinos and Education, 1(1), 7-28.

Tzeng R. (2010). Cultural Capital and Cross-Border Career Ladders: Western Professional Migrants in Taiwan. International Sociology, 25(1), 123-143.

Veenstra G, Luginaah I, Wakefield S, Birch S, Eyles J, and Elliott S. (2005). Who you know, where you live: social capital, neighbourhood and health. Social Science \& Medicine, 60, 2799-2818.

Wacquant L. (1989). Towards a Reflexive Sociology: A Workshop with Pierre Bourdieu. Sociological Theory, 7(1), 26-63.

Wagner E, Austin B, Davis C, Hindmarsh M, Schaefer J, and Bonomi A. (2001). Improving Chronic Illness Care: Translating Evidence Into Action. Health Affairs, 20(6), 64-78.

Wakefield S, and Poland B. (2005). Family, friend or foe? Critical reflections on the relevance and role of social capital in health promotion and community development. Social Science \& Medicine 60(12), 2819-2832.

Walker T, Signal L, Smiler K, Tuhiwai-Ruri R, Otaki Community Health Centre, Te Wakahuia Hauora, Te Aitanga a Hauiti Hauora, and Turanga Health. (2008). The road we travel: Māori experience of cancer New Zealand Medical Journal, 121(1279), 27-35.

Warren C. (2002). Qualitative Interviewing. In Handbook of Interview Research, edited by Gubrium J and Holstein J. California: Sage Publications, 83-101.

Webb J, Schirato T, and Danaher G. (2002). Understanding Bourdieu. London: Sage Publications.

Weininger E, and Lareau A. (2007). Cultural Capital. In Encyclopedia of Sociology, edited by Ritzer G. Oxford: Blackwell.

Wengraf T. (2001). Qualitative research interviewing: biographic narrative and semistructured methods. London: Sage Publications.

Williams S. (1995). Theorising class, health and lifestyles: can Bourdieu help us? Sociology of Health \& Illness, 17(5), 577-604. 
Williams T, and Robinson D. (2002). Social Capital-based Partnerships: A Maori Perspective and a Comparative Approach. In Building Social Capital, edited by Robinson D. Wellington: Victoria University of Wellington, 14-30.

Wolf M. (2007). Bourdieu's "rules of the game": an introspection into methodological questions of translation sociology. Matraga, 14(20), 130-145.

Wood R, and Della-Monica N. (2011). Psychosocial Factors Influencing Breast Cancer Risk Appraisal Among Older Women. Qualitative Health Research, first published on March 16, 2011 doi 10.1177/1049732311401036.

Yamamoto Y, and Brinton M. (2010). Cultural Capital in East Asian Educational Systems: The Case of Japan. Sociology of Education, 83(1), 67-83.

Yosso T. (2005). Whose culture has capital? A critical race theory discussion of community cultural wealth. Race Ethnicity \& Education, 8(1), 69-91. 


\section{Appendix A: Introductory email}

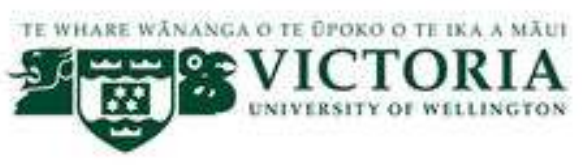

Victoria University of Wellington

PO Box 600

Wellington 6140

kim.dobson@vuw.ac.nz

Cell 0272093890

Work (04) 4635233 ext 6710

Hello friends and family,

As many of you will be aware, I am embarking on my Masters degree in Sociology at Victoria University exploring breast cancer patients' perceptions and experiences of health systems.

To conduct research in this area $I$ am inviting 10-12 women who have completed their breast cancer treatment in New Zealand between 2000 and 2007 to take part in an interview that will explore their perceptions and experiences of the New Zealand health systems.

I was wondering if you knew of any women who might want to be interviewed and if so, whether you may be able to pass this information on, and ask her to contact me if she is interested in getting involved.

I have attached a copy of a participant information sheet containing a general overview of the project. 
Any assistance you would be able to give would be much appreciated.

I look forward to hearing from you or your friends or family.

You can contact me via this email address, kim.dobson@vuw.ac.nz, or phone me on (04) 4635233 ext. 6710 with any questions.

Kind Regards,

Kim Dobson

MA Student, Department of Sociology

Victoria University, Wellington

Or should you wish to contact my supervisor, Professor Kevin Dew, his details are:

Professor Kevin Dew

Sociology lecturer

Victoria University of Wellington

P O Box 600

Wellington

Phone (04) 4635291

Email: kevin.dew@vuw.ac.nz 


\section{Appendix B: Participant information sheet}

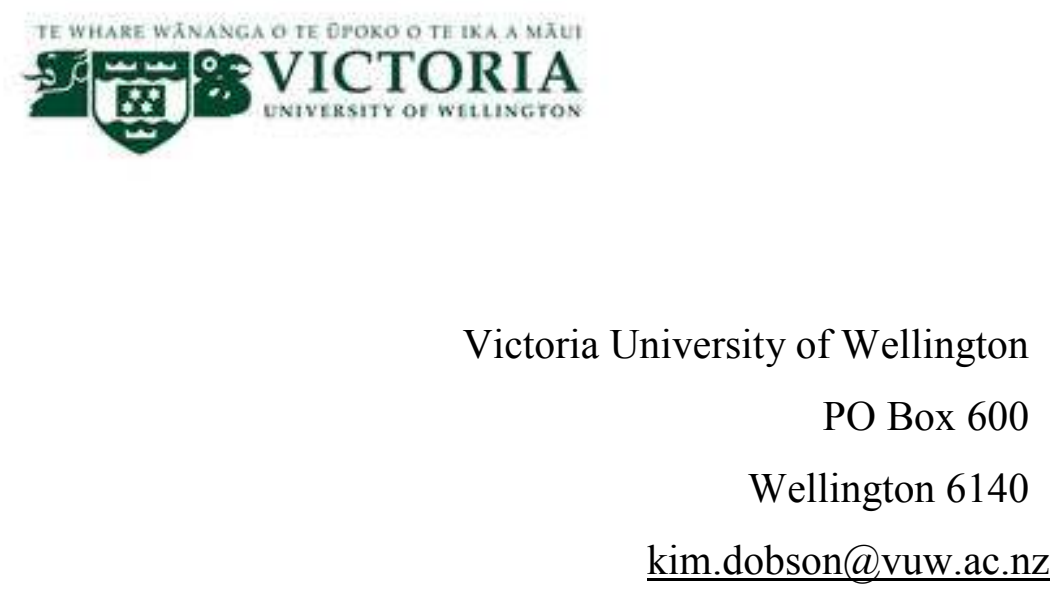

Cell 027209 3890, Work (04) 4635233 ext 6710

\section{Participant information sheet \\ A comparison of breast cancer patients' perceptions and experiences of private and public health sectors in New Zealand.}

Dear Prospective Research Participant,

You are invited to take part in a project exploring breast cancer patients' perceptions and experiences of health sectors in New Zealand. The aim of the research is to explore and analyse former breast cancer patients' perceptions and experiences surrounding their choice of health system for their treatment.

I am hoping to interview between 10-12 women who completed their breast cancer treatment in New Zealand between 2000 and 2007, recruited through my family and friends.

Participation in the study is voluntary and, if you agree to participate in the research, I anticipate that the interview will take between one to one and a half hours in total. You can have a friend, family, or whānau support to help you understand the risks and/or benefits of this study and any other explanation you may require. If you need an interpreter, I will arrange one. You do not have to answer any questions you do not feel 
comfortable answering and you may stop the interview at any time. Should you feel the need to withdraw from the project, you may do so without question at any time before the interview material is analysed.

Benefits of the research could include having the chance to share your story surrounding your experiences and perceptions of the health systems. Risks could include old feelings regarding your illness coming back. These risks will be minimised through the centring the interview on the topic of health care systems.

With your consent, this interview will be digitally recorded and transcribed so that I can refer back to and analyse the interview. You can request a summary of the research results and a CD copy of their interview at the completion of the project.

Responses collected will form the basis of my research project and will be put into a written report on an anonymous basis. The material is confidential and no other person besides my supervisor, Professor Kevin Dew, and I will have access to the interview transcripts or digital audio recordings. The interview material will not be used for any purpose other than those stated above without further consent.

The research will be primarily to fulfil the requirements for a Master of Arts by thesis at Victoria University of Wellington. The thesis will be submitted for marking to the School of Social and Cultural Sciences and deposited in the University Library. It is intended that one or more articles will be submitted for publication in scholarly journals.

Interview transcripts and digital recordings will be destroyed ten years after the end of the project and will be stored securely in a locked filing cabinet at Victoria University in Professor Dew's office during this time.

If you have any queries or concerns regarding your rights as a participant in this study, you may wish to contact an independent health and disability advocate: Free phone: 0800555 050, Free fax: 08002 SUPPORT (0800 2787 7678) or Email: advocacy@,hdc.org.nz. 
If you have any questions, or would like to further information about the project, please feel free to contact me:

\section{Kim Dobson}

Master of Arts Candidate

Victoria University of Wellington

PO Box 600

Wellington 6140

New Zealand

Phone: $\quad$ Cell 0272093890

Work (04) 4635233 ext 6710

Email: $\quad$ kim.dobson@vuw.ac.nz

Or should you wish to contact my supervisor, Professor Kevin Dew, his details are:

Professor Kevin Dew

Sociology and Social Policy Programme

Victoria University of Wellington

P O Box 600

Wellington

Phone: $\quad$ (04) 4635291

Email: $\quad$ kevin.dew@vuw.ac.nz

Thank you in advance for your time

\section{Kim Dobson}

This study has received ethical approval from the Multi-region Ethics Committee, which reviews national and multi regional studies, ethics reference number MEC/10/23/EXP 


\section{Appendix C: Consent form}

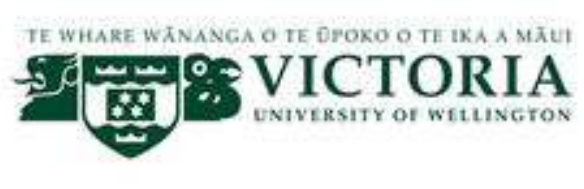

Victoria University of Wellington

PO Box 600

Wellington 6140

kim.dobson@vuw.ac.nz

Cell 0272093890

Work (04) 4635233 ext 6710

\section{Consent for participation in research \\ A comparison of breast cancer patients' perceptions and experiences of private and public health systems in New Zealand.}

I have read and I understand the information sheet dated _ I $/ 2010$ for volunteers taking part in the study designed to investigate breast cancer patients' perceptions and experiences of public and private health sectors.

I have had the opportunity to discuss this study and I am satisfied with the answers I have been given.

I have had the opportunity to use whānau support or a friend to help me ask questions and understand the study.

I understand that taking part in this study is voluntary (my choice), and that I may withdraw from the study at any time before the interview material is analysed.

I understand that my participation in this study is confidential and that no material that could identify me will be used in any reports on this study 


\begin{tabular}{|l|c|r|}
\hline I consent to my interview being audio taped & Yes & No \\
\hline I wish to receive a CD copy of my interview & Yes & No \\
\hline $\begin{array}{l}\text { I wish to receive a copy of the results when the research is } \\
\text { completed }\end{array}$ & Yes & No \\
\hline $\begin{array}{l}\text { I would like the researcher to discuss the outcomes of the study } \\
\text { with me. }\end{array}$ & Yes & No \\
\hline
\end{tabular}

\section{Request for interpreter}

\begin{tabular}{|l|l|l|l|}
\hline English & I wish to have an interpreter & Yes & No \\
\hline Deaf & $\begin{array}{l}\text { I wish to have a NZ sign } \\
\text { language interpreter }\end{array}$ & Yes & No \\
\hline Māori & $\begin{array}{l}\text { E hiahia ana ahau ki tetahi } \\
\text { kaiwhaka Māori/kaiwhaka } \\
\text { pakeha korero }\end{array}$ & Ae & Kao \\
\hline Cook Island Māori & $\begin{array}{l}\text { Ka inangaro au i tetai } \\
\text { tangata uri reo }\end{array}$ & Ae & Kare \\
\hline Fijian & $\begin{array}{l}\text { Au gadreva me dua e } \\
\text { vakadewa vosa vei au }\end{array}$ & Io & Sega \\
\hline Niuean & $\begin{array}{l}\text { Fia manako au ke fakaaoga } \\
\text { e taha tagata fakahokohoko } \\
\text { kupu }\end{array}$ & E & Nakai \\
\hline Sāmoan & $\begin{array}{l}\text { Ou te mana'o ia i ai se } \\
\text { fa'amatala upu }\end{array}$ & Ioe & Leai \\
\hline Tokelaun & $\begin{array}{l}\text { Ko au e fofou ki he tino ke } \\
\text { fakaliliu te gagana Peletania } \\
\text { ki na gagana o na motu o te } \\
\text { Pahefika }\end{array}$ & Ioe & Leai \\
\hline Tongan & $\begin{array}{l}\text { Oku ou fiema'u ha } \\
\text { fakatonulea }\end{array}$ & Io & Ikai \\
\hline
\end{tabular}

I

hereby consent to take part in this study.

(full name)

Date: 
Contact phone number for researcher:

0272093890

(04) 4635233 ext 6710

Project explained by:

Kimberly Dobson

Project role:

Researcher

Signature:

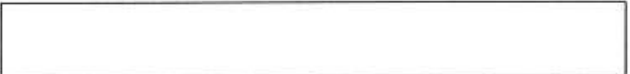

Date:

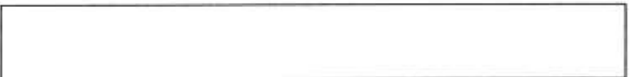




\section{Appendix D: Demographic survey}

Some of these questions may seem unrelated but they will help me to construct my theoretical construct for my project.

Please answer all the questions you feel comfortable answering.

\begin{tabular}{|l|l|}
\hline Question & Answer \\
\hline How old are you? & \\
\hline What is your ethnicity? & \\
\hline Time of breast cancer diagnosis? & \\
\hline Type of treatment for breast cancer? & \\
\hline What is your highest level of education? & \\
\hline What is your occupation? & \\
\hline What was your mother's occupation? & \\
\hline
\end{tabular}

Thank you! 


\section{Appendix E: Demographic survey information}

\begin{tabular}{|c|c|}
\hline & DEMOGRAPHIC SURVEY CONDUCTED WITH INTERVIEWS \\
\hline & Linda \\
\hline How old are you? & 53 \\
\hline What is your ethnicity? & Pakeha \\
\hline Time of breast cancer diagnosis? & 2000 \\
\hline Type of treatment for breast cancer? & Surgery, chemotherapy, radiotherapy, Tamoxifin \\
\hline What is your highest level of education? & Bachelor of Education, Special teaching needs diploma \\
\hline What is your occupation? & Complex Case Manager, ACC \\
\hline What was your mother's occupation? & Housewife \\
\hline \multirow[t]{2}{*}{ What was your father's occupation? } & Telehone engineer \\
\hline & Jan \\
\hline How old are you? & 59 \\
\hline What is your ethnicity? & Maori \\
\hline Time of breast cancer diagnosis? & May in 2004 \\
\hline \multicolumn{2}{|l|}{ Type of treatment for breast cancer? } \\
\hline \multicolumn{2}{|l|}{ What is your highest level of education? } \\
\hline \multicolumn{2}{|l|}{ What is your occupation? } \\
\hline \multicolumn{2}{|l|}{ What was your mother's occupation? } \\
\hline \multicolumn{2}{|l|}{ What was your father's occupation? } \\
\hline & Glenda \\
\hline How old are you? & 56 \\
\hline What is your ethnicity? & Kiwi \\
\hline Time of breast cancer diagnosis? & 2006 \\
\hline Type of treatment for breast cancer? & Surgery, chemotherapy Radiotherapy, White Blood cell injections \\
\hline What is your highest level of education? & NDH (Horticulture) \\
\hline What is your occupation? & Home slave (did run her own business pre cancer) \\
\hline What was your mother's occupation? & Office worker \\
\hline \multirow[t]{2}{*}{ What was your father's occupation? } & Truck driver \\
\hline & Heather \\
\hline How old are you? & 64 \\
\hline What is your ethnicity? & English/NZ citizenship \\
\hline Time of breast cancer diagnosis? & Mammogram June 2004 \\
\hline Type of treatment for breast cancer? & Mastectomy \\
\hline What is your highest level of education? & GCE O levels, Shorthand typing, book keeping \\
\hline What is your occupation? & Weaver \\
\hline What was your mother's occupation? & Owned Grocery shop \\
\hline \multirow[t]{2}{*}{ What was your father's occupation? } & Owned Grocery shop \\
\hline & Rose \\
\hline How old are you? & 55 \\
\hline What is your ethnicity? & European New Zealander \\
\hline
\end{tabular}




\begin{tabular}{|c|c|}
\hline Time of breast cancer diagnosis? & 2004 \\
\hline Type of treatment for breast cancer? & Radiotherapy, $2 \mathrm{x}$ surgery \\
\hline What is your highest level of education? & $\begin{array}{l}\text { School Certificate, Graphic Design Certificate, Tarot, Herbal } \\
\text { Certificate }\end{array}$ \\
\hline What is your occupation? & Artist \\
\hline What was your mother's occupation? & Mother \\
\hline \multirow[t]{2}{*}{ What was your father's occupation? } & Dairy Farmer \\
\hline & Barbara \\
\hline How old are you? & 54 \\
\hline What is your ethnicity? & Cornish \\
\hline Time of breast cancer diagnosis? & 2004 \\
\hline Type of treatment for breast cancer? & Removal of lump, Tamoxifin, radiotherapy \\
\hline What is your highest level of education? & MSc \\
\hline What is your occupation? & Student \\
\hline What was your mother's occupation? & Farmer's wife \\
\hline \multirow[t]{2}{*}{ What was your father's occupation? } & Farmer \\
\hline & Eleanor \\
\hline How old are you? & 64 \\
\hline What is your ethnicity? & New Zealander \\
\hline Time of breast cancer diagnosis? & 2004 \\
\hline Type of treatment for breast cancer? & Tamoxifin \\
\hline What is your highest level of education? & 2 Years at high school and night courses \\
\hline What is your occupation? & Retired \\
\hline What was your mother's occupation? & Farmers wife \\
\hline \multirow[t]{2}{*}{ What was your father's occupation? } & Farmer \\
\hline & Carol \\
\hline How old are you? & 54 \\
\hline What is your ethnicity? & New Zealand European \\
\hline Time of breast cancer diagnosis? & $9 / 06 / 2004$ \\
\hline Type of treatment for breast cancer? & $\begin{array}{l}\text { Wide local Excision (lumpectomy), Auxillary Dissection } \\
\text { (lymphnode 17), Tamoxifin } 5 \text { years, Radiotherapy }\end{array}$ \\
\hline What is your highest level of education? & $\mathrm{BA}$ \\
\hline What is your occupation? & Property Manager \\
\hline What was your mother's occupation? & Mother/Housewife \\
\hline \multirow[t]{2}{*}{ What was your father's occupation? } & Cabinet maker \\
\hline & Mary \\
\hline How old are you? & 53 \\
\hline What is your ethnicity? & New Zealander \\
\hline Time of breast cancer diagnosis? & 2001 and 2007 \\
\hline Type of treatment for breast cancer? & $\begin{array}{l}\text { Partial Mastectomy and radiotherapy and the second time } \\
\text { mastectomy and pectoral resection }\end{array}$ \\
\hline What is your highest level of education? & Diploma of Occupational therapy \\
\hline What is your occupation? & Occupational Therapist \\
\hline What was your mother's occupation? & Kafafane nurse \\
\hline \multirow[t]{2}{*}{ What was your father's occupation? } & Orcharist \\
\hline & Karen \\
\hline
\end{tabular}




\begin{tabular}{|l|l|} 
How old are you? & 41 \\
\hline What is your ethnicity? & New Zealander \\
\hline Time of breast cancer diagnosis? & 2004 \\
\hline Type of treatment for breast cancer? & Surgery, chemo, Taxitur, Radiotherapy, Reconstruction \\
\hline What is your highest level of education? & 4th form \\
\hline What is your occupation? & Caregiver, Administration \\
\hline What was your mother's occupation? & Homemaker \\
\hline What was your father's occupation? & Labour \\
\hline & Nancy \\
\hline How old are you? & 88 \\
\hline What is your ethnicity? & New Zealander \\
\hline Time of breast cancer diagnosis? & 2004 \\
\hline Type of treatment for breast cancer? & Mascestomy \\
\hline What is your highest level of education? & Left school at 12 did a tayloring qualification \\
\hline What is your occupation? & $\begin{array}{l}\text { Many unpaid voulnteer jobs, Tupperware manager, shop work } \\
\text { (paid office work until 83) }\end{array}$ \\
\hline What was your mother's occupation? & N/A \\
\hline What was your father's occupation? & Shop owner, traffic officer, tram driver \\
\hline
\end{tabular}




\section{Appendix F: Interview guide}

Did you get your treatment in the public or private sector?

Why did you choose that particular sector for your treatment?

(this question can lead on to the next two questions)

What were your views around the public sector?

What are your views around the private sector?

From your experiences, can you explain how these two sectors differed?

(Private patients would have experienced both private and public hospital care so they might be able to give a lived experience of both sectors)

What were your perceptions of the sector you received your treatment in before your treatment?

How did the standard of care measure up to your expectations?

How did these perceptions change after your treatment?

Reflect back on situations in the hospital during your treatment where you felt you had control over your health care decisions.

Why did you feel in control in this situation?

Why they felt control and autonomy in specific situations and why they felt this way?

Ask about the specific stages of treatment referral to specialist, referral to surgeon, time in hospital, during chemotherapy, during radiotherapy.

Reflect back on situations in the hospital during your treatment where you felt you had a lack of control over your health care decisions.

Why did you feel a lack control in this situation?

Do you have medical insurance? 
IF YES What reasoning backed your decision to get medical insurance?

IF NO Why did you choose not to have medical insurance?

What information were you given about treatment and health systems before the treatment began?

Did you find these resources and explanations easy to understand?

What sorts of other resources did you use to investigate your treatment and health systems?

Do you have any other comments you would like to add? 